\title{
Particle-associated and free-living microbial assemblages are distinct in a permanently redox-stratified freshwater lake
}

\author{
Ashley B. Cohen ${ }^{1}$ \\ School of Marine and Atmospheric Sciences, Stony Brook University, NY, USA, \\ ashley.cohen@stonybrook.edu, ORCID: 0000-0003-2215-2307 \\ Vanja Klepac-Ceraj \\ Department of Biological Sciences, Wellesley College, Wellesley, MA, USA \\ vklepacc@wellesley.edu, ORCID: 0000-0001-5387-5706 \\ Kristen Butler \\ Department of Earth and Planetary Sciences, University of Tennessee, Knoxville, TN, USA, \\ kbutle28@vols.utk.edu, ORCID: 0000-0002-4467-7107 \\ Felix Weber \\ School of Marine and Atmospheric Sciences, Stony Brook University, NY, USA \\ felix.weber@stonybrook.edu \\ Arkadiy I. Garber \\ Biodesign Center for Mechanisms of Evolution, Arizona State University, Tempe, AZ, USA, \\ agarber4@asu.edu, ORCID: 0000-0001-7935-0246 \\ Lisa N. Christensen \\ Cold Spring Harbor Laboratory, NY, USA, \\ christe@cshl.edu \\ Jacob A. Cram \\ University of Maryland Center for Environmental Sciences -- Horn Point Laboratory, MD, USA, \\ jcram@umces.edu, ORCID: 0000-0001-9546-1130 \\ Michael L. McCormick \\ Biology department, Hamilton College, Hamilton, NY, USA, \\ mmccormi@hamilton.edu, ORCID: 0000-0002-7403-7186

\section{Gordon T. Taylor} \\ School of Marine and Atmospheric Sciences, Stony Brook University, NY, USA, \\ gordon.taylor@stonybrook.edu, ORCID: 0000-0002-6925-7571
}

Keywords: Particle-associated, free-living, microbial community, meromictic lake, Fayetteville Green Lake, redox-stratified, anoxic, 16S rRNA, biogeochemistry, geobiology, sulfur cycle

\footnotetext{
${ }^{1}$ Currently at Montana State University, Bozeman, MT, USA, ashley.cohen@montana.edu
} 


\section{Abstract}

Microbial assemblages associated with biogenic particles are phylogenetically distinct

3 from free-living counterparts, yet biogeochemically coupled. Compositions may vary with organic

4 carbon and inorganic substrate availability and with redox conditions, which determine reductant

5 and oxidant availability. To explore microbial assemblage compositional responses to steep

6 oxygen and redox gradients and seasonal variability in particle and substrate availability, we

7 analyzed taxonomic compositions of particle-associated (PA) and free-living (FL) bacteria and

8 archaea in permanently redox-stratified Fayetteville Green Lake. PA and FL assemblages $(>2.7$

$9 \mu \mathrm{m}$ and $0.2-2.7 \mu \mathrm{m}$ ) were surveyed at the peak (July) and end (October) of concurrent

10 cyanobacteria, purple and green sulfur bacteria blooms that result in substantial vertical fluxes of

11 particulate organic carbon. Assemblage compositions varied significantly among redox conditions

12 and size fractions (PA or FL). Temporal differences were only apparent among samples from the

13 mixolimnion and oxycline, coinciding with seasonal hydrographic changes. PA assemblages of

14 the mixolimnion and oxycline shifted from aerobic heterotrophs in July to fermenters, iron-

15 reducers, and denitrifiers in October, likely reflecting seasonal variability in photoautotroph

16 biomass and inorganic nitrogen. Within a light-scattering layer spanning the lower oxycline and

17 upper monimolimnion, photoautotrophs were more abundant in July than in October, when

18 Desulfocapsa, a sulfate-reducing and sulfur-disproportionating bacterium, and Chlorophyte

19 chloroplasts were abundant in PA assemblages. In this layer, microbial activity and cell

20 concentrations were also highest. Below, the most abundant resident taxa were sulfate-reducing

21 bacteria and anaerobic respirers. Results suggest PA and FL assemblage niche partitioning

22 interconnects multiple elemental cycles that involve particulate and dissolved phases.

\section{Introduction}


Biogenic debris can be rich in organic matter, inorganic nutrients, and minerals and teem

25 with microbes that extract those resources more efficiently than free-living microbes in

26 surrounding, nutrient-depleted waters. (Smith et al., 1992, Taylor et al., 2009). As microbes carry

27 out remineralization or photosynthesis in particles, they generate byproducts such as dissolved

28 organic matter and inorganic nutrients that diffuse out to free-living microbes in the vicinity of the

29 particles over spatial scales up to 100 times larger than the particle itself (Kiørboe et al., 2001).

30 This interplay between the particle-associated (PA) and free-living (FL) microbial assemblages

31 intensifies seasonally during algal blooms, when chemical gradients emanating from algal-rich

32 particles (the phycosphere) support FL microbes that consume algal exudates (Cai et al., 2014,

33 Louati et al., 2015; Kieft et al., 2021).

34 In permanently redox-stratified meromictic lakes, marine basins, marine oxygen-deficient

35 zones, and many fjords, settling particles pass through distinctive redox zones with

36 correspondingly distinctive FL microbial assemblages as they transit towards the underlying

37 sediment by gravitational settling (Fuchsman et al., 2011, Suter et al., 2018). Therefore, the

38 interplay between microbes in particles with resident free-living microbes likely differs with redox

39 conditions due to the changing oxidant and reductant availability. In these quiescent, diffusion-

40 dominated environments, redox conditions can vary with both depth and particle attributes. Owing

41 to minimal advective chemical exchange between particles and water (Alldredge and Cohen, 1987,

42 Plough et al., 1997, Kiørboe et al., 2001), aerobic respiration, fermentation, denitrification, sulfate

43 reduction, methanogenesis, and anaerobic methane oxidation can all be supported simultaneously

44 in oxyclines existing at spatial scales of micrometers to meters (Fuchsman et al., 2011, Lauro et

45 al., 2011, Wright et al., 2012, Ganesh et al., 2015, Suter et al., 2018, Torres-Beltrán et al., 2019). 
To explore how ambient redox conditions and seasonally varying organic carbon substrates

47 influence the interplay between PA and FL microbes, we used permanently redox-stratified

48 (meromictic), sulfidic, Fayetteville Green Lake (FGL), NY, USA (4303'32.3"N, $\left.75^{\circ} 58^{\prime} 18.4^{\prime \prime} \mathrm{W}\right)$

49 as a natural laboratory. FGL is one of the most extensively studied meromictic lakes, and has

50 served as a natural laboratory to study many aspects of biogeochemistry in permanently redox-

51 stratified water columns (e.g., Zerkle et al., 2010, Meyer et al., 2011, Havig et al., 2015, 2018,

52 Fulton et al., 2018). FGL has unusually high sulfate concentrations $(\sim 15 \mathrm{mM})$ for a freshwater

53 environment because groundwater entering near the upper oxycline boundary, and potentially in

54 the deep lake, passes through gypsum-bearing shale $\left(\mathrm{CaSO}_{4} \cdot 2 \mathrm{H}_{2} \mathrm{O}\right)($ Brunskill and Ludlam, 1969 ,

55 Havig et al., 2015). The high sulfate concentrations and permanent density stratification result in

56 vertical biogeochemical zonation similar to marine anoxic basins, such as the Cariaco Basin and

57 Black Sea. Zones include a fully oxygenated mixed layer (mixolimnion) and a sulfidic deep layer

58 (monimolimnion) separated by an oxycline within which dissolved $\mathrm{O}_{2}$ concentrations attenuate

59 steeply until hydrogen sulfide first appears. FGL's mixolimnion $(0-15 \mathrm{~m})$ is normoxic $\left(\mathrm{O}_{2} \geq 93\right.$

$60 \mu \mathrm{M})$, while the oxycline $(15-20 \mathrm{~m})$ varies from oxic to hypoxic $\left(93>\mathrm{O}_{2} \geq 3 \mu \mathrm{M}\right)$ and suboxic $\left(\mathrm{O}_{2}\right.$

$61<3 \mu \mathrm{M}$, no measurable $\mathrm{H}_{2} \mathrm{~S}$ ), and the monimolimnion $\left(\geq 20 \mathrm{~m}\right.$ ) is euxinic (measurable $\mathrm{H}_{2} \mathrm{~S}$ ) Havig

62 et al. $(2015,2018)$ as defined in Scranton et al. (2014) and Taylor et al. (2018).

63 Photoautotrophic populations in FGL have been extensively studied for more than 50 years.

64 These include cyanobacteria in the mixolimnion and near the lower oxycline boundary that induce

65 calcium carbonate precipitation ("whiting events"), and populations of purple and green sulfur-

66 oxidizing anoxygenic photoautotrophs at and just below the lower oxycline boundary (Culver and

67 Brunskill, 1969, Thompson et al., 1990, 1997, Fulton et al., 2018, Block et al., 2021). They bloom

68 during July, when particulate organic carbon fluxes to the deep lake are elevated, and senesce 
69 during October, when particulate organic carbon fluxes to the deep lake decrease (Brunskill, 1969,

70 Culver and Brunskill, 1969), suggesting that they are a significant source of organic carbon to

71 anoxic waters and to the lakebed.

72 Less is known about the non-photoautotrophic members of FGL microbial assemblages

73 and their roles in biogeochemical cycling. Interactions between photoautotrophs and putative

74 chemoautotrophic sulfur-disproportionating bacteria in the oxycline and upper monimolimnion

75 (15-21 m) and between chemoorganotrophic sulfate-reducing and fermentative bacteria in the

76 shallow monimolimnion $(22-25 \mathrm{~m})$ couple the lake's complex carbon and sulfur cycles (Block et

77 al., 2021). In the deeper monimolimnion (21-52 m), organic substrates (e.g., chitin, lignin,

78 cellulose, acetate, butyrate) appeared to be more influential on assemblage composition than

79 electron acceptors in enrichment incubations, suggesting that the niche-partitioning of

80 organotrophs drives its structure and function (Rojas et al., 2021). Complex, higher molecular

81 weight organic substrates are likely delivered to the deeper monimolimnion by gravitational

82 settling of biogenic particles from the water column above, while monomeric organic substrates

83 are likely produced in situ from anaerobic diagenetic processes. Photoautotrophic blooms appear

84 to be the major source of POC-associated substrates, as $74 \%$ of the lake's annual POC flux to the

85 deep monimolimnion occurs during the bloom period (calculated from Brunskill, 1969).

86 Biogenic particles seem to be major foci of coupled biogeochemical cycles and interactions

87 between primary producers and chemoorganotrophs in FGL. However, to our knowledge, the

88 identities of microorganisms populating PA and FL assemblages in this system are still not known.

89 At the least, their identities are needed to infer the functions of and synergies between PA and FL

90 assemblages and how they affect biogeochemical cycling in FGL. These inferred functionalities

91 can be developed into testable hypotheses and may aid in building models of biogeochemical 
92 cycling. Furthermore, few studies characterizing PA and FL assemblages in shallow, permanently

93 redox-stratified water bodies with intensive blooms of anaerobic photoautotrophs (e.g.,

94 meromictic lakes, fjords, Lauro et al., 2011, Torres-Beltrán et al., 2019) exist. To date, such studies

95 have been conducted primarily in large-scale marine anoxic basins (Fuchsman et al., 2011, Suter

96 et al., 2018, Suomenin et al., 2020), despite the key role played by lakes and oxygen-depleted

97 waters in global carbon sequestration and climate change (Downing et al., 2008, Brietburg et al., 98 2015).

Here, we examine prokaryotic PA and FL assemblages in FGL throughout all redox zones.

100 Our goal is to better understand the roles of PA microbes in biogeochemical processes under

101 varying redox conditions in freshwater systems. We characterize how PA and FL assemblages

102 organize throughout the FGL water column using 16S rRNA gene amplicon sequences and

103 geochemical/hydrographic profiling. We sampled during the peak of concurrent cyanobacteria and

104 purple and green sulfur bacteria blooms in July and at their termination in October to gain some

105 insight into how seasonal surface processes affect community structure and biogeochemical

106 cycles. We hypothesize that redox conditions, bloom events, and particle formation (assemblage

107 type) are the strongest determinants of community structure and activity. Through this work, we

108 hope to highlight the importance of biogenic particles in biogeochemical cycling in FGL and other

109 permanently redox-stratified freshwater environments and build hypotheses for more targeted

110 future studies.

\section{Materials and methods}

112 Sample and sensor data collection

113 We conducted field work on 5-7 October 2016 and 17-21 July 2017 above the deepest part

114 of the lake $\left(43^{\circ} 03^{\prime} 01.9^{\prime \prime} \mathrm{N}, 75^{\circ} 57^{\prime} 58.9^{\prime \prime} \mathrm{W}, \sim 52 \mathrm{~m}\right.$ deep) from a rowboat and a pontoon boat. 
115 Sampling depths spanned the entire water column and strategically targeted the lower oxycline

116 through upper euxinic zone, where physico-chemical features are narrowly distributed (Havig et

117 al., 2015, 2018), at finer (meter to sub-meter) vertical resolution (Table 1). To determine the basic

118 physico-chemical structure and redox-zonation of the water column, a suite of continuous sensor

119 data measurements and hydrogen sulfide concentration measurements were made. Concentrations

120 of oxygen, phycoerythrin and chlorophyll-a, as well as turbidity, salinity, oxidation-reduction

121 potential (ORP), total dissolved solids, and $\mathrm{pH}$ were all continuously profiled using a YSI EXO1

122 sonde sensor package. Discrete samples for hydrogen sulfide concentration measurements and

123 DNA recovery and analyses were collected using Tygon tubing held straight with a planar weight

124 attached to the sampling end and connected to a peristaltic pump. Hydrogen sulfide samples (10

$125 \mathrm{~mL}$ ) were collected in triplicate by immersing a glass gas-tight syringe in an open 60 cc syringe

126 body continuously flushed with water from the collection depth. The glass syringe was purged

127 several times, and contents were immediately expelled into vial with $1 \mathrm{~mL}$ of $1 \mathrm{M}$ zinc acetate

128 preserving dissolved sulfide as $\mathrm{ZnS}$. Samples were refrigerated in the dark until analysis (Li et al.

129 2008, Zerkle et al., 2010, Li and Astor, 2011). Samples for prokaryotic cell counts (50 mL) were

130 collected in duplicate at each depth, immediately fixed with freshly $0.2 \mu \mathrm{m}$ filtered borate-buffered

131 formaldehyde ( $2 \%$ final conc.), and frozen on dry ice. Samples were stored at $-20^{\circ} \mathrm{C}$ upon returning

132 to Stony Brook University, NY, USA.

133 Samples reserved for DNA recovery and analyses were separated into particle-associated

134 (PA) and free-living (FL) operationally-defined fractions by filtering the one liter of lakewater

135 collected from each sampling depth sequentially through sterile $2.7 \mu \mathrm{m}$ QMA and $0.2 \mu \mathrm{m}$

136 Sterivex ${ }^{\mathrm{TM}}$ in-line filters using a peristaltic pump. We recognize that some sequences recovered

137 from the PA fraction may actually be symbiotically-associated with protists or occur in cell 
138 aggregates. By the same token, some sequences in the FL fraction may have detached from

139 particles during sample processing. To ensure representation of in situ assemblages, samples were

140 immediately placed on ice in the dark when collected and filtered on shore within 2-3 hours of

141 sampling. Filters were immersed in lysis buffer (40 mM EDTA, pH $8.350 \mathrm{mM}$ Tris, $0.73 \mathrm{M}$

142 sucrose) and immediately snap frozen on dry ice (Suter et al., 2018). Upon returning to the

143 laboratory, samples were stored at $-80^{\circ} \mathrm{C}$ until processing.

144 Radiotracer incubations and processing

145 To measure total autotrophic and bacterial heterotrophic production rates, radiotracer

146 incubation samples were pumped directly into Pierce ${ }^{\mathrm{TM}}$ screw-top glass septum vials from each

147 sampling depth. Oxygen contamination was avoided by slowly filling vials from the bottom up,

148 overfilling the vial volume three times and constantly dripping fresh ambient water from the

149 collection depth over the Teflon-lined butyl rubber septum while sealing (Taylor et al., 2001).

150 Vials were placed on ice in the dark until incubations were started in 1-3 hours after sampling.

151 Inorganic carbon assimilation radiotracer samples were amended with $\mathrm{N}_{2}$-purged ${ }^{14} \mathrm{C}$ -

152 labelled bicarbonate (Moravek Biochemicals) to a final activity of $0.045 \mu \mathrm{Ci} / \mathrm{mL}$, which equates

153 to an addition of $7.76 \times 10^{-4} \mathrm{mM}$ radioactive bicarbonate to $5-10 \mathrm{mM}$ ambient FGL dissolved

154 inorganic carbon pools (Havig et al., 2018). Vials were incubated for $24 \mathrm{~h}$ and terminated with

155 orthophosphoric acid (0.03 $\mathrm{N}$ final concentration) (Taylor et al., 2001).

To measure the total bacterial heterotrophic production, samples were amended with $\mathrm{N}_{2}$ -

157 purged ${ }^{3} \mathrm{H}$-leucine (MP Biomedicals), a representative labile dissolved organic carbon substrate, 158 to a final activity of $0.016 \mu \mathrm{Ci} / \mathrm{mL}$. The working solution was created by adding radioactive leucine

159 to a cold leucine carrier such that the final leucine concentration in incubations was $22 \mathrm{nM}$. This

160 leucine concentration is believed to be sufficient to saturate bacterial uptake systems and therefore 
161 measure potential assimilation rates in FGL, which is oligotrophic (approximately half the

162 concentration required for uptake saturation in eutrophic lakes, Bastviken and Tranvik, 2001).

163 Vials were incubated for $8 \mathrm{~h}$ and terminated with trichloroacetic acid $(5 \%$ TCA w/w final

164 concentration) (Kirchman 1993, Taylor et al. 2001).

165 Sample vials and TCA-killed controls were incubated in mesh bags layered to transmit 5.4,

1663.2 and $2.5 \%$ photosynthetic active radiation (PAR) to mimic in situ PAR and were placed in open

167 water incubators (one for each FGL temperature zone) to maintain in situ temperatures

168 (Supplementary materials, Fig. S4). Bags were immersed on floating racks to maintain desired

169 temperatures and illumination. Vials from aphotic depths were placed in opaque dark bags at the

170 bottom of the incubator. Temperatures were maintained by adding ice or warm water as needed.

171 In situ PAR was calculated as in Taylor et al. (2003) using published July Secchi depths (Culver

172 and Brunskill, 1969).

173 Terminated inorganic carbon assimilation samples were vacuum filtered $(\leq 200 \mathrm{~mm} \mathrm{Hg})$

174 onto $0.2 \mu \mathrm{m}$ nitrocellulose filters (25mm diam. GVS S.p.A) to dryness. Filters were then rinsed

175 twice with chilled, freshly filter-sterilized, acidified lake water (adjusted to $\mathrm{pH} 3.5$ with $\mathrm{H}_{3} \mathrm{PO}_{4}$ ) to

176 remove unincorporated ${ }^{14} \mathrm{C}$-bicarbonate. To further remove unincorporated ${ }^{14} \mathrm{C}$-bicarbonate, filters

177 were fumigated in their glass scintillation vials within a sealed basin containing an open vial of

178 concentrated (12N) $\mathrm{HCl}$ for $24 \mathrm{~h}$ and then air-dried.

179 Terminated bacterial heterotrophic production samples were maintained at $80^{\circ} \mathrm{C}$ for $20 \mathrm{~min}$

180 in vented test tubes to precipitate proteins, then chilled before further handling. Precipitated

181 proteins were captured on $0.2 \mu \mathrm{m}$ nitrocellulose filters $(25 \mathrm{~mm}$ diameter $)$ by vacuum filtration $(\leq$

$182200 \mathrm{~mm} \mathrm{Hg}$ ). Filters were rinsed twice with $3 \mathrm{ml}$ of chilled 5\% TCA, twice with $3 \mathrm{ml}$ of chilled 
$18380 \%$ ethanol, then saturated dropwise with a final $1 \mathrm{ml} 80 \%$ ethanol rinse. Filters were dissolved

184 with $0.5 \mathrm{ml}$ ethyl acetate in glass scintillation vials (Kirchman, 1993).

185 During each round of bacterial heterotrophic production and inorganic carbon assimilation

186 filtrations, killed controls for abiotic sorption or precipitation of labelled materials were filtered

187 after all environmental samples. For specific activity calculations, the same tracer volume

188 inoculated into samples was added to a small volume of filter-sterilized lake water. These solutions

189 account for how much radioactive tracer is available for biological uptake once accounting for

190 matrix effects. Sample membranes and specific activity solutions were then radioassayed by liquid

191 scintillation counting. ${ }^{14} \mathrm{C}$-bicarbonate radioactivity counts (disintegrations per minute, dpm) were

192 converted to inorganic carbon assimilation rates as in Taylor et al. (2001) using published

193 dissolved inorganic carbon concentrations for FGL from Havig et al. (2015). ${ }^{3} \mathrm{H}-\mathrm{leucine}$

194 radioactivity dpm were converted to bacterial heterotrophic production according to Kirchman

195 (1993) and Taylor et al. (2001).

Hydrogen sulfide sample processing

197 We used Cline's method (Cline, 1969) to quantify hydrogen sulfide. Hydrogen sulfide

198 standards were made by adding $\mathrm{Na}_{2} \mathrm{~S} * 9 \mathrm{H}_{2} \mathrm{O}$ to de-aerated (boiled) nitrogen-purged $\mathrm{ddH}_{2} \mathrm{O}$ and

199 diluted to produce 7-8-point calibration curves. Standards were preserved in the same manner as

200 field samples. Prior to analysis, samples, blanks, and standards were allowed to come to room

201 temperature in the dark and split equally into two Falcon tubes containing $44.5 \mathrm{~mL}$ of dd $\mathrm{H}_{2} \mathrm{O}$ each.

202 In this study, $2 \mathrm{ml}$ of diamine reagent was added to each Falcon tube, sample color development

203 proceeded for $30 \mathrm{~min}$ in the dark at room temperature, and absorbance at $665 \mathrm{~nm}$ was measured

204 spectrophotometrically.

205 Prokaryotic cell enumeration 
To obtain total prokaryotic cell counts, subsamples $(2-5 \mathrm{ml})$ were stained with 4',6diamidino-2-phenylindole (DAPI), then filtered through $0.2 \mu \mathrm{m}$ black polycarbonate membranes

208 (25 mm diam. Whatman Nuclepore ${ }^{\mathrm{TM}}$ ) according to standard protocols (Porter and Feig 1980). To

209 optimize cell dispersion, membranes were dipped in freshly filtered $(0.2 \mu \mathrm{m}) 0.01 \%$ Triton X-100

210 (Sigma-Aldrich) detergent and mounted on water-saturated nitrocellulose backing filters on metal

211 vacuum filtration frits. Membranes were air dried and mounted with a 4:1 mixture of Citifluor ${ }^{\mathrm{TM}}$

212 (Ted Pella, Inc.) and Vectashield ${ }^{\circledR}$ (Vector Laboratories Inc.) mounting solutions. Cells were

213 enumerated on a Zeiss Axioscope epifluorescence microscope at 1000x magnification among

214 sufficient fields of view to achieve $\leq 10 \%$ relative standard deviation (typically between 10 and

21520 fields of view).

216 DNA extraction and amplicon sequencing

217 To recover high-quality genomic DNA for Illumina 16S rRNA amplicon sequencing,

218 DNA was extracted, purified, and concentrated as in Suter et al. (2018). Briefly, sample and

219 negative control lysates were sequentially extracted with agitation using Lysozyme (Fisher

220 Bioreagents) and SDS combined with Proteinase K (Fisher Bioreagents, Sigma-Aldrich ${ }^{\circledR}$ )

221 enzyme at elevated temperature $\left(37^{\circ} \mathrm{C}\right.$ and $55^{\circ} \mathrm{C}$, respectively), followed by $\mathrm{pH}$ 8-buffered

222 25:24:1 phenol:chloroform:isomyl alcohol and 24:1 chloroform:isomyl alcohol (Sigma-

223 Aldrich ${ }^{\circledR}$ ). Extracts were concentrated using $100 \mathrm{kDa}$ membrane centrifugation (Amicon ${ }^{\circledR}$ ), and

224 then further concentrated and purified using a Zymo Genomic DNA Clean \& Concentrator® kit.

225 Quality-indicating A260/280 ratios and double-stranded DNA concentrations of purified DNA

226 samples were measured in triplicate using a NanoDrop Lite (Thermo Scientific). 
TCCTACGGGAGGCAGCAGT-3') and Bac797R (5’-

230 GGACTACCAGGGTATCTAATCCTGTT-3'), which amplify the bacterial 16S rRNA gene

231 (Nadkarni et al. 2002). For each undiluted sample, 10-fold and 100-fold dilutions prepared with

232 nuclease-free water were used as templates in separate PCR reactions prepared with Lucigen

233 Failsafe ${ }^{\mathrm{TM}}$ reagents. Reactions using Pre-mix J and $600 \mathrm{nM}$ forward and reverse primer were

234 prepared according to the manufacturer's instructions. All reactions were run along with a no

235 template control (NTC) and a full procedural blank using a LabNet MultiGene ${ }^{\text {TM }}$ Optimax

236 thermal cycler. Reactions were subjected to a pre-denaturation stage of 5 min at $95^{\circ} \mathrm{C}$ for 1 cycle,

237 a 40 cycle PCR stage consisting of 0.5 min denaturation at $95^{\circ} \mathrm{C}$, annealing at $50^{\circ} \mathrm{C}$ for $0.5 \mathrm{~min}$,

238 and extension at $72^{\circ} \mathrm{C}$ for 1.5 min per cycle, and a final 1 cycle extension stage at $72^{\circ} \mathrm{C}$ for 15

239 min. PCR products were qualitatively evaluated using a UVP GelDoc-It ${ }^{\circledR}$ system after gel

240 electrophoresis using a 1\% agarose gel.

241 Bacterial and archaeal community composition, diversity, and assemblage-partitioning was

242 assessed by sequencing amplicons of the V4-V5 hypervariable regions of the 16S rRNA gene. We

243 used the universal primers 515FY (5'-GTGYCAGCMGCCGCGGTAA-3') and 926R (5'-

244 CCGYCAATTYMTTTRAGTTT-3') (Parada et al., 2016). These primers had suitable Illumina

245 adapters and unique barcodes, allowing all samples to be run simultaneously in a single flow cell.

246 All samples were prepared for sequencing following the Microbiome Amplicon Sequencing

247 Workflow (Comeau et al., 2017). Amplicons were amplified in duplicate samples from the 1:1 and

248 1:10 DNA template dilution with the exception of 20 and $20.5 \mathrm{~m}$ July samples, which were

249 amplified from the 1:10 and 1:100 DNA template dilutions due to inhibitively high DNA

250 concentrations. Paired-end read sequencing $(\sim 350 \mathrm{bp})$ was performed by the Integrated

251 Microbiome Resource (Dalhousie U., Halifax, Nova Scotia, Canada) using an Illumina MiSeq 
252 sequencing platform, producing on average 44,000 raw reads per sample. Raw sequence files were

253 deposited to the NCBI Sequence Read Archive under the BioProject accession number

254 PRJNA752637.

255 Processing sequence data

256 Taxonomic assignments of amplicon sequence variants (ASVs), ASV counts per sample,

257 the relative abundances of taxa at specified taxonomic levels, analysis of microbial community

258 (ANCOM) statistics, and alpha (mean species) and beta diversity (community differentiation)

259 matrices were generated using QIIME 2 ${ }^{\mathrm{TM}}$ version 2020.2 (Boylen et al., 2019), based on the

260 LangilleLab workflow (Comeau et al., 2017) and QIIME 2 ${ }^{\mathrm{TM}}$ moving pictures tutorials with slight

261 modifications, as described below.

262 First, the raw sequences (demultiplexed Casava 1.8 format) were prescreened for adapter

263 sequence contamination, min and max read length and low-quality reads and these were removed

264 prior to trimming primers from the reads. Read files were then further examined using FastQC

265 (Andrews, 2010) to determine the portion of forward and reverse reads retained during read

266 truncation.

267 Using the QIIME 2 ${ }^{\mathrm{TM}}$ plugin 'q2-cutadapt trim-paired,' primer sequences were trimmed

268 from reads and all reads that did not begin and end with the forward and reverse primer sequences

269 were removed (Martin, 2011). Trimmed reads were truncated and denoised with DADA2 using

270 the 'q2-dada2' plugin (Callahan et al., 2016) with the allowable base-call error for forward and

271 reverse reads set to 3 , which retained an average of 23,078 non-chimeric reads per sample. The

272 resulting table of sequence (QIIME 2 ${ }^{\mathrm{TM}}$ "feature") frequency per sample from the DADA2 output

273 was then frequency-filtered to retain sequences with a minimum frequency of 20 reads in at least

274 one sample to exclude features that likely occurred due to MiSeq bleed-through between runs. 
The frequency-filtered sequence frequency table was then used to filter the sequence table

276 from the DADA2 output to create a table of representative ASVs. Those ASVs were classified

277 using 'q2-classifier' plugin (Bokulich et al. 2018) with a classifier that was pre-trained against the

278 SILVA database for our primers (silva_132_99_16S_V4.V5_515F_926R database) using the

279 Naive-Bayes approach implemented in the 'scikit-learn' Python library. The classified frequency-

280 filtered frequency table was then filtered by taxonomy to exclude chloroplasts and mitochondria

281 using the "taxa filter-table" command. The removed chloroplast and mitochondria sequences that

282 did not belong to cyanobacteria were run through megaBLASTN ${ }^{+}$to identify eukaryote algae

283 according to the accepted definition of an operational taxonomic unit $(>97 \%$ amplicon percent

284 identity) (Altschul et al., 1990, Morgulis et al., 2008, Camacho et al., 2008). Steps preceding

285 filtration by taxonomy were then repeated with the taxonomy-and-frequency filtered sequence

286 frequency table to produce the final sequence and taxonomy tables. Counts per sample tables were

287 output in both the ASV format and with ASVs collapsed into taxa at desired taxonomic levels by

288 exporting the taxonomy-filtered feature frequency table or using the "taxa collapse" command.

The mitochondria-and-chloroplast free ASVs were then aligned with the multiple

290 alignment program for amino acid or nucleotide sequences (MAFFT, Katoh et al., 2002) using

291 default settings. Aligned ASVs were used to construct a phylogenetic tree with fasttree2 (Price et

292 al, 2010) using default settings through the 'q2-phylogeny' plugin. To ensure that sequencing

293 depth fully saturated the alpha diversity of samples with a lower number of reads, a rarefication

294 plot of various alpha diversity metrics versus reads was produced by rarifying to 4900 sequences

295 (the minimum number of reads out of all samples) per sample with a step size of 20 sequences.

296 Using the ‘q2-diversity’ plugin, we calculated alpha diversity indices, Shannon’s Diversity Index

297 (H) that accounts for both taxon abundance and evenness (Shannon and Weaver, 1949) and Pielou- 
evenness that assesses how evenly taxa are distributed within the community (Pielou, 1966), and

299 beta diversity indices, Bray-Curtis that quantifies compositional similarities between two

300 communities (Bray and Curtis, 1957) and weighted unifrac that quantifies compositional

301 similarities and incorporates phylogenetic distances of taxa within the communities (Lozupone et

302 al., 2007).

303 To determine if any ASVs were significantly more abundant in assemblages defined by

304 metadata categories, analysis of microbial community (ANCOM) (Mandal et al., 2015) was

305 performed. A pseudo-counted chloroplast-and-mitochondria-free filtered ASV table was subject

306 to ANCOM using the QIIME 2" "composition ancom" command; the pseudo-count increases all

307 ASV counts by one because zero is not allowed as input. ANCOM tests determine if ASVs'

308 relative abundances in two assemblages are significantly different by calculating pairwise log

309 relative abundance ratios between all representative ASVs in each assemblage. Per ASV, from

310 these pairwise ratios, a W-statistic (the number of ratios that are significantly different between

311 the two assemblages by an f one-way test) is calculated. The relative abundance of the ASV in the

312 two assemblages assemblages is considered significantly different if the W-statistic is above an

313 empirical threshold. To ensure that significant W-statistics were not due to the ASV having a

314 higher relative abundance than most ASVs in a given sample, ANCOM test results were examined

315 in clr (the $\log _{2}$-transformed arithmetic mean-normalized relative abundance)-W statistic space.

316 Then only significant ASVs that were not over-represented (in the upper left-hand quadrant of the

317 volcano plot) were retained.

318 All correlation analyses between alpha and beta diversity metrics and metadata were

319 performed using a categorical version of the metadata. A categorical metadata table was created 
by binning all continuous metadata measurements after histogram visualization other than redox zones, which were defined as presented in the introduction.

323 a given sample was calculated by:

$324 \mathrm{OF}=\ln \left(\frac{\mathrm{PA}_{\mathrm{ra}}}{\overline{\mathrm{G}}_{\mathrm{PA}}}\right)-\ln \left(\frac{\mathrm{FL}_{\mathrm{ra}}}{\overline{\mathrm{G}}_{\mathrm{FL}}}\right)$,

325 where $\mathrm{PA}_{\mathrm{ra}} / \overline{\mathrm{G}}_{\mathrm{PA}}$ is the relative abundance of that taxon in the particle-associated assemblage

326 normalized to that particle-associated sample's relative abundance geometric mean. $\mathrm{FL}_{\mathrm{ra}} / \overline{\mathrm{G}}_{\mathrm{FL}}$ is

327 the relative abundance of the same taxon in the free-living assemblage normalized to that free-

328 living sample's relative abundance geometric mean. A taxon was considered over-represented in

329 the particle-associated or free-living assemblage if their OF was 1.25 or -1.25 , respectively. These

330 bounds correspond to a 3.5 -fold difference.

This metric, based on log-transformed geometric mean-normalized relative abundances,

332 was created in lieu of a standard enrichment factor (log-transformed $\left.\frac{\mathrm{PA}_{\mathrm{ra}}}{\mathrm{FL}_{\mathrm{ra}}}\right)$ to allow true between-

333 sample numeric comparisons. Log-transformed geometric mean-normalized relative abundances,

334 also known as "center log ratio (clr) transformed," are commonly used in microbiome analyses.

335 Clr-transformation allows for scale-invariant between-sample comparisons regardless of the

336 abundance distributions of taxa in individual samples, making between-sample statistics more

337 meaningful (Gloor et al., 2017, Badri et al., 2018). As an example, clr-transformed abundance data

338 is commonly plotted against test statistic data on volcano plots as part of ANCOM analyses to

339 ensure that ASVs are not returned as significant due to skewed abundance data (e.g., Cendron et

340 al., 2020, Li et al., 2020).

341 All alpha and beta diversity statistics other than the dissimilarity matrices were calculated 342 using the python sci-kit bio ${ }^{\mathrm{TM}}$ library (v.0.5.6). Principal coordinate analysis (PCoA) was 
343 performed on both Bray Curtis and weighted unifrac beta QIIME $2^{\mathrm{TM}}$ dissimilarity matrices. This

344 produces principal coordinates from combinations of the matrix such that new variables are

345 uncorrelated and most matrix variance is found in the first two or three variables. Sample clustering

346 in PCoA matrices was visualized in the three-dimensional space of the first three principal

347 coordinates. Samples were color-coded by categorical metadata to match categories to clustering

348 patterns. Bray-Curtis and weighted unifrac visualizations were compared to determine if

349 incorporating phylogenetic tree branch lengths improved pattern matching between metadata

350 categories and clustering patterns. Permutational analysis of variance (PERMANOVA) was

351 performed on beta diversity matrices to determine if metadata variables explained dissimilarity

352 among samples. PERMANOVA compares the ratio of the sum of squares of a chosen distance

353 metric (in this case, Bray-Curtis or weighted unifrac dissimilarity) within a group to the sum of

354 squares between groups to multiple data permutations. An ANOSIM test was run on beta diversity

355 matrices grouped by field campaign month, redox regime, and assemblage type (particle-

356 associated or free-living). The null hypothesis of an ANOSIM test is that similarities among

357 samples within a particular category/grouping are less than or equal to similarities among samples

358 in the other categories/groupings. The test statistic $\mathrm{R}$ is calculated as the ratio of the difference

359 between the average rank similarity between sample pairs from within categories and between

360 categories. $\mathrm{R}$ can be anywhere from -1 to 1 , with positive values indicating similarity within a

361 category and negative values indicating dissimilarity among categories.

362 For each metadata variable, Kruskal-Wallis tests were run for each unique categorical bin

363 combination with Pielou evenness values to determine if the variable accounted for significant

364 differences in sample alpha diversity. False discoveries were corrected using the

365 Benjamini/Hochberg (non-negative) method (Benjamini and Hochberg 1995, 2000). 


\section{Results}

Major biogeochemical features

The depth of the wind-mixed, oxygenated layer in the mixolimnion, and the depth of the lower oxycline boundary, defined by the first appearance of $\mathrm{H}_{2} \mathrm{~S}$ and precipitous drop in oxidation reduction potential, was shallower during July ( $3 \mathrm{~m}$ and $20 \mathrm{~m}$, respectiveley) than during October

371 (9 $\mathrm{m}$ and $21 \mathrm{~m}$, respectively) (Figs. 1, 2, Supplementary materials Fig. S5). During both

372 sampling times, the upper oxycline boundary was located at $15 \mathrm{~m}$, and a pronounced light-

373 scattering layer (measured turbidity) was found between 19 and $23 \mathrm{~m} . \mathrm{H}_{2} \mathrm{~S}$ concentrations in the

374 deep monimolimnion reached maximum concentrations of $1.62 \mathrm{mM}$ (40 m) during July and 2.55

$375 \mathrm{mM}(45 \mathrm{~m})$ during October (Fig. 1). These measurements are consistent with previous studies with

376 the exception of the maximum October $\mathrm{H}_{2} \mathrm{~S}$ concentration, which was approximately $14 \%$ greater

377 than reported values at similar times of the year (Havig et al., 2015, 2018, Fulton et al., 2018, Rojas

378 et al., 2021, Block et al., 2021).

The light-scattering layer had elevated microbial activity and hosted stratified populations of different photoautotrophs during both sampling times. A deep cyanobacterial population was detected by phycoerythrin fluorescence and a deep $\mathrm{O}_{2}$ enrichment of approximately $25 \mu \mathrm{M}$ near the top of the layer (19-19.75 m) in July (Fig. 3). These features overlapped with the maximum rate of bacterial heterotrophic production. Phycoerythrin fluorescence was barely detectable during

384 October, when maximum bacterial heterotrophic production was nearly five-fold lower, deep $\mathrm{O}_{2}$ 385 enrichment was 3-fold lower, but chlorophyll-a fluorescence was approximately 3-fold higher 386 (Fig. 3). Brightfield microscopy and observations of intense purple and green water color during 387 both field samplings revealed purple and green sulfur bacteria populations within layers from 2038821 and 21-23 m, respectively. The purple sulfur bacteria population coincided with maxima in 
transmissometer light attenuation (measured turbidity), total inorganic carbon assimilation rates, total cell concentrations, and $\mathrm{pH}$ at or directly below the lower oxycline boundary (Fig. 3,

391 Supplementary materials Fig. S6).

392 Diversity analyses

394 characterize richness and evenness of the PA and FL assemblages across sampled depths. During

395 October and July, the light-scattering layer (19-23 m) was the least diverse in the water column

396 (Fig. 4). Within this layer, distinctive H minima in PA and FL assemblages were observed

397 during July at $21 \mathrm{~m}(\mathrm{PA} \mathrm{H}=4.7, \mathrm{FL} \mathrm{H}=3.9)$ and October at $20 \mathrm{~m}(\mathrm{PA} \mathrm{H}=2.6, \mathrm{FL} \mathrm{H}=5.0)$,

398 coinciding with purple and green sulfur bacteria and Desulfobulbaceae populations. Pielou

399 evenness index profiles were very similar to the $\mathrm{H}$ index, suggesting that low $\mathrm{H}$ values are likely

400 caused by a few highly abundant taxa (Fig. 4). When Pielou evenness scores were binned by

401 inorganic carbon assimilation rate, evenness of samples with elevated rates, a characteristic of

402 the light-scattering layer, was significantly different from all other groups (false discovery-

403 corrected pairwise Kruskall-Wallace test $p<q$, Supplementary materials Table S1).

404 Excluding the light-scattering layer, alpha diversity generally increased with depth. During

405 both sampling times, FL assemblages were typically more diverse than PA assemblages except

406 within the mixolimnion, where PA and FL assemblages were approximately equally diverse $(\mathrm{H}=$

407 4-5). One exception was at $40 \mathrm{~m}$ during October ( $\mathrm{PA} \mathrm{H}=6.8, \mathrm{FL} \mathrm{H}=5.6)$. The difference in diversity

408 between PA and FL assemblages was smaller during July than during October (typically by less

409 than 0.5$)$ and remained similar over depth with the exception of the deepest (40 m) sample (PA

$410 \mathrm{H}=4.3, \mathrm{FL} \mathrm{H}=5.6$ ). In contrast, during October, differences ranged from 1.5- to 2-fold within the

411 oxycline and was nearly 3-fold within the light-scattering layer. These results suggest that 
412 assemblage partitioning varies seasonally. Possibly, this can be attributed to greater rates of

413 physical particle aggregation and disaggregation (and therefore greater similarity) in summer,

414 when particulate matter concentrations are likely higher as a result of the blooms.

415 To characterize compositional differences among samples (beta diversity), we calculated

416 the Bray-Curtis dissimilarity metric and performed a PCoA on the resulting dissimilarity matrix .

417 The first three coordinates of the Bray-Curtis PCoA explained 53.2\% of total sample variance.

418 When metadata variables were mapped over the samples in coordinate space, we found that the

419 FGL community was strongly partitioned by ORP, assemblage-type, and by field campaign (time-

420 of-year). We verified that these community composition groups were significantly different from

421 one another by multiple statistical tests (ANOSIM and PERMANOVA, $p<0.05$ ). Detailed Bray-

422 Curtis PCoA PERMANOVA results are provided in supplemental materials (Supplementary

423 materials Table S2). ORP separated clusters from one another along PC1 in PC1-PC2 space,

424 accounting for the largest variance (Fig. 5). Interestingly, samples from non-euxinic depths did

425 not further separate from one another along PC1 by redox condition (i.e., suboxic, hypoxic,

426 normoxic). However, samples did separate into two subclusters by sampling date along PC2,

427 primarily due to variations in seasonal surface processes (Fig. 5). Assemblage type (PA or FL)

428 separated clusters from one another along PC3 in PC2-PC3 space (Fig. 5).

429 Taxonomic composition

430 We found that the archaeal and bacterial 16S rRNA gene amplicon community

431 composition of the FGL water column during July and October varies with assemblage type (PA

432 or FL), redox-zonation, and time-of-year. Across all depths, Bacteroidetes (Jul.=52.3\%,

433 Oct. $=26.1 \%), \quad$ Proteobacteria $\quad(\mathrm{Jul} .=21.1 \%, \quad$ Oct. $=37.3 \%), \quad$ Cyanobacteria $\quad(\mathrm{Jul} .=11.0 \%$,

434 Oct. $=11.9 \%)$, Actinobacteria (Jul. $=6.3 \%$, Oct. $=11.0 \%)$, and Verrucomicrobia $(\mathrm{Jul} .=0.9 \%$, 
435 Oct. $=0.8 \%$ ) were the most abundant phyla among total reads during both sampling dates (Fig. 6).

436 Amplicons from Bacteroidetes had no discernable depth dependent patterns. Actinobacteria,

437 Cyanobacteria and Verrucomicrobia sequences were more abundant in the mixolimnion and

438 oxycline than in deeper waters by approximately 1 to 1.5 orders of magnitude. The relative

439 abundance of Proteobacteria in 16S rRNA gene libraries decreased over depth from 85.0 to $17.7 \%$

440 between 5 and $40 \mathrm{~m}$ in FL assemblages during October. During July, Proteobacteria were far more

441 abundant in the deepest sample $(40 \mathrm{~m})$ in both assemblage-types $(\mathrm{PA}=71.4 \%, \mathrm{FL}=55.8 \%)$ than

442 throughout the rest of the water column $(\mathrm{PA}=4.9-31.7 \%, \mathrm{FL}=11.0-26.4 \%)$. During October,

443 however, they had much greater relative abundances in the shallowest sample $(5 \mathrm{~m})$ in both

444 assemblage-types $(\mathrm{PA}=94.4 \%, \mathrm{FL}=85.0 \%)$ than throughout the rest of the water column

$445 \quad(\mathrm{PA}=17.7-61.2 \%, \mathrm{FL}=17.3-51.1 \%)$. Chlorophyte algal chloroplast 16S rRNA amplicon sequences

446 were also highly abundant in October, especially near the lower oxycline boundary. Chloroplast

447 depth distriubtions aligned well with those of the chlorophyll-a fluorescence (Supplementary

448 materials Figs. S9, S10). Chloroplast sequences were scarce in all July samples.

449 The most abundant families in the 16S rRNA amplicon libraries varied more strongly with

450 depth than the most abundant phyla (Fig. 7). Family abundances differed most between sampling

451 dates in mixolimnion and oxycline samples, while compositions between sampling dates in the

452 monimolimnion were similar. The most abundant families in the July mixolimnion and oxycline

453 belonged to the Flavobacteriales $(\mathrm{PA}=23.7-62.7 \%, \mathrm{FL}=9.5-18.0 \%)$, Cytophagales $(\mathrm{PA}=0.7-3.7 \%$,

$454 \mathrm{FL}=3.2-9.5 \%)$, Synechococcales $(\mathrm{PA}=3.9-24.9 \%, \mathrm{FL}=3.8-28.8 \%)$, Frankiales $(\mathrm{PA}=2.8-6.1 \%$,

$455 \mathrm{FL}=11.5-31.6 \%)$, Microtrichales $(\mathrm{PA}=2.0-4.0 \%, \quad \mathrm{FL}=2.1-4.9 \%)$ and $\mathrm{SAR} 11(\mathrm{PA}=0.4-1.8 \%$,

$456 \quad \mathrm{FL}=2.5-4.0 \%)$ orders. 

$(\mathrm{PA}=0.1-2.7 \%, \mathrm{FL}=4.2-34.5 \%)$ orders remained abundant in October, but other families abundant in July represented much less of the October mixolimnion and oxycline assemblages. Instead,

460 families in the Bacillales $(\mathrm{PA}=0.0-46.1 \%, \mathrm{FL}=0.0-2.7 \%)$, Ignavibacteriales ( $\mathrm{PA}=0.0-8.5 \%$, $461 \quad \mathrm{FL}=0.0-0.2 \%), \quad$ Betaproteobacteriales $\quad(\mathrm{PA}=1.4-67.0 \%, \quad \mathrm{FL}=16.9-59.3 \%), \quad$ Chitinophagales $462(\mathrm{PA}=1.8-28.7 \%, \mathrm{FL}=1.5-6.5 \%)$, Rhizobiales $(\mathrm{PA}=0.4-4.4 \%, \mathrm{FL}=0.1-10.0 \%)$ and Pirellulales $463(\mathrm{PA}=0.2-8.9 \%, \mathrm{FL}=0.0-1.7 \%)$ orders were more highly represented. The Caulobacterales and 464 Bacillales orders were represented by single genera (Brevundimonas and Exiguobacterium, 465 respectively). ASVs from the Burkholderiaceae family (Betaproteobacteria) contributed the 466 greatest number of identifiable genera as well as unclassified members (e.g., Limnohabitans, 467 Polynucleobacter, Aquabacterium, Hydrogenophaga, Ideonella, Rhodoferax). Ferribacterium was the sole representative of the Rhodocyclaceae family (Betaproteobacteriales). Ferribacterium 469 was by far the most abundant genus in the October mixolimnion and oxycline and was significantly more abundant in October than in July samples (ANCOM test, W-statistic=888).

472 the light-scattering layer (19-23 m) were photoautotrophic Cyanobiaceae (cyanobacteria), 473 Chromatiaceae (purple sulfur bacteria) and Chlorobiaceae (green sulfur bacteria). In the light474 scattering layer, these families combined made up $3.9-54.4 \%$ of PA assemblages and 3.9- $68.9 \%$ 475 of FL assemblages during July and $16.7-33.3 \%$ of PA assemblages and 5.5-30.4\% of FL 476 assemblages during October. Within this layer, the Desulfobulbaceae and PHOS-HE36 were also 477 especially abundant. Desulfobulbaceae sequences represented a single genus capable of sulfate 478 reduction and sulfur disproportionation, Desulfocapsa. Desulfobulbaceae (PA=0.1-52.9\%, $479 \quad \mathrm{FL}=0.0-0.6 \%)$ and PHOS-HE36 $(\mathrm{PA}=0.0-8.5 \%, \mathrm{FL}=0.0 \%)$ sequences were more abundant in 
480 October, when photoautotroph abundances were lower. Below the light-scattering layer, the

481 relative abundance of purple sulfur bacteria decreased with depth but was highly enriched in the

482 deepest July sample (40 m, PA=42.5\%, FL=4.5\%). Chlorobiaceae (green sulfur bacteria)

483 decreased with depth in both July and October by approximately an order of magnitude between

484 their maximum within the light-scattering layer $(21 \mathrm{~m})$ and the deepest sample $(40 \mathrm{~m})$. Retrieval

485 of photoautotroph sequences from depths below the photic zone likely represents sedimenting

486 senescing or dead cells, indicating that material is being vertically transported from the light-

487 scattering layer towards the lakebed. Depth distributions and the assemblage-partitioning of

488 Desulfobulbaceae and purple sulfur bacteria sequences were similar, suggesting physical

489 association in particles.

490 The most abundant taxa recovered from below the light-scattering layer during both field

491 campaigns were organotrophic anaerobes. These included sequences from the sulfate-reducing

492 families Desulfarculaceae (consisting entirely of Desulfatiglans) and Syntrophaceae (combined:

493 Jul. $\mathrm{PA}=1.8-3.4 \%, \mathrm{FL}=8.9-12.4 \%$; Oct. $\mathrm{PA}=5.7-7.7 \%, \mathrm{FL}=7.9-14.4 \%$ ). Fermentative and/or

494 respiratory organotrophic taxa were highly represented by ASVs from the Lentimicrobiaceae,

495 Spirochaetaceae (entirely Sphaerochaeta), Prolixibacteraceae, Marinilabiliaceae, and families

496 belonging to the order Bacteroidales (Bacteroidetes BD2-2, VC2.1 Bac22). Below the light-

497 scattering layer these families combined accounted for $11.0-32.3 \%$ of PA assemblages and 16.4-

$49821.7 \%$ of FL assemblages during July and $17.7-30.0 \%$ of PA assemblages and $23.4-46.9 \%$ of FL

499 assemblages during October. Several putative organohalide-respiring taxa were also abundant,

500 including the environmental family S15A-MN91 and the GIF9 order of Dehalococcodia (Jul.

$501 \mathrm{PA}=2.3-5.6 \%, \mathrm{FL}=1.0-2.8 \%$; Oct. $\mathrm{PA}=3.3-9.0 \%, \mathrm{FL}=1.4-3.2 \%)$. An unassignable member of the 
502 archaeal class Woesearchaeia was also abundant at one depth $(25 \mathrm{~m})$ during July $(\mathrm{PA}=1.7 \%$,

$503 \quad \mathrm{FL}=1.0 \%)$ (Fig. 7).

504 Assemblage partitioning

505 The assemblage-partitioning (PA or FL) of archaeal and bacterial 16S rRNA gene

506 amplicons was evident throughout the FGL water column during July and October at the family

507 level. Of the five most abundant phyla, only Actinobacteria were more abundant in one type of

508 assemblage (FL). As expected, algal chloroplasts were primarily captured in PA assemblages

509 because they represent phototrophic eukaryote cells. Assemblage partitioning of some families

510 differed between sampling dates. For example, families in the Flavobacteriales order were highly

511 over-represented in PA assemblages throughout the water column in July, but neutral or even

512 slightly over-represented in FL assemblages in October (Fig. 8). In contrast, families that were

513 most abundant in the light-scattering layer, such as Chromatiaceae, Desulfobulbaceae,

514 Pirellulaceae and PHOS-HE36, were recovered almost entirely from PA assemblages during both

515 campaigns. An ASV classified as the purple sulfur bacterium, Thiodictyon, was significantly more

516 abundant in PA assemblages than in FL assemblages in all samples (ANCOM test, W-

$517 \quad$ statistic $=885)$.

518 Sulfate-reducing bacteria, organohalide-respirers, and other fermentative and/or

519 respiratory organotrophic families that were highly abundant below the light-scattering layer were

520 low-abundance, but highly over-represented (over-representation factor $\geq 2$, or $\geq 7.4$-fold more

521 abundant) in PA assemblages within the mixolimnion and shallow oxycline (Fig. 8). More taxa,

522 and notably those that are less oxygen-tolerant, displayed this pattern in July, possibly due to

523 enhanced thermal stratification in the upper water column. These included Spirochaetaceae,

524 Desulfobulbaceae, Desulfarculaceae, Syntrophaceae, and Bacteroidetes BD2-2 during July, GIF9, 
S15A-MN91 and VC2.1 Bac22 during October, and Marinilabiliaceae during both field campaigns.

Because the most abundant families belong to four phyla and have only a few putative metabolisms, over-representation factors of all phyla were considered to look for less abundant,

533 from the mixolimnion and are vertically transported in particles to the deep monimolimnion.

534 Supporting this hypothesis, members of these phyla often attach to sinking particles in the shallow

535 waters and therefore have this type of over-representation distribution (Delong et al., 1993, Bižić-

536 Ionescu et al., 2014a, Thiele et al., 2015, Duret et al., 2018). Anaerobic phyla that were moderately

537 abundant in the monimolimnion were rare but highly over-represented in PA assemblages in the

538 July mixolimnion and oxycline samples, such as Marinimicrobia (SAR406), Atribacteria (entirely

539 the class JS1), and Nanoarchaeota.

540 Most over-represented phyla in PA assemblages were low abundance anaerobes and often

541 represented by one or two families. These included Altiarchaeota, Armatimonadetes, Chloroflexi,

542 Euryarcheaota, Hydrogenedentiales, Kiritimatiellaeota and Spirochaetes. Euryarcheota sequences

543 consisted entirely of an uncultured methanogenic order Methanofastiodiosales and the methanogen

544 Methanoregula. Altiarchaeota sequences arose entirely from the uncultured class Altiarchaeia.

545 Hydrogenedentiales was entirely represented by the family Hydrogenedensaceae. Spirochaetes 546 sequences were entirely from the family Spirochaetaceae.

\section{Discussion}




\section{Particles shape microbial composition and diversity}

Microbes associated with particles are taxonomically and functionally distinct from free-

550 living microbes in aquatic environments, but are intertwined with one another in biogeochemical

551 interplay. Differences are shaped by the availability of organic substrates, nutrients, reductants,

552 and oxidants required for microbial metabolisms. However, their interactions are driven by

553 cooperation, antagonism, symbiosis and syntrophy and the physical exchange of dissolved and

554 particulate reactants. In permanently redox-stratified water bodies, these assemblages are

555 additionally shaped by ambient redox conditions, which determines the availability of reductants

556 and oxidants over depth. Lakes play a critical role in global carbon sequestration (Downing et al.,

557 2008), and many are likely to become permanently redox-stratified due to global climate change

558 (Lau et al., 2020). However, studies of PA and FL microbial assemblages in permanently redox-

559 stratified water bodies have primarily focused on larger marine systems (Fuchsman et al., 2011,

560 Suter et al., 2018, Suomenin et al., 2020).

This study revealed that the community phylogenetic composition of all samples from FGL

562 varied among redox condition (oxidation reduction potential) and assemblage type (PA or FL),

563 while only samples from non-sulfidic depths differed by sampling date (Fig. 6). In permanently

564 stratified water columns, deeper, anoxic waters are usually isolated from surface seasonal physico-

565 chemical changes by a pycnocline, a water density gradient. Therefore, the nearly temporally

566 invariant geochemistry at depth likely also shapes community composition independently of

567 seasonal variables (e.g., grazing pressure, wind mixing, organic matter production and flux, 568 temperature).

Richness and evenness of the microbial assemblages also varied with redox condition and

570 assemblage type, with differences between assemblages varying temporally. Consistent with other 
571 studies of redox-stratified water bodies and of FGL, alpha diversity generally increased over depth,

572 except within the light-scattering layer (Fuchsman et al., 2011, Suter et al., 2018, Suomenin et al.,

573 2020, Rojas et al., 2021, Block et al., 2021). However, alpha diversity was greater in FL

574 assemblages than in PA assemblages, contrary to what has been reported in marine anoxic basins

575 (Fig. 5a,b) (Fuchsman et al., 2011, Suter et al., 2018, Suomenin et al., 2020). In FGL, this may

576 reflect vertical transport of low-diversity PA assemblages from the mixolimnion and light-

577 scattering layer towards the lakebed by gravitational settling. This hypothesis is supported by the

578 presence of highly over-represented taxa from the mixolimnion and light-scattering layer at depth

579 (Figs. 6, 7, 8, 9). Additionally, recalcitrant particulate organic substrates that have been vertically-

580 transported to the monimolimnion (e.g., chitin, lignin, cellulose) may select for specialist

581 assemblages of lower diversity (Rojas et al., 2021).

Composition of the mixolimnion and oxycline differs by sampling date

In aquatic environments, nutrient and organic matter availability varies seasonally,

resulting from a combination of physical mixing, primary production, and other biological activity

585 (Sarmiento and Gruber, 2013). In FGL, as in all permanently redox-stratified water bodies, these

586 processes are restricted to water above the pycnocline, unless there are lateral oxygen intrusions.

587 Compositional differences between the July and October mixolimnion and oxycline assemblages

588 in FGL likely reflect seasonal availability of organic carbon substrates and inorganic nitrogen. The

589 concentration and quality of organic carbon substrates is likely lower in October than in July

590 because the shallow cyanobacteria bloom (a major source of labile dissolved and particulate

591 organic carbon) had ended. At the same time, inorganic nitrogen availability is higher in October

592 than in July (Fulton et al., 2018), likely due to lower uptake by the senescing shallow cyanobacteria

593 population and deeper wind-mixing (Fig. 10). 
We hypothesize that lower organic $\mathrm{C}$ to inorganic $\mathrm{N}$ ratios in October should favor nitrogen removal from FGL through denitrification and anaerobic oxidation of ammonia

596 (anammox) over nitrogen recycling by the dissimilatory reduction of nitrate to ammonium

597 (DRNA) (Nizzoli et al., 2010; Chutivisut et al., 2018). Supporting this hypothesis, dissolved 598 organic carbon concentrations in FGL are nearly invariant between summer and autumn (Havig et 599 al., 2015, 2018), while nitrate concentrations are nearly two-fold greater in autumn than summer.

600 As a result, the dissolved organic $\mathrm{C}$ to inorganic $\mathrm{N}$ ratio is nearly two-fold lower in autumn.

601 Therefore, the taxonomic composition of the July mixolimnion and oxycline should reflect organic

602 matter abundance (aerobic heterotrophy) and inorganic nitrogen scarcity (diazotrophy), while the

603 composition of the October mixolimnion and oxycline should reflect nitrogen-removal

604 (denitrification, anammox) and organic matter scarcity (oxidation and/or fermentation of

605 recalcitrant organic carbon substrates). Indeed, the most abundant families in the July mixolimnion

606 and oxycline were aerobic heterotrophs and diazotrophs, while the most abundant families in the

607 October mixolimnion and oxycline were putative and known denitrifiers, iron-reducers, and

608 fermenters. Although the abundance of the obligatory anammox bacterium Candidatus

609 anammoximicrobium in the oxycline did not vary between July and October, the taxon's

610 assemblage parititioning did; it was almost entirely recovered from PA assemblages in the July

611 oxycline and almost entirely recovered from FL assemblages in the October oxycline.

$612 \quad$ July mixolimnion and oxycline

613 The Crocinitomicaceae and Flavobacteriaceae families within Flavobacteriales order were

614 especially abundant and over-represented in July PA assemblages (Figs. 8, 9, and 10). These

615 families metabolize complex, proteinaceous substrates that other microbes are unable to access

616 directly. Therefore, they are dominant during algal blooms in freshwater and marine environments, 
617 and are integral to initiating particle remineralization (DeLong et al., 1993, Bižić-Ionescu et al.,

618 2014a, b, Duret et al., 2019). The algicidal Cytophagales order, which is often associated with

619 particles and functionally similar to the Flavobacteria (Kirchman, 2002), were more abundant in

620 FL assemblages (Figs. 8, 9). However, there are reports of the Cytophagales families being most

621 abundant in FL assemblages during freshwater cyanobacteria blooms (Akins et al., 2018).

622 Consistent with other niche partitioning studies during freshwater algal blooms, the other

623 abundant aerobic heterotrophs (families within SAR11 and Microtrichales) and diazotrophs

624 (families within Frankiales) were over-represented in FL assemblages (Fig. 9) (Salcher et al., 2011,

625 Bižić-Ionescu et al., 2014b, Morrison et al., 2017, Akins et al., 2018). Diazotrophy is advantageous

626 under the nitrogen-limited conditions typical of algal blooms (Shin et al., 2019) because nitrogen

627 requirements can be met with little available nitrate. These taxa do not access their organic

628 substrates within or on particles like the Flavobacteria. However, they are associated with blooms

629 because the labile dissolved organic substrates they consume originate from particles and algal

630 lysates, in part, from the activity of microbes like the Flavobacteria (Mayali and Azam, 2004,

631 Alonso and Pernthaler, 2006, Salcher et al., 2011, Zheng et al., 2020). The interconnectedness of

632 seasonal particle production (biomass) and consumption of labile dissolved organic substrates is

633 hinted at by the overlapping distributions bacterial heterotrophic production and phycoerythrin

634 concentrations in the July profiles. This alignment suggests that bacterial heterotrophic production

635 is responsive to cyanobacteria abundances (Figs. 2c, 3a).

636 October mixolimnion and oxycline

637 The most abundant families in the October mixolimnion and oxycline appear to have a 638 competitive advantage when organic carbon substrates are scarce and less labile and/or when 639 inorganic nitrogen is more abundant. Under these limitations, the putative metabolisms of the taxa 
over-represented in PA assemblages (Pirellulaceae, families within Chitinophagales, Rhizobaceae and Burkholderiaceae, Figs. 8, 9), are likely connecting multiple elemental cycles (iron, nitrogen,

642 hydrogen, and carbon) in particles. For example, many of the Burkholderiaceae genera, including

643 Aquabacterium, Hydrogenophaga, Ideonella and unclassified Burkholderiaceae, are capable of

644 consuming aromatic compounds or hydrocarbons (e.g., pyrene, benzene and petroleum

645 hydrocarbons) that are integral to producing volatile fatty acids for co-existing iron-reducers

646 (Kalmbach et al., 1999, van der Zaan et al., 2012, Zhang et al., 2016, Yan et al., 2017, Wieczorek

647 et al., 2019, Liu et al., 2020, Fig. 10).

Burkholderiaceae-rich consortia have also recently been linked to enhanced denitrification,

649 which could be attributable to the metabolic flexibility of the most common genera. Metabolic

650 flexibility to mediate organotrophic and/or chemoautotrophic nitrogen and iron cycling reactions

651 could be beneficial when organic substrates are scarce. (Zhang et al., 2016, Liu et al., 2020). For

652 example, Hydrogenophaga can couple hydrogen oxidation with denitrification (Liu et al., 2020)

653 or aromatic carbon oxidation with iron reduction (Yan et al., 2017). Aquabacterium can mediate

654 iron oxidation or chemoorganotrophic denitrification (Kalmbach et al., 1999, Zhang et al., 2016).

655 Notably, these were also the most common identifiable genera of Burkholderiaceae during 656 October.

657 A potential connection between recalcitrant organic carbon oxidation and iron reduction in 658 FGL during October is supported by the much higher abundance of obligate iron-reducers in the 659 mixolimnion and oxycline compared to July, including Ferribacterium (Rhodocyclaceae, Figs. 8, 660 9) and Rhodoferax (Cummings et al., 1999, Finneran et al., 2003, Chan et al., 2018). Iron-reducers 661 were expected to be more common in PA assemblages, because reducible iron is particulate. 662 However, Ferribacterium and Rhodoferax sequences were equally likely to be recovered in both 
663 assemblage types (over-representation factor $\sim 0$ ). This unexpected assemblage partitioning of

664 iron-reducers could be explained by the documented existence of particulate-iron-rich extracellular

665 polymeric substances (EPS) at non-sulfidic depths in FGL (Kamennaya et al., 2020), as iron

666 cycling is promoted in EPS (Chiu et al., 2017). If iron-reducers do reside in EPS in FGL, which is

667 easily disturbed during filtration (Engel, 2009), they could pass through the $2.7 \mu \mathrm{m}$ filter.

668 The high abundance of the above-described taxa and other denitrifiers that are dominant in

669 natural waters and bioreactors (e.g., Pirellulaceae, PHOS-HE36, Exiguobacterium), especially

670 those with low organic $\mathrm{C}$ to inorganic $\mathrm{N}$ ratios, points to overall nitrogen-removal from FGL in

671 October (Dabert et al., 2001, Singh et al., 2015, Kelogg et al., 2016, Gutiérrez -Preciado et al.,

672 2017, Zhou et al., 2019). Other than the anaerobic ammonium oxidizer, Candidatus

673 anammoximicrobium, taxa within the Pirellulaceae family exclusively mediate nitrification and

674 organotrophic denitrification (Kelogg et al., 2016, Song and Liu, 2019). Over-representation of

675 these taxa in PA assemblages suggests that particles are important microhabitats for denitrifiers

676 under subsaturated oxygenated conditions as found in other studies (Fuchsman et al., 2011, Ganesh

677 et al., 2015, Suter et al., 2018).

678 Anaerobic remineralization in the monimolimnion

679 In permanently redox-stratified water bodies, deeper, anoxic waters host diverse 680 assemblages of anaerobes that derive energy from fermentation, chemoorganotrophic sulfate, iron 681 and manganese oxide reduction, chemoautotrophic oxidation or disproportionation of reduced 682 sulfur species, and the chemoautotrophic oxidation of iron, manganese, ammonium, and methane.

683 Due to low energy yields and the need to remove inhibitory metabolic byproducts (e.g., formate 684 and hydrogen during fermentation), microbes mediating these reactions are often physically 685 associated in cellular aggregates (Sieber et al., 2012, Morris et al., 2013). Physical association 
686 facilitates the metabolic cooperation of microbes that mediate different reactions because nutrients,

687 oxidants, reductants, and electrons can be easily exchanged. This type of cooperation is especially

688 common in energy limited, low- $\mathrm{O}_{2}$ environments because metabolic reactions that alone yield too

689 little energy to sponateously occur (endergonic) can become energetically favorable (exergonic)

690 when combined and benefit all participants (=syntrophy). As such, multiple parts of elemental

691 cycles (e.g., sulfate reduction and sulfide oxidation, iron oxidation and reduction) and different

692 elemental cycles (methanogenesis and sulfate reduction) have synergistic interplay in particles.

693 During October and July, excluding taxa originating from the light-scattering layer and

694 above (likely dead cells), the most abundant families in the monimolimnion were similar. These

695 taxa broadly fall into two categories. Those in the first category are capable of metabolizing

696 complex organic carbon substrates (e.g., carbohydrates, chitin, cellulose, lignin), and likely play a

697 role in initiating anaerobic remineralization of biogenic or autochthonous debris that have been

698 vertically transported towards the lakebed by gravitational settling. Those in the second category

699 are common in methanogenic, sulfate-reducing, hydrocarbon-oxidizing consortia that are

700 characteristic of petroleum-rich environments (Fig. 10). In petroleum-free environments,

701 hydrocarbons can instead originate from decomposing primary producer cells, especially

702 cyanobacteria (Lea-Smith et al., 2015, Love et al., 2021). If this is the case in FGL, the anaerobic

703 remineralization of export primary production in the deep monimolimnion could contribute to

704 hydrogen sulfide, methane, and low molecular weight dissolved organic matter production through

705 hydrocarbon oxidation. Within both categories, further niche-partitioning appears to be driven by

706 putative organic carbon substrate usage (e.g., alkanes versus aromatic compounds, proteins versus

707 carbohydrates). 
The families that likely play a role in initiating the remineralization of biogenic or

709 autochthonous debris below the light-scattering layer include Lentimicrobiaceae,

710 Marinilabiliaceae, families in the Bacteroidales order (Bacteroidetes BD2-2, and

711 Prolixibacteraceae), and the archaeal Woesarchaeia. Lentimicrobiaceae ferment polysaccharides

712 (Sun et al., 2016), a common component of algae and their associated mucopolysaccharides or of

713 plant debris. Marinilabiliaceae, Bacteroidetes BD2-2, Prolixibacteraceae, and the archael class

714 Woesarchaeia are able adhere to particles and remineralize proteins and polysaccharides (Mei et

715 al., 2020, Suominen et al., 2020). Notably, not only are Marinilabiaceae associated with algal

716 blooms, but sometimes exclusively scavenge compounds from decaying cyanobacteria (Smith et

717 al., 2017, Ben Hania et al., 2017). This hints that some of the decaying biomass being turned over

718 in the monimolimnion is cyanobacterial.

719 The families that are common in methanogenic, sulfate-reducing, hydrocarbon-oxidizing

720 consortia include Desulfarculaceae, Syntrophaceae, VC2.1 Bac22, Sphaerochaeta, GIF9, S15-

721 MN91, Bathyarchaeota, Methanofastidiosales, and possibly Rhodopseudomonas. The

722 representative Desulfarcularceae sequences in this study arose from a single genus, Desulfatiglans,

723 which shares the most similarity $(95.7 \%$ API) with the genome reference sequence Desulfatiglans

724 anilini DSM 4660 (RefSeq no. NZ_AULM01000006.1). This species, belonging to group 1 of

725 Desulfatiglans, inhabits sulfate-rich environments, and oxidizes aromatic compounds,

726 organosulfonates, and organohalides by dissimilatory sulfate reduction (Jochum et al., 2018).

727 Notably, many of the group 1 Desulfatiglans reference sequences have been recovered from

728 petroleum-rich environments (Jochum et al., 2018). The other sulfate-reducing family,

729 Syntrophaceae, is likewise abundant in crude oil-replete environments. However, they oxidize

730 hydrocarbons instead of more refractory organic carbon compounds (e.g., alkane, xylene, or 
731 toluene, with alkanes being the preferred substrate) (Edwards and Grbić-Galić, 1994, Gray et al.,

732 2011). The byproducts of hydrocarbon oxidation are consumed by syntrophic methanogens,

733 linking the carbon and sulfur cycles (Gray et al., 2011).

734 The obligate and putative organohalide-respirers, GIF9 and S15-MN91, also oxidize

735 hydrocarbons in partnership with methanogens (Nedelkova et al., 2005, Hug et al., 2013). They

736 instead use the more refractory long chain alkyl substituted hydrocarbons that are left behind after

737 the preferential biodegradation of lower molecular weight hydrocarbons like alkanes (Cheng et al.,

738 2019). This suggests even further niche partitioning of dissolved organic carbon consumers by

739 hydrocarbon type. The fermentative taxa, including Sphaerochaeta and VC2.1 Bac22, have also

740 been recovered from petroleum reservoirs and methane seeps, and found in physical association

741 with sulfate-reducing bacteria, suggesting that they are also part of hydrocarbon-oxidizing, sulfate-

742 reducing, methanogenic consortia (Trembath-Reichert et al., 2016, Dong et al., 2018, Grouzdev et

743 al., 2018, Kleindienst et al., 2012, 2020).

744 Methanogen sequences were recovered throughout the monimolimnion, supporting the

745 hypothesis that all these organisms are involved in methane production. These included

746 unclassified Bathyarchaeia (now Bathyarchaeota), Methanofastidiosales, Methanoregula, and the

747 putative bacterial methanogen Rhodopseudomonas (Zheng et al., 2018). Other than

748 Rhodopseudomonas, present only during July in the $40 \mathrm{~m}$ FL assemblage (3.6\%), methanogens

749 were present at low abundances $(<0.05 \%$ in any assemblage). Methanogen composition appeared

750 to be structured over depth by ambient geochemical conditions and possibly, competition with

751 sulfate reducing bacteria for substrates (e.g., hydrogen, acetate). The only hydrogenotrophic

752 methanogen (Methanoregula, Beaver et al., 2016, 2021), was restricted to 20 and $20.5 \mathrm{~m}$, where

753 hydrogen sulfide concentrations, and presumably rates of microbial sulfate reduction are low. 
754 Notably, Methanoregula is often associated with particulate iron oxide (Beaver et al., 2016, 2021),

755 as would be expected at these depths due to an active iron redox shuttle (Havig et al., 2015).

756 In the deeper monimolimnion, where high concentrations of hydrogen sulfide presumably

757 originate from bacterial sulfate reduction, methanogens will be easily outcompeted for acetate and

758 hydrogen by sulfate-reducers (Lovely et al., 1982, Schönheit et al., 1982, Robinson and Tiedje,

759 1984). The most abundant methanogens were therefore Bathyarchaeota and Methanofastidiosales.

760 Bathyarchaeota can use carbon substrates that most methanogens cannot, such as detrital proteins,

761 polysaccharides, aromatic compounds, and methylated compounds; Methanofastidiosales is a

762 methylotrophic methanogen (Evans et al., 2015, Nobu et al., 2016, Zhou et al., 2018). These

763 methanogens can likely make a living co-existing with sulfate-reducers because they are not

764 restricted to using hydrogen and acetate. Finally, Rhodopseudomonas was the dominant putative

765 methanogen only in the deepest monimolimnion sample $(40 \mathrm{~m})$. Rhodopseudomonas produces

$766 \mathrm{CH}_{4}$ by fixing $\mathrm{CO}_{2}$ using the iron-only nitrogenase when there is a high dissolved iron to

767 molybdenum ratio and a high $\mathrm{CO}_{2}$ concentration (Zheng et al., 2018). These conditions are met in

768 the deep monimolimnion (Havig et al., 2015). Its presence only during July could be explained by

769 the secondary chemocline in the deep lake at approximately this depth, which is likely stronger

770 during summer, when there is more precipitation (Torgersen et al., 1981). Additionally, it is

771 possible that the benthic fluxes of dissolved iron and $\mathrm{CO}_{2}$ into the deep monimolimnion are

772 enhanced during the summer through greater sedimentary remineralization due the higher flux of

773 biomass to the lakebed.

774 Assemblage partitioning

775 The chemoorganotrophic aerobes and anaerobes that were common in PA assemblages

776 both metabolize complex organic substrates that are found in particles (e.g., proteins, 
777 polysaccharides, chitin, lignin, cellulose), and have particle-adhering abilities. The proportion of

778 taxa that specialize in oxidizing proteinaceous substrates (e.g., Flavobacteriales, Verrucomicrobia,

779 Planctomycetes, DeLong et al., 1993, Duret et al., 2019) and taxa that oxidize or ferment refractory

780 organic carbon substrates (e.g., Kiritimatiellaeota, Burkholderiaceae, van Vliet et al., 2019, Garrity

781 et al., 2015) appear to vary with time-of-year and with redox condition (corresponding to depth).

782 These variables parallel temporal and depth gradients in labile organic carbon availability. The

783 temporal variability of labile organic carbon substrates is likely driven by the seasonality of the

784 photoautotroph blooms (a source of labile organic carbon in summer) versus decaying plant matter

785 (a source of refractory organic carbon in autumn). The decreasing availability of labile organic

786 carbon over depth is likely caused by the continuous remineralization of biogenic debris as they

787 sink towards the lakebed. Our phylum-level analyses revealed that low-abundance

788 chemoorganotrophic environmental candidate phyla belonging to the so-called "microbial dark

789 matter" may collectively also participate in organic carbon remineralization in particles. These

790 phyla have been found attached to particles in marine microbial mats (Armatimonadetes, Burns et

791 al., 2004, Ley et al., 2006) and are enriched in particles in hypoxic and anoxic marine water

792 (Kiritimatiellaeota, Capo et al., 2020). Omics studies have shown that they have surface-adhesion

793 and metabolic abilities similar to better studied taxa that were over-represented in particles in FGL

794 (Eloe-Fadrosh et al., 2016, van Vliet et al., 2019). Other taxa that were over-represented in PA

795 assemblages consume fermentation products like hydrogen and methanol (Hydrogendentes,

796 Methanofastidiosales), and are likely benefiting from the remineralization of organic carbon

797 substrates on particles.

\section{Conclusion}


Oxygen-depleted water bodies like FGL are a window into the geologic past and, likely,

800 the future. As oxygen-deficient waters continue to geographically expand due to global climate

801 change (Stramma et al., 2008, Wright et al., 2012, Moffitt et al., 2015, Breitburg et al., 2018),

802 similar biogeochemical processes are likely to profoundly impact interconnected global

803 biogeochemical cycles (e.g., iron, hydrogen, sulfur, carbon, nitrogen). Ultimately, the

804 remineralization of organic carbon substrates in particles as they sink through distinctive redox

805 zones drives many of these complex interplays. These synergistic processes could potentially

806 contribute to nitrogen deficits through denitrification, enhanced primary production through

807 enriched dissolved iron availability, increased greenhouse gas emissions through methanogenesis,

808 and harm to macrofauna through acidification and hydrogen sulfide production. Therefore,

809 studying the niche-partitioning and drivers of diversity within and between particle-associated and

810 free-living microbial assemblages in these systems is critical.

811 In permanently redox-stratified FGL, the 16S rRNA amplicon composition of all samples

812 significantly differed among redox conditions and assemblage types, and those from the

813 mixolimnion and oxycline also differed by sampling date. These compositional differences all

814 appear to ultimately be driven by availability and composition of organic carbon substrates and

815 oxidants. Particle-associated organotrophs specialized in surface-adhesion and metabolizing

816 complex organic carbon substrates or fermentation products, whereas free-living

817 chemoorganotrophs seemed to metabolize dissolved amino acids, volatile fatty acids, or

818 hydrocarbons. Variations in organic carbon substrate and oxidant availability above the pycnocline

819 were likely caused by seasonal phenomena, with photoautotrophy being dominant in summer, and

820 wind mixing and potentially allochthonous plant input being more important in autumn. At depth,

821 organic carbon availability may be regulated by vertical transport and remineralization of primary 
822 production products from the mixolimnion and light-scattering layer by particle-associated

823 assemblages. The byproducts of remineralized primary production are likely an important source

824 of dissolved organic substrates for the free-living anaerobes in the monimolimnion. Although

825 functionality of taxa in this phylogenetic study was carefully deduced based on thorough literature

826 review and ancillary analyses, we recommend a metagenomic study of FGL PA and FL

827 assemblages to reveal their functional potential through the construction of metagenome

828 assembled genomes (MAGs) as well as targeted biogeochemical experiments for future research

829 efforts.

\section{Acknowledgements}

831 We thank Dr. Adith Ramamurti, Daniel Garatea, and John Baum for assistance in sample 832 collection during October 2016 and July 2017. We also thank Drs. Robert Aller and Christina

833 Heilbrun for assistance in quantifying hydrogen sulfide. Finally, we thank Mark Wiggins (building

834 manager, School of Marine and Atmospheric Sciences) and Ian Dwyer (PhD candidate, School of

835 Marine and Atmospheric Sciences) for assistance with preparatory work in the machine shop. This

836 research was supported in part by NSF Grant OCE-1259110 and in part by the Wellesley College

837 Fiske Award (to V. Klepac-Ceraj)

\section{Conflict of interest}

839 None declared. 
841 Table 1 Discrete sample analyses performed per sampling depth during July and October.

$842 \mathrm{~N} / \mathrm{A}=$ not applicable, depth not sampled. "All” indicates that samples were recovered for 16S rRNA

843 gene amplicon sequencing, hydrogen sulfide concentration measurements, total prokaryote cell

844 counts, bacterial heterotrophic production rate measurements, and inorganic carbon assimilation

845 rate measurements.

\begin{tabular}{l|ll} 
& $5-7$ Oct. 2016 & $17-21$ Jul. 2017 \\
\hline \hline Depth (m) & & N/A \\
10 & N/A & all \\
15 & all & all \\
16 & only hydrogen sulfide and 16S rRNA amplicons & all \\
19 & only hydrogen sulfide and 16S rRNA amplicons & all \\
20 & all & all \\
20.5 & N/A & all \\
21 & only hydrogen sulfide and 16S rRNA amplicons & all \\
23 & N/A & all \\
25 & all & all \\
\hline \hline
\end{tabular}



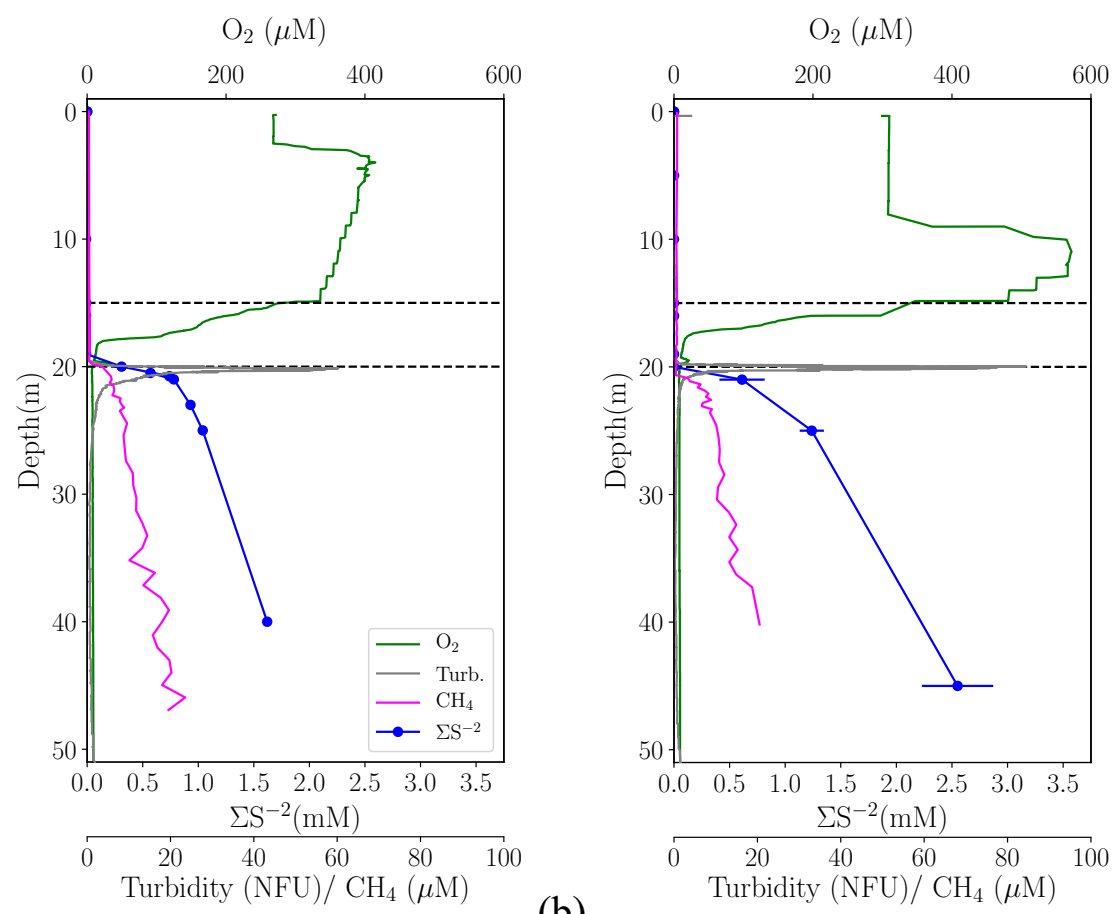

848 Figure 1 Vertical profiles of major biogeochemical features measured during (a) July 2017 and

849 (b) October 2016, with the exception of methane $\left(\mathrm{CH}_{4}\right)$, which was measured in July 2015 and

850 November 2012 (Havig et al., 2018). Broken lines indicate oxycline boundaries. The standard

851 deviations of sulfide measurements are represented by error bars, but they are too small to be seen.
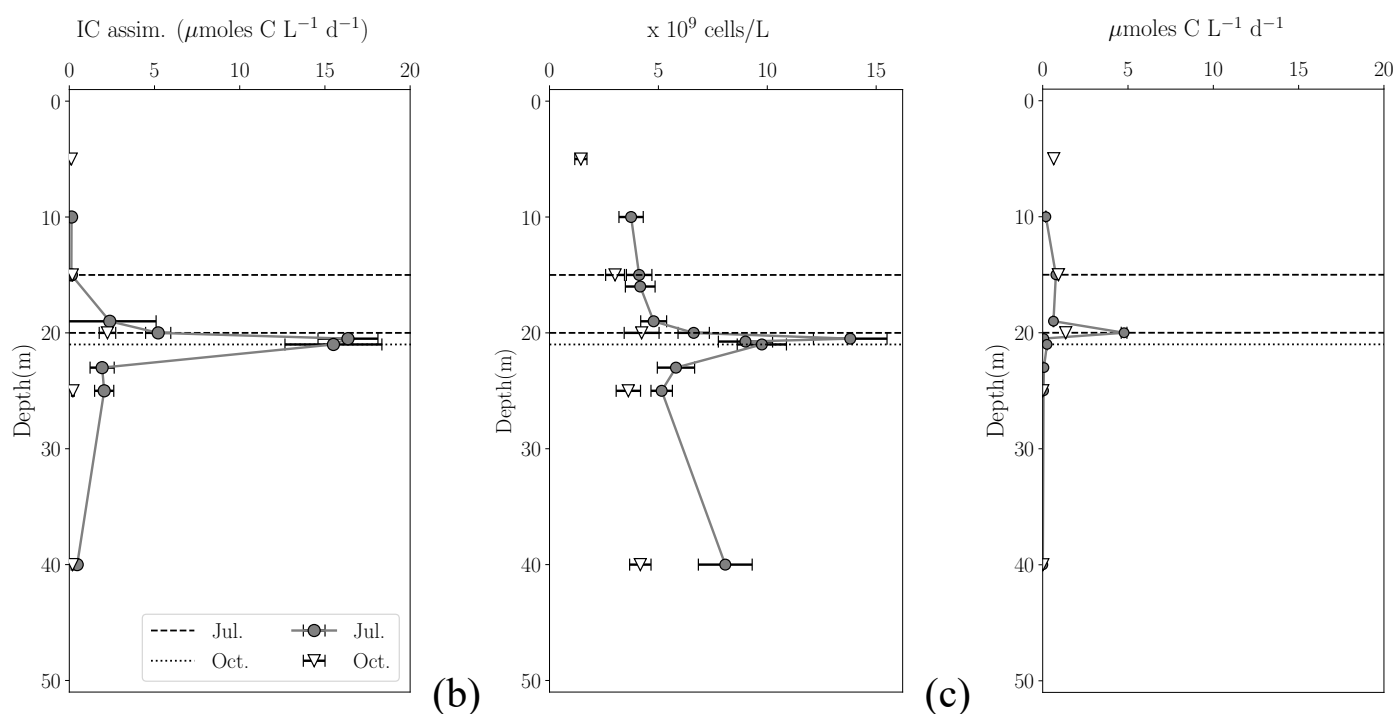

853 Figure 2 Vertical profiles of (a) inorganic carbon assimilation (ICA) rates, (b) DAPI-stainable cell 
854 concentrations (total prokaryotic biomass) and (c) bacterial heterotrophic production (BHP) during

855 July 2017 and October 2016. The lower oxycline boundary is shown as a dotted line for October

856 and as a dashed line for July. The upper oxycline boundary is shown as a dashed line in all plots.

$857 \quad(a)$

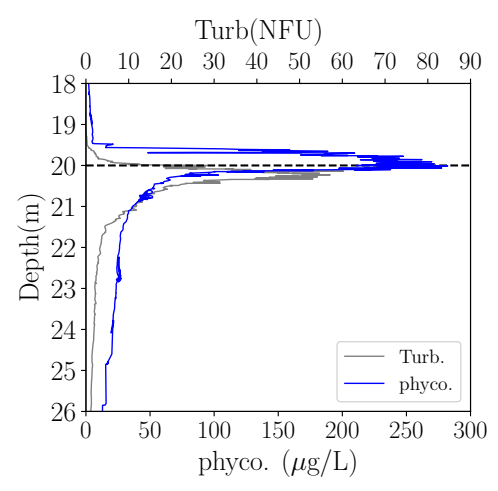

Chlorophyll-a $(\mu \mathrm{g} / \mathrm{L})$

$858 \quad(c)$

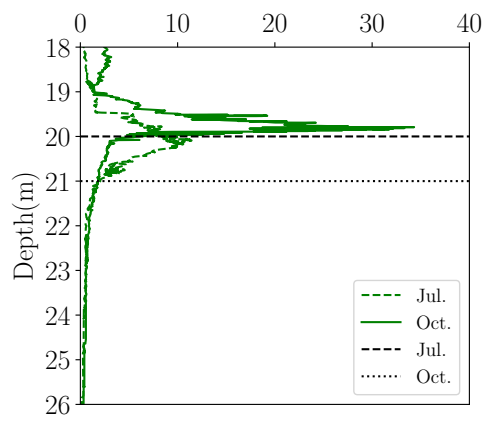

$\operatorname{Turb}(\mathrm{NFU})$

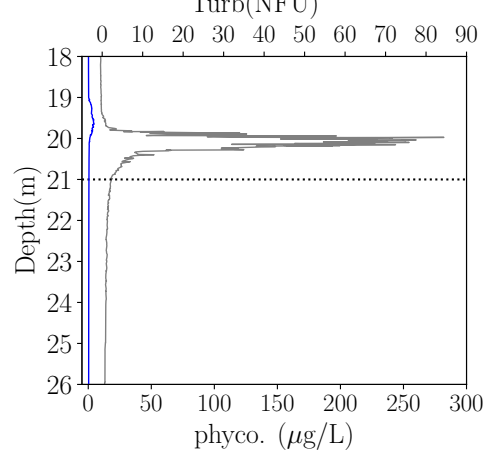

(b)

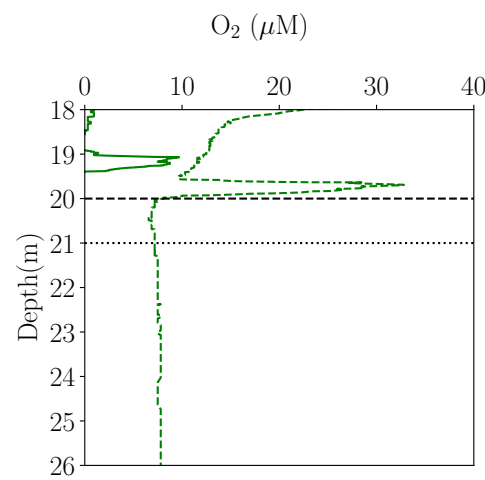

859 Figure 3 Finer vertical resolution profiles across the lower oxycline and upper monimolimnion of:

860 phycoerythrin fluorescence (cyanobacterial pigment) and turbidity during (a) July 2017 and (b)

861 October 2016. (c) chlorophyll-a fluorescence during July 2017 and October 2016. (D) $\mathrm{O}_{2}$

862 concentration during July 2017 and October 2016. The lower oxycline boundary is shown as a

863 dotted line for October and as a dashed line for July. 
bioRxiv preprint doi: https://doi.org/10.1101/2021.11.24.469905; this version posted November 25, 2021. The copyright holder for this preprint (which was not certified by peer review) is the author/funder, who has granted bioRxiv a license to display the preprint in perpetuity. It is made available under aCC-BY-NC-ND 4.0 International license.

864

(a)

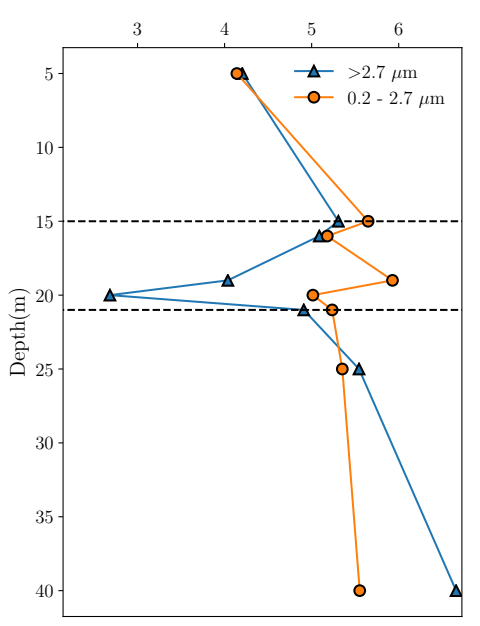

Shannon Diversity

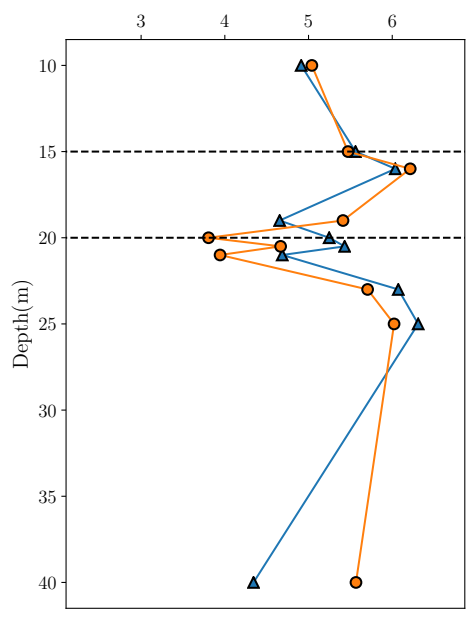

865 (b)

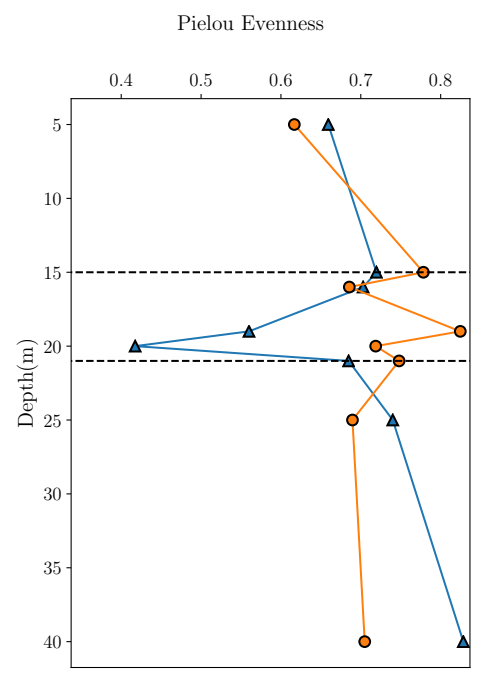

Pielou Evenness

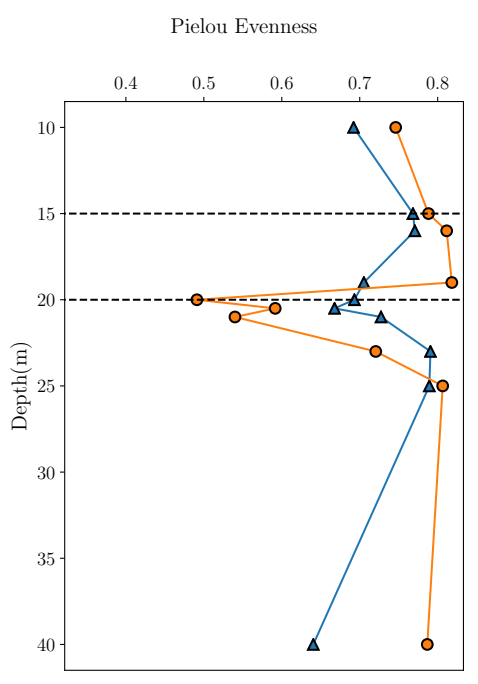

(c)

(d)

866 Figure 4 Alpha diversity of PA and FL assemblages as measured by Shannon diversity, $H(\mathrm{a}, \mathrm{c})$

867 and Pielou evenness indices $(b, d)$ for Oct $(a, b)$ and Jul $(c, d)$ samples. Broken lines represent oxycline boundaries on those dates. 

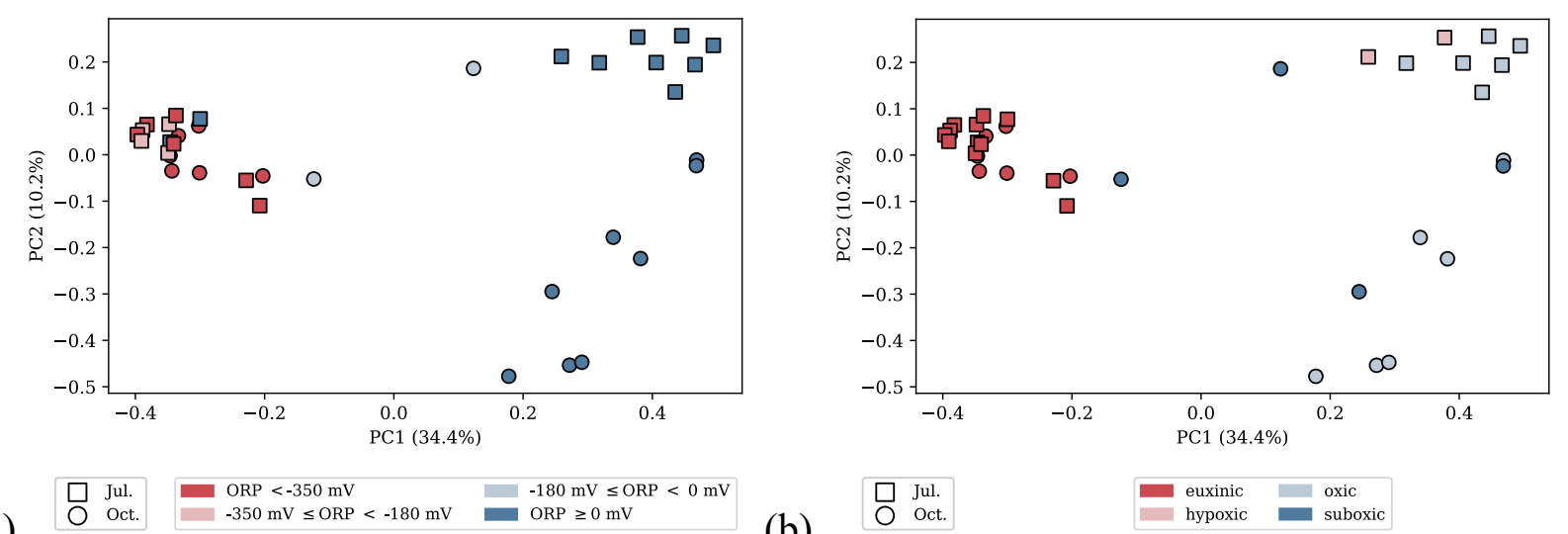

869

(a)
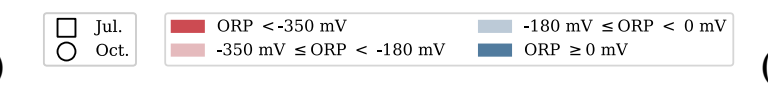

(b)

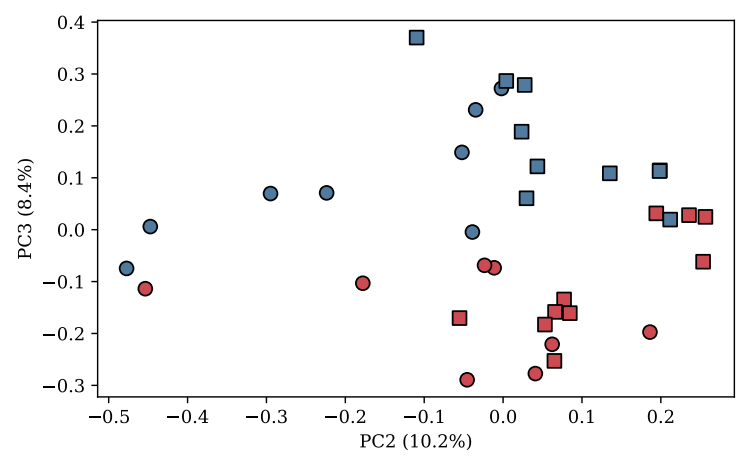

$870 \quad$ (c)

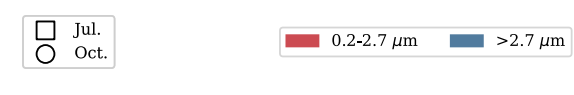

871 Figure 5 Beta diversity Bray-Curtis PCoA for all samples shown in $(\mathrm{a}, \mathrm{b})$ in PC1-PC2 space and

872 (c) PC2-PC3 space. Samples in (a) are color-coded by ORP ranges. Samples in (b) are color coded

873 by redox condition as defined by oxygen concentration and presence or absence of sulfide.

874 Samples in $(\mathrm{c})$ are color-coded as PA $(>2.7 \mu \mathrm{m})$ and FL $(0.2-2.7 \mu \mathrm{m})$. Percentages of total variance

875 explained appear on axes. 
bioRxiv preprint doi: https://doi.org/10.1101/2021.11.24.469905; this version posted November 25, 2021. The copyright holder for this preprint (which was not certified by peer review) is the author/funder, who has granted bioRxiv a license to display the preprint in perpetuity. It is made available under aCC-BY-NC-ND 4.0 International license.
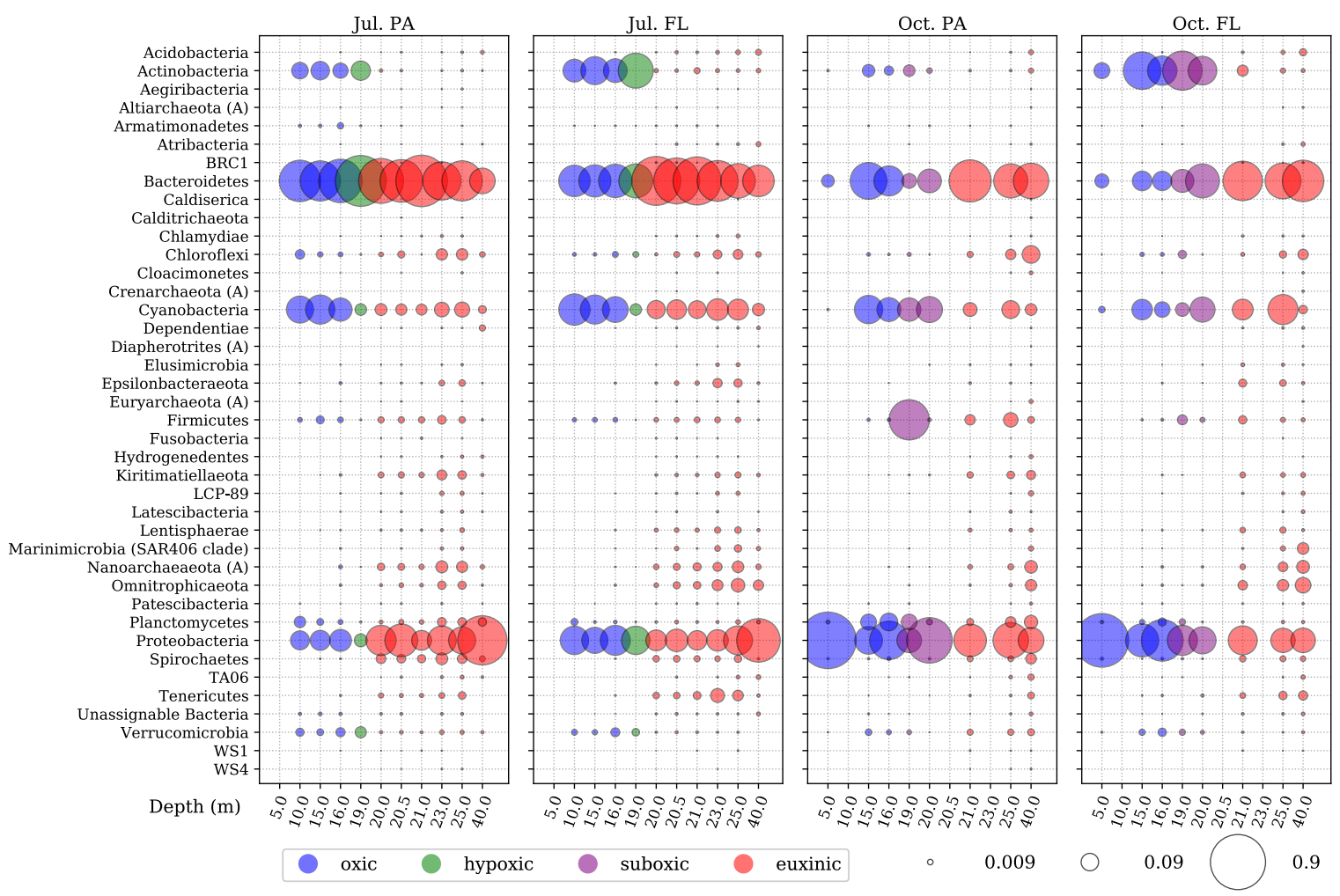

877 Figure 6 Relative abundances of all recovered phyla in PA and FL assemblages throughout the

878 FGL water column during July 2017and October 2016. Bubble size scales with relative abundance and bubble color corresponds to redox condition. 
bioRxiv preprint doi: https://doi.org/10.1101/2021.11.24.469905; this version posted November 25, 2021. The copyright holder for this preprint (which was not certified by peer review) is the author/funder, who has granted bioRxiv a license to display the preprint in perpetuity. It is made available under aCC-BY-NC-ND 4.0 International license.
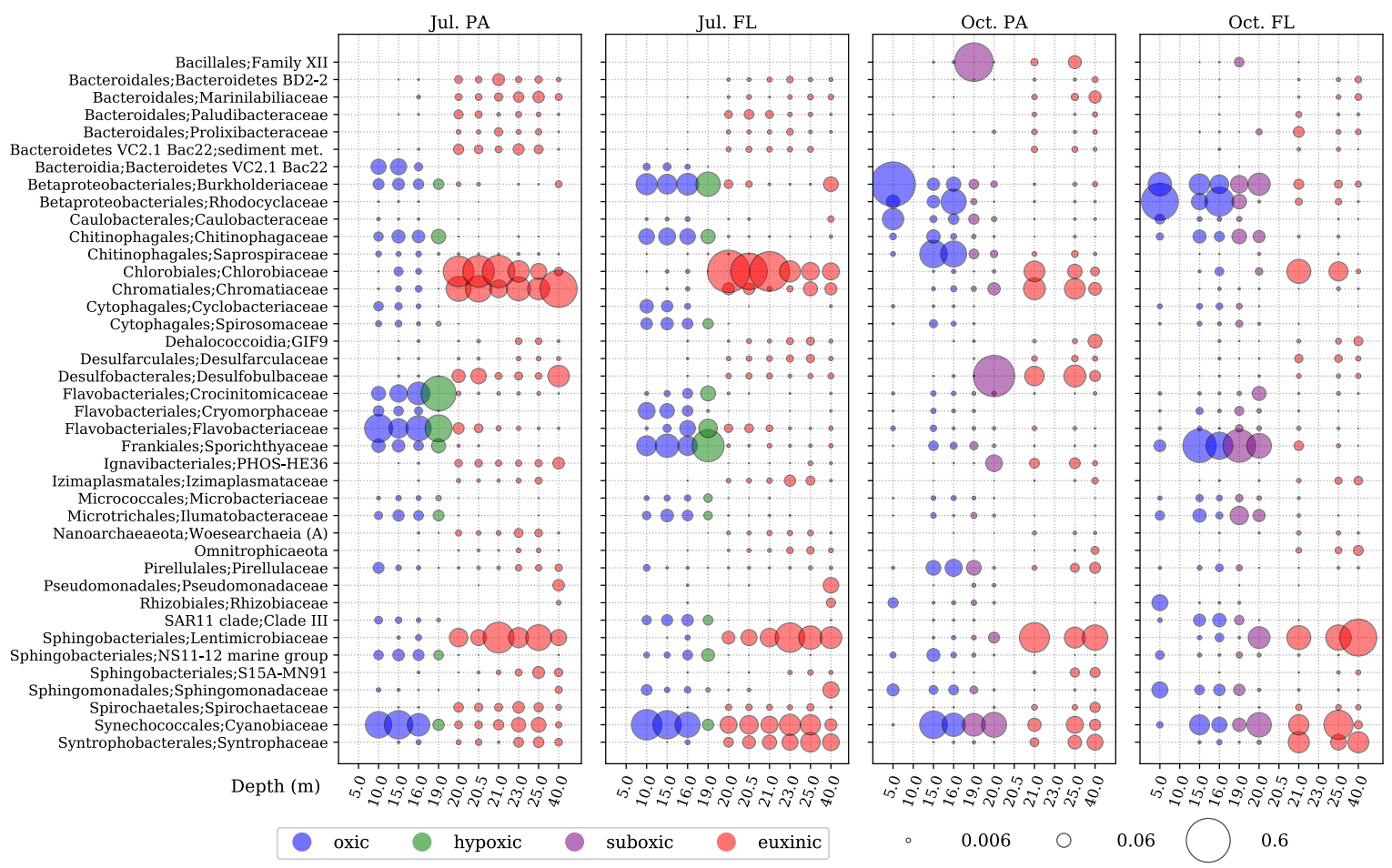

881 Figure 7 Relative abundances of top families in PA and FL assemblages recovered throughout the

882 FGL water column during July 2017 and October 2016. Bubble size scales with relative abundance

883 and bubble color corresponds to redox condition. 
bioRxiv preprint doi: https://doi.org/10.1101/2021.11.24.469905; this version posted November 25, 2021. The copyright holder for this preprint (which was not certified by peer review) is the author/funder, who has granted bioRxiv a license to display the preprint in perpetuity. It is made available under aCC-BY-NC-ND 4.0 International license.

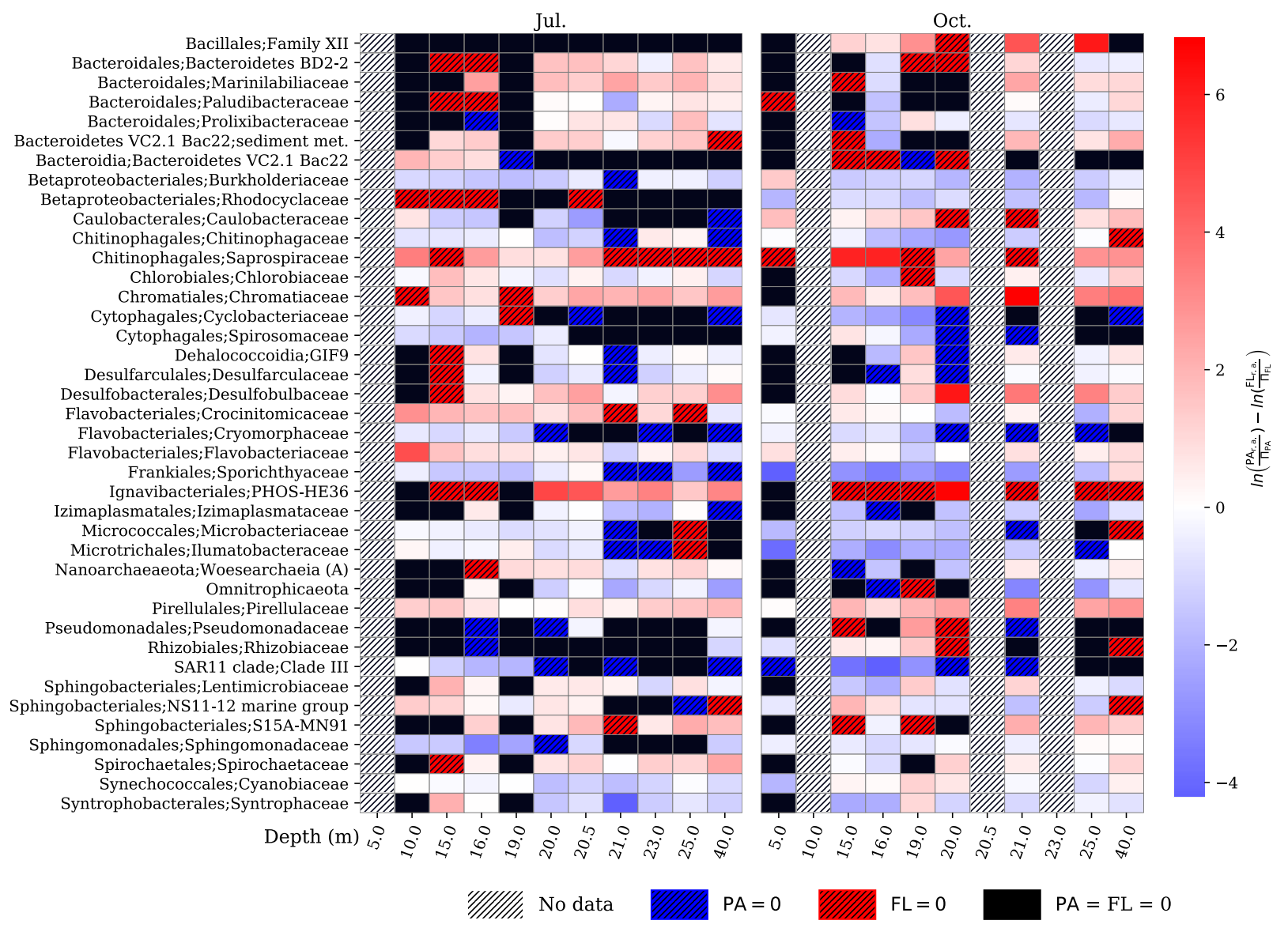




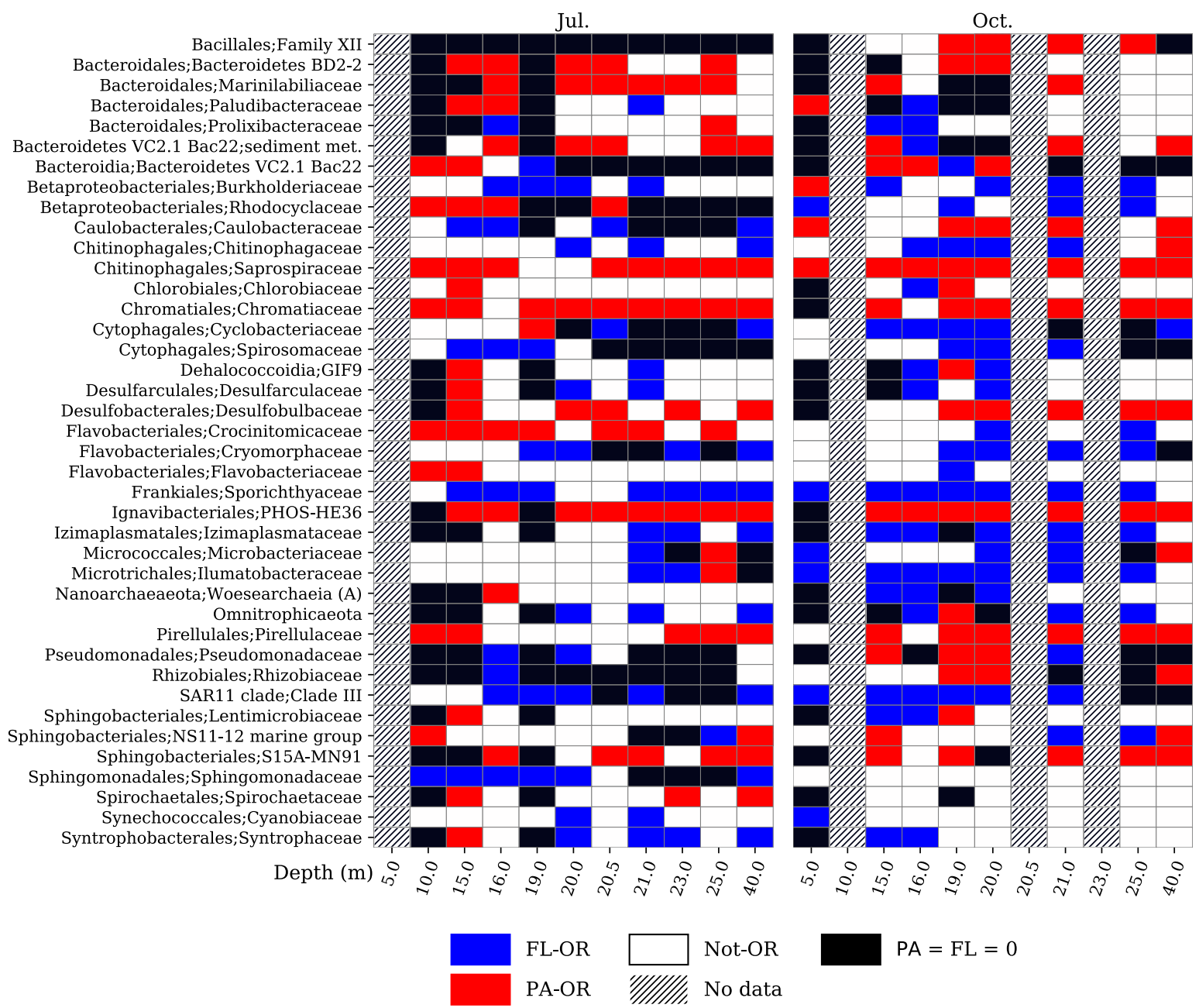

888 Figure 8 (a) Overrepresentation factors (OFs) of top families recovered throughout the FGL water

889 column during July 2017 and October 2016. Positive (red) OFs indicate overrepresentation in the

890 PA assemblage, while negative (blue) values indicate overrepresentation in the FL assemblage. (b)

891 The same data classified by overrepresentation factor as over-represented in particle-associated

892 assemblages $(\geq 1.25$, PA-OR), over-represented in free-living assemblages $(\leq-1.25$, FL-OR), or

893 neither (Not-OR). 
bioRxiv preprint doi: https://doi.org/10.1101/2021.11.24.469905; this version posted November 25, 2021. The copyright holder for this preprint (which was not certified by peer review) is the author/funder, who has granted bioRxiv a license to display the preprint in perpetuity. It is made available under aCC-BY-NC-ND 4.0 International license.

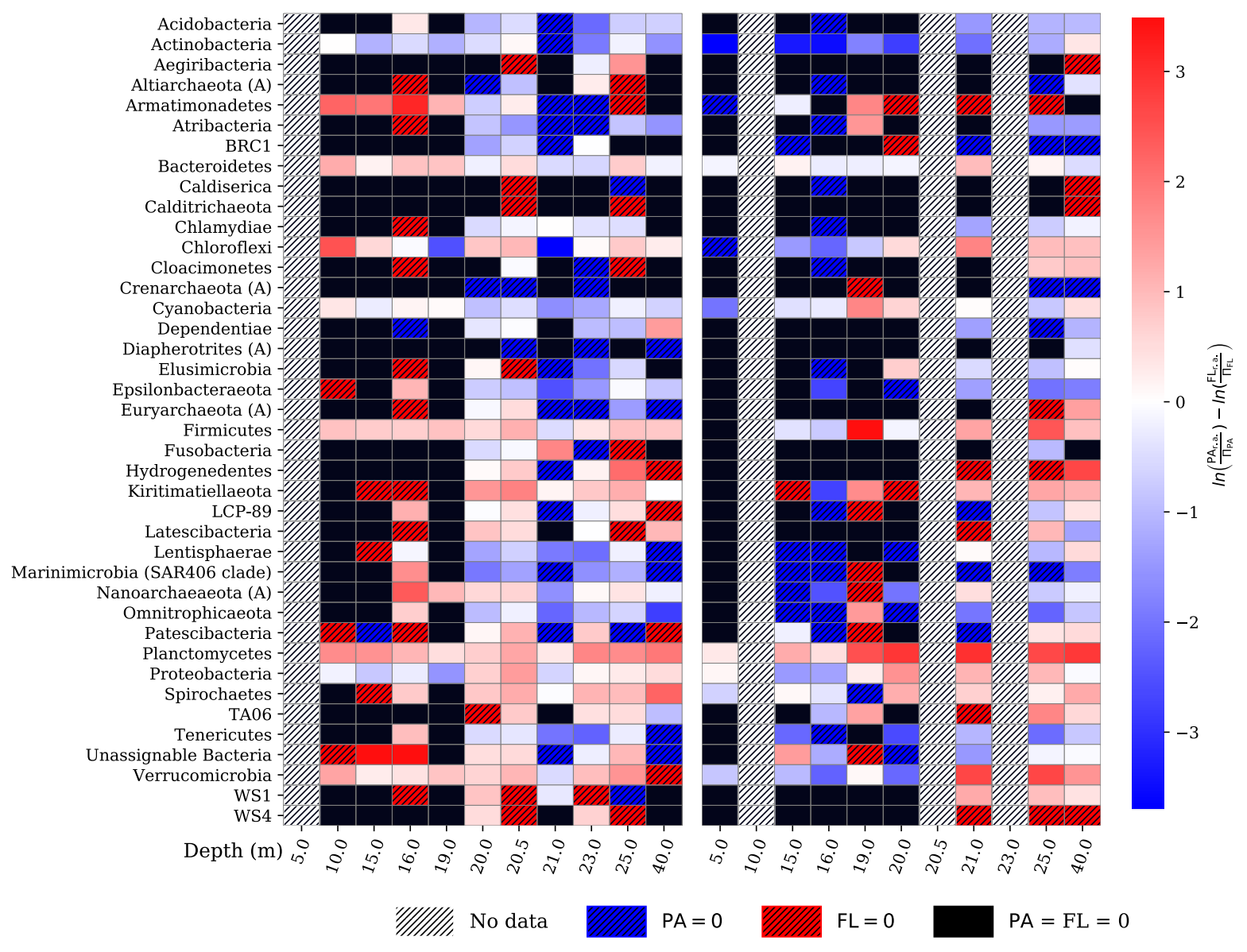

896 


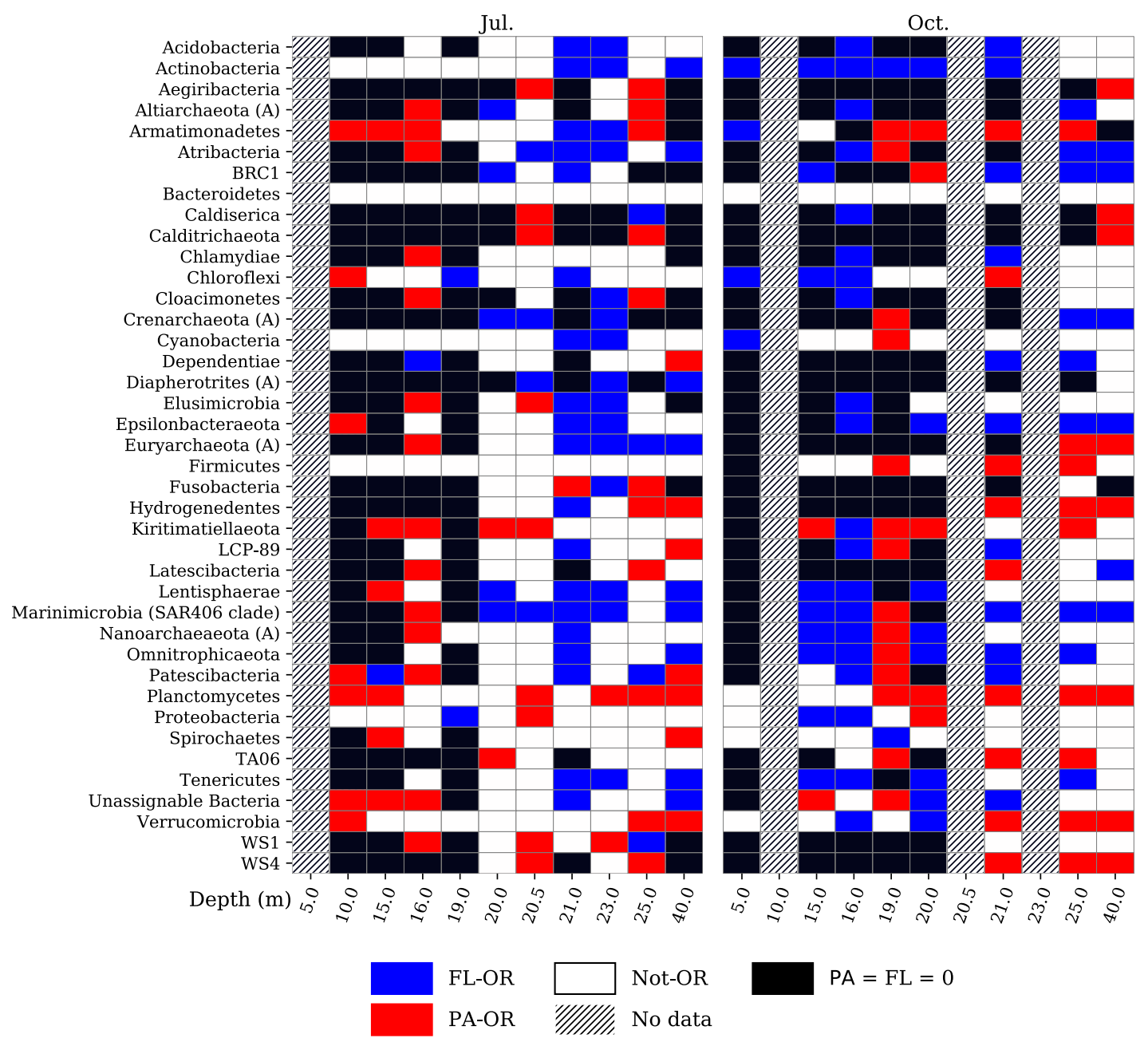

902 Figure 9 (a) Overrepresentation factors (OFs) of all recovered phyla throughout the FGL water

903 column during July 2017 and October 2016. Positive (red) OFs indicate overrepresentation in the

904 PA assemblage, while negative (blue) values indicate overrepresentation in the FL assemblage. (b)

905 The same data classified by overrepresentation factor as over-represented in particle-associated

906 assemblages $(\geq 1.25$, PA-OR), over-represented in free-living assemblages $(\leq-1.25$, FL-OR), or

907 neither (Not-OR). 

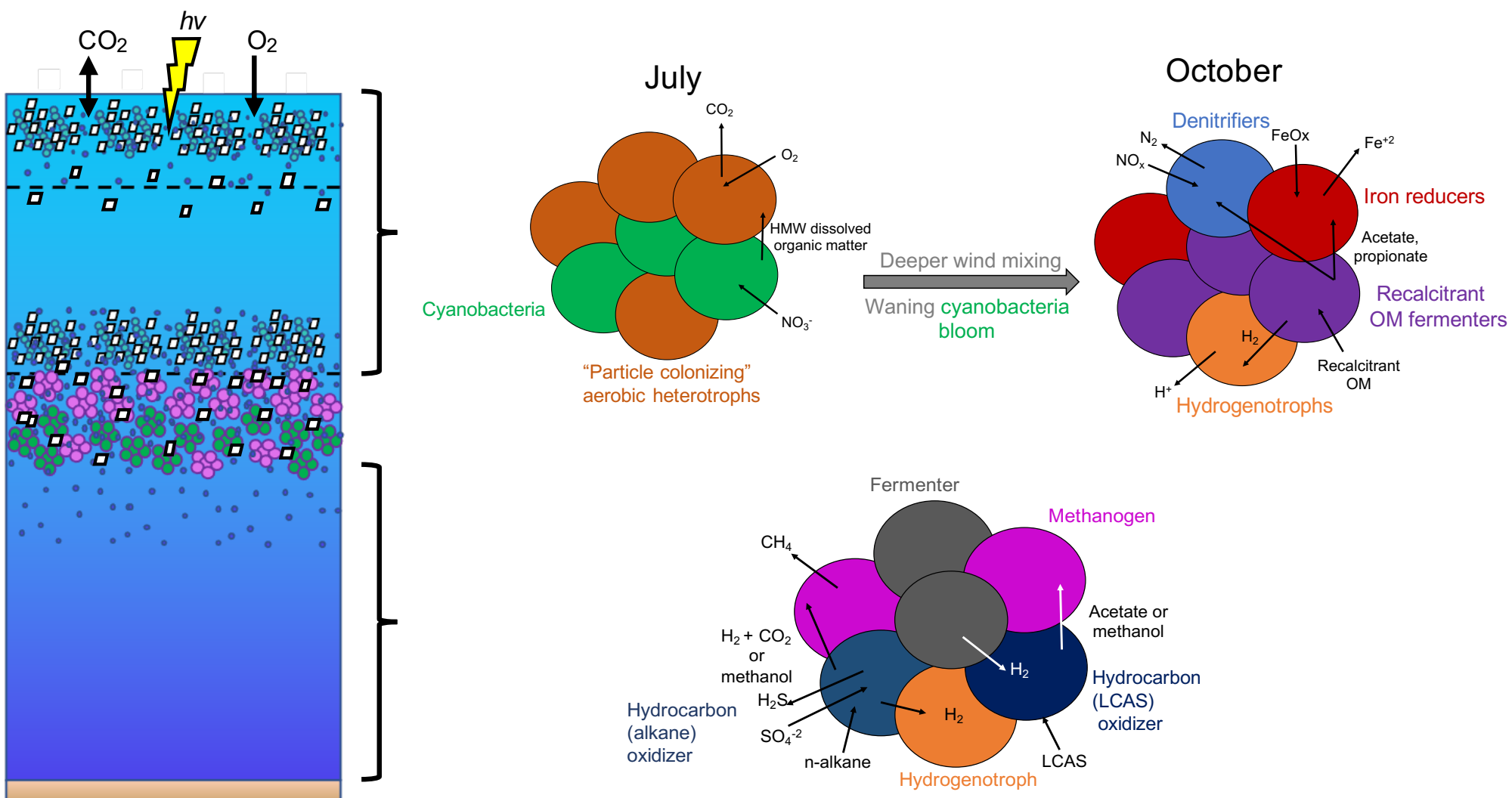

$\mathrm{CaCO}_{3} \bullet$ Cyanobacteria

Green sulfur bacteria

910 Figure 10 A conceptual diagram of major microbial processes in the FGL water column. Cyanobacteria populations in the mixolimnion

911 and near the lower oxycline boundary carry out oxygenic photosynthesis and cause $\mathrm{CaCO}_{3}$ precipitation. Green and purple sulfur bacteria

912 at the lower oxycline boundary and in the upper monimolimnion mediate photoautotrophic sulfur oxidation. In July, the mixolimnion is

913 dominated by PA aerobic heterotrophs that colonize algal biomass. In October, the mixolimnion and oxycline instead hosts abundant 
914 denitrifiers, iron reducers, hydrogenotrophs, and fermenters. Below the light-scattering layer, the seasonally invariant monimolimnion

915 community consists of taxa that are common in hydrocarbon oxidizing, methanotrophic, syntrophic consortia. HMW=High molecular

916 weight. LCAS=Long chain alkyl substituted

917 


\section{Works Cited}

919 Akins, L.N., Ayayee, P. and Leff, L.G. 2018. Composition and diversity of cyanobacteria-associated and free-living bacterial communities during cyanobacterial blooms. Annals of Microbiology. 68(8):

Alldredge, A.L. and Cohen, Y. 1987. Can microscale chemical patches persist in the sea? Microelectrode study of marine snow, fecal pellets. Science. 235(4789): 689-691. doi:

Alonso, C. and Pernthaler, J. 2006. Roseobacter and SAR11 dominate microbial glucose uptake in coastal North Sea waters. Environ Microbiol 8: 2022-2030.doi: 10.1111/j.1462-2920.2006.01082.x

Altschul, S.F., Gish, W., Miller, W., Myers, E.W. and Lipman, D.J. 1990. Basic local alignment search tool. J. Mol. Biol. 215:403-410. doi: 10.1016/S0022-2836(05)80360-2 Available online at: http://www.bioinformatics.babraham.ac.uk/projects/fastqc/

931 Badri, M., Kurtz, Z.D., Müller, C.L. and Bonneau, R. 2018. Normalization methods for microbial abundance data strongly affect correlation estimates. bioRxiv: 406264. doi: 10.1101/406264; t

933 Bastviken, D. and Tranvik, L. 2001. The leucine incorporation method estimates bacterial growth equally well in both oxic and anoxic lake waters. Applied and Environmental Microbiology. 67(7): 2916-

936 Beaver, C.L., Williams, A.E., Atekwana, E.A., Mewafy, F.M., Abdel Aal, G., Slater, L.D. and Rossbach, 937 S. 2016. Microbial communities associated with zones of elevated magnetic susceptibility in $938 \quad$ hydrocarbon-contaminated sediments. Geomicrobiology Journal. 33(5): 441-452. doi: 
940 Beaver, C.L., Atekwana, E.A., Bekins, B.A., Ntarlagiannis, D., Slater, L.D. and Rossbach, S. 2021. Methanogens and their Syntrophic Partners Dominate Zones of Enhanced Magnetic Susceptibility at a Petroleum Contaminated Site. Frontiers in Earth Science. 9: 156. doi: 10.3389/feart.2021.598172

944 Ben Hania, W., Joseph, M., Bunk, B., Spröer, C., Klenk, H.P., Fardeau, M.L. and Spring, S. 2017. Characterization of the first cultured representative of a Bacteroidetes clade specialized on the scavenging of cyanobacteria. Environmental microbiology.19(3): 1134-1148. doi: 10.1111/1462-

Benjamini, Y. and Hochberg, Y. 1995. Controlling the false discovery rate: A practical and powerful approach to multiple testing. Journal of the Royal Statistical Society, Series B. 57: 289-300. doi: 10.1111/j.2517-6161.1995.tb02031.x

951 Benjamini, Y. and Hochberg, Y. 2000. On the adaptive control of the false discovery rate in multiple testing with independent statistics. Journal of Educational and Behavioral Statistics. 25: 60-83. doi:

\section{$10.3102 / 10769986025001060$}

Bižić-Ionescu, M., Zeder, M., Ionescu, D., Orlić, S., Fuchs, B.M., Grossart, H.-P., and Amann, R. $2014 a$. Comparison of bacterial communities on limnic versus coastal marine particles reveals profound differences in colonization. Environ. Microbiol. 1-36. doi:10.1111/1462-2920.12466

Bižić-Ionescu, M., Amann, R. and Grossart, H.P. 2014b. Massive regime shifts and high activity of heterotrophic bacteria in an ice-covered lake. PloS one. 9(11). p.e113611. doi: 10.1371/journal.pone.0113611

Block, K.R., O'Brien, J.M., Edwards, W.J. and Marnocha, C.L. 2021. Vertical structure of the bacterial diversity in meromictic Fayetteville Green Lake. MicrobiologyOpen. 10(4): 1228. doi: 10.1002/mbo3.1228 
963 Bokulich N.A., Kaehler B.D., Rideout J.R., Dillon, M., Bolyen,E., Knight,R., Huttley, G.A. and Caporaso,

964

965

966

967

968

969

970

971

972

973

974

975

976

977

978

979

980

981

982

983

984

J.G. .2018. Optimizing taxonomic classification of marker-gene amplicon sequences with QIIME 2's q2-feature-classifier plugin. Microbiome.6:90. doi: 10.1186/s40168-018-0470-z

Bolyen, E., Rideout, J.R., Dillon, M.R., Bokulich, N.A. et al. 2019. Reproducible, interactive, scalable and extensible microbiome data science using QIIME 2. Nature Biotechnology 37: 852-857. doi: $10.1038 / \mathrm{s} 41587-019-0209-9$

Bray J.R. and Curtis J.T. 1957. An ordination of upland forest communities of southern Wisconsin. Ecol Monogr. 27: 325-349. doi: 10.2307/1942268

Breitburg, D., Levin, L.A., Oschlies, A., Grégoire, M., Chavez, F.P., Conley, D.J., Garçon, V., Gilbert, D., Gutiérrez, D., Isensee, K. and Jacinto, G.S. 2018. Declining oxygen in the global ocean and coastal waters. Science. 359(6371). doi: 10.1126/science.aam7240

Brunskill, G.J. and Ludlam, S.D. 1969. Fayetteville Green Lake, New York. I. Physical and chemical limnology 1. Limnology and Oceanography. 14(6): 817-829. doi: 10.4319/lo.1969.14.6.0817

Brunskill, G.J., 1969. Fayetteville Green Lake, New York. II. Precipitation and sedimentation of calcite in a meromictic lake with laminated sediments 1. Limnology and Oceanography. 14(6): 830-847. doi: $10.4319 / 10.1969 .14 .6 .0830$

Burns, B.P., Goh, F., Allen, M., Neilan, B.A. 2004. Microbial diversity of extant stromatolites in the hypersaline marine environment of Shark Bay, Australia. Environmental microbiology 6(10):1096-1101. doi:10.1111/j.1462-2920.2004.00651.x

Cai, H., Jiang, H., Krumholz, L.R. and Yang, Z. 2014. Bacterial community composition of size-fractioned aggregates within the phycosphere of cyanobacterial blooms in a eutrophic freshwater lake. PloS one. 9(8): p.e102879. doi: 10.1371/journal.pone.0102879 
985 Callahan BJ, McMurdie P.J., Rosen M.J., Han, A.J., Johnson, A.J.A. and Holmes, S.P. 2016. DADA2: high-resolution sample inference from Illumina amplicon data. Nat Methods. 13:581-583. doi: 10.1038/nmeth.3869

988

989

990

991

992

993

994

995

996

997

998

999

1000

1001

1002

1003

1004

1005

1006

1007

Camacho C., Coulouris G., Avagyan V., Ma N., Papadopoulos J., Bealer K., and Madden, T.L.2008. BLAST+: architecture and applications. BMC Bioinformatics 10:421. doi:10.1186/1471-2105-10421

Capo, E., Bravo, A.G., Soerensen, A.L., Bertilsson, S., Pinhassi, J., Feng, C., Andersson, A.F., Buck, M. and Björn, E. 2020. Deltaproteobacteria and Spirochaetes-like bacteria are abundant putative mercury methylators in oxygen-deficient water and marine particles in the Baltic Sea. Frontiers in microbiology. 11. doi: 10.3389/fmicb.2020.574080

Cendron, F., Niero, G., Carlino, G., Penasa, M. and Cassandro, M. 2020. Characterizing the fecal bacteria and archaea community of heifers and lactating cows through $16 \mathrm{~S}$ rRNA next-generation sequencing. Journal of Applied Genetics. 61(4): 593-605. doi: 10.1007/s13353-020-00575-3

Chan, C.S., McAllister, S.M., Garber, A., Hallahan, B.J. and Rozovsky, S. 2018. Fe oxidation by a fused cytochrome-porin common to diverse Fe-oxidizing bacteria. Biorxiv, p.228056. doi: $10.1101 / 228056$

Cheng, L., Shi, S.B., Yang, L., Zhang, Y., Dolfing, J., Sun, Y.G., Liu, L.Y., Li, Q., Tu, B., Dai, L.R. and Shi, Q. 2019. Preferential degradation of long-chain alkyl substituted hydrocarbons in heavy oil under methanogenic conditions. Organic Geochemistry. 138: 103927. doi: 10.1016/j.orggeochem.2019.103927

Chiu, B.K., Kato, S., McAllister, S.M., Field, E.K. and Chan, C.S. 2017. Novel pelagic iron-oxidizing Zetaproteobacteria from the Chesapeake Bay oxic-anoxic transition zone. Frontiers in microbiology. 8: 1280. doi: 10.3389/fmicb.2017.01280 
1008 Chutivisut, P., Isobe, K., Powtongsook, S., Pungrasmi, W. and Kurisu, F. 2018. Distinct microbial community performing dissimilatory nitrate reduction to ammonium (DNRA) in a high C/NO3reactor. Microbes and environments. ME17193. doi: 10.1264/jsme2.ME17193

Cline J. D. 1969. Spectrophotometric determination of hydrogen sulfide in natural waters. Limnol. Oceanogr. 14: 454-458. doi:10.4319/1o.1969.14.3.0454

\section{3}

1014 workflow for microbiome research. MSystems. 2(1). doi: 10.1128/mSystems.00127-16

Culver, D.A. and Brunskill, G.J., 1969. Fayetteville Green Lake, New York. V. Studies of primary production and zooplankton in a meromictic marl lake 1. Limnology and Oceanography. 14(6): 862-873.doi: 10.4319/1o.1969.14.6.0862C

Cummings, D.E., Caccavo Jr, F., Spring, S. and Rosenzweig, R.F. 1999. Ferribacterium limneticum, gen. nov., sp. nov., an Fe (III)-reducing microorganism isolated from mining-impacted freshwater lake sediments. Archives of Microbiology, 171(3):183-188. doi: 10.1007/s002030050697

Dabert, P., Sialve, B., Delgenès, J.P., Moletta, R. and Godon, J.J. 2001. Characterisation of the microbial 16S rDNA diversity of an aerobic phosphorus-removal ecosystem and monitoring of its transition to nitrate respiration. Applied microbiology and biotechnology. 55(4):500-509. doi: $10.1007 / \mathrm{s} 002530000529$

Delong, E.F., Franks, D.G., and Alldredge, A.L. 1993. Phylogenetic diversity of aggregate-attached vs. free-living marine bacterial assemblages. Limnol. Oceanogr. 38: 924-934. doi:10.4319/lo.1993.38.5.0924

Dong, X., Greening, C., Brüls, T., Conrad, R., Guo, K., Blaskowski, S., Kaschani, F., Kaiser, M., Laban, N.A. and Meckenstock, R.U. 2018. Fermentative Spirochaetes mediate necromass recycling in 
anoxic hydrocarbon-contaminated habitats. The ISME journal, 12(8):2039-2050. doi: $10.1038 / \mathrm{s} 41396-018-0148-3$

1032 Downing, J. A., J. J. Cole, J. J. Middelburg, R. G. Striegl, C. M. Duarte, P. Kortelainen, Y. T. Prairie, and K. A. Laube. 2008. Sediment organic carbon burial in agriculturally eutrophic impoundments over the last century. Global Biogeochem. Cycles. 22: GB1018. doi:10.1029/2006GB002854

Duret, M.T., Lampitt, R.S. and Lam, P. 2019. Prokaryotic niche partitioning between suspended and sinking marine particles. Environmental microbiology reports. 11(3): 386-400. doi: 10.1111/17582229.12692

Edwards, E.A. and Grbić-Galić, D., 1994. Anaerobic degradation of toluene and o-xylene by a methanogenic consortium. Applied and Environmental Microbiology. 60(1): 313-322.

1040 Eloe-Fadrosh, E.A., Paez-Espino, D., Jarett, J., Dunfield, P.F., Hedlund, B.P., Dekas, A.E., Grasby, S.E., bacterial candidate phylum in geothermal springs. Nature communications. 7(1): 1-10. doi: $10.1038 /$ ncomms 10476

Engel, A., 2009. Determination of marine gel particles. In Practical guidelines for the analysis of seawater: $125-142$.

Evans, P.N., Parks, D.H., Chadwick, G.L., Robbins, S.J., Orphan, V.J., Golding, S.D. and Tyson, G.W. 2015. Methane metabolism in the archaeal phylum Bathyarchaeota revealed by genome-centric metagenomics. Science. 350(6259): 434-438.

Finneran, K.T., Johnsen, C.V. and Lovley, D.R. 2003. Rhodoferax ferrireducens sp. nov., a psychrotolerant, facultatively anaerobic bacterium that oxidizes acetate with the reduction of Fe(III). Int. J. Sys. Evol. Microbolo. 53: 669-673. doi: 10.1099/ijs.0.02298-0 
1052 Fuchsman, C.A., Kirkpatrick, J.B., Brazelton, W.J., Murray, J.W., and Staley, J.T. 2011. Metabolic strategies of free living and aggregate-associated bacterial communities inferred from biologic and chemical profiles in the Black Sea suboxic zone. FEMS Microbiol Ecol 78: 586-603. doi: 10.1111/j.1574-6941.2011.01189.x

Fulton, J.M., Arthur, M.A., Thomas, B. and Freeman, K.H. 2018. Pigment carbon and nitrogen isotopic signatures in euxinic basins. Geobiology. 16(4): 429-445. doi:10.1111/gbi.12285

Garrity, G.M., Bell, J.A. and Lilburn, T. 2015. Burkholderiaceae fam. nov. in Bergey's Manual of Systematics of Archaea and Bacteria. doi: 10.1002/9781118960608.fbm00181

Ganesh, S., Bristow, L.A., Larsen, M., Sarode, N., Thamdrup, B. and Stewart, F.J. 2015. Size-fraction partitioning of community gene transcription and nitrogen metabolism in a marine oxygen minimum zone. The ISME journal. 9(12): 2682-2696. doi: 10.1038/ismej.2015.44

Gloor, G.B., Macklaim, J.M., Pawlowsky-Glahn, V. and Egozcue, J.J. 2017. Microbiome datasets are compositional: and this is not optional. Frontiers in microbiology. 8: 2224. doi: $10.3389 /$ fmicb.2017.02224

Gray, N.D., Sherry, A., Grant, R.J., Rowan, A.K., Hubert, C.R.J., Callbeck, C.M., Aitken, C.M., Jones, D.M., Adams, J.J., Larter, S.R. and Head, I.M.2011. The quantitative significance of Syntrophaceae and syntrophic partnerships in methanogenic degradation of crude oil alkanes. Environmental microbiology. 13(11): 2957-2975. doi:10.1111/j.1462-2920.2011.02570.x

Grouzdev, D.S., Bidzhieva, S.K., Sokolova, D.S., Tourova, T.P., Patutina, E.O., Poltaraus, A.B. and Nazina, T.N. 2018. Draft Genome Sequence of a Fermenting Bacterium,"Sphaerochaeta halotolerans" 4-11T, from a Low-Temperature Petroleum Reservoir in Russia. Microbiology resource announcements. 7(21). doi: 10.1128/MRA.01345-18 
1074 Gutiérrez-Preciado, A., Vargas-Chávez, C., Reyes-Prieto, M., Ordoñez, O.F., Santos-García, D., Rosas-

1075

1076

1077

1078

1079

1080

1081

1082

1083

1084

1085

1086

1087

1088

1089

1090

1091

1092

1093

1094

1095

1096

Pérez, T., Valdivia-Anistro, J., Rebollar, E.A., Saralegui, A., Moya, A. and Merino, E. 2017. The genomic sequence of Exiguobacterium chiriqhucha str. N139 reveals a species that thrives in cold waters and extreme environmental conditions. PeerJ: e3162. doi: 10.7717/peerj.3162

Havig, J.R., McCormick, M.L., Hamilton, T.L. and Kump, L.R. 2015. The behavior of biologically important trace elements across the oxic/euxinic transition of meromictic Fayetteville Green Lake, New York, USA. Geochimica et Cosmochimica Acta. 165: 389-406. doi: 10.1016/j.gca.2015.06.024

Havig, J.R., Hamilton, T.L., McCormick, M., McClure, B., Sowers, T., Wegter, B. and Kump, L.R. 2018. Water column and sediment stable carbon isotope biogeochemistry of permanently redox-stratified Fayetteville Green Lake, New York, USA. Limnology and Oceanography.63(2): 570-587. doi: 10.1002/lno.10649

Hug, L.A., Castelle, C.J., Wrighton, K.C., Thomas, B.C., Sharon, I., Frischkorn, K.R., Williams, K.H., Tringe, S.G. and Banfield, J.F. 2013. Community genomic analyses constrain the distribution of metabolic traits across the Chloroflexi phylum and indicate roles in sediment carbon cycling. Microbiome. 1(1): 1-17. doi: 10.1186/2049-2618-1-22

Jochum, L.M., Schreiber, L., Marshall, I.P., Jørgensen, B.B., Schramm, A. and Kjeldsen, K.U. 2018. Single-cell genomics reveals a diverse metabolic potential of uncultivated Desulfatiglans-related Deltaproteobacteria widely distributed in marine sediment. Frontiers in microbiology, 9: 2038. doi: 10.3389/fmicb.2018.02038

Kalmbach, S., Manz, W., Wecke, J. and Szewzyk, U. 1999. Aquabacterium gen. nov., with description of Aquabacterium citratiphilum sp. nov., Aquabacterium parvum sp. nov. and Aquabacterium commune sp. nov., three in situ dominant bacterial species from the Berlin drinking water system. 
International Journal of Systematic and Evolutionary Microbiology, 49(2): 769-777. doi:

1099 Kamennaya, N.A., Hu, P. and Jansson, C. 2020. Sedimentation of ballasted cells-free EPS in meromictic Fayetteville Green Lake. Geobiology. 18(1):80-92. doi: 10.1111/gbi.12366

1101 Katoh K., Misawa K., Kuma K. and Miyata T. 2002. MAFFT: a novel method for rapid multiple sequence alignment based on fast Fourier transform. Nucleic Acids Res. 30(14):3059-3066. doi:

Kellogg, C.A., Ross, S.W. and Brooke, S.D. 2016. Bacterial community diversity of the deep-sea octocoral Paramuricea placomus. PeerJ. 4: e2529. doi: 10.7717/peerj.2529

1109 Kirchman, D.L. 2002. The ecology of Cytophaga-Flavobacteria in aquatic environments. FEMS microbiology ecology. 39(2): 91-100. doi: 10.1111/j.1574-6941.2002.tb00910.x

1111 Kieft, B, Li, Z., Bryson,S., Hettich, H.L., Pan, C, Mayali, X., and Mueller, R.S. 2021. Phytoplankton exudates and lysates support distinct microbial consortia with specialized metabolic and ecophysiological traits. PNAS. 118(41): e2101178118. doi: 10.1073/pnas.2101178118

1117 Kleindienst, S. 2012. Hydrocarbon-degrading sulfate-reducing bacteria in marine hydrocarbon seep sediments. Doctoral Dissertation. Max Planck Institute for Marine Microbiology, Bremen, Germany. 
1120 Kleindienst, S. and Knittel, K. 2020. Anaerobic Hydrocarbon-Degrading Sulfate-Reducing Bacteria at 1121 Marine Gas and Oil Seeps. In Marine Hydrocarbon Seeps. 21-41. Springer, Cham. doi: 10.1007/978-3-030-34827-4_2

1123 Lau, M.P., Valerio, G., Pilotti, M. and Hupfer, M. 2020. Intermittent meromixis controls the trophic state of warming deep lakes. Scientific reports. 10(1): 1-16. doi: 10.1038/s41598-020-69721-5

1125 Lauro, F.M., DeMaere, M.Z., Yau, S., Brown, M.V., Ng, C., Wilkins, D., Raftery, M.J., Gibson, J.A., Andrews-Pfannkoch, C., Lewis, M. and Hoffman, J.M. 2011. An integrative study of a meromictic lake ecosystem in Antarctica. The ISME journal. 5(5): 879-895. doi: 10.1038/ismej.2010.185

1128 Lea-Smith, D.J., Biller, S.J., Davey, M.P., Cotton, C.A., Sepulveda, B.M.P., Turchyn, A.V., Scanlan, D.J., Smith, A.G., Chisholm, S.W. and Howe, C.J. 2015. Contribution of cyanobacterial alkane production to the ocean hydrocarbon cycle. Proceedings of the National Academy of Sciences.

1132 Ley, R.E., Harris, J.K., Wilcox, J., Spear, J.R., Miller, S.R., Bebout, B.M., Maresca, J.A., Bryant, D.A., Sogin, M.L., Pace, N.R. 2006. Unexpected diversity and complexity of the Guerrero Negro hypersaline microbial mat. Appl Environ Microbiol 72(5):3685-3695. conditions and chemoautotrophic production in the Cariaco Basin. Mar. Chem. 112: 53-64. doi:10.1016/j.marchem.2008.06.002

1139 Li, X., and Y. Astor. 2011. Method 4: Determination of Hydrogen Sulfide, p. 120-125. In Y. Astor, L. 1140 Lorenzoni, and M.I. Scranton [eds.], Handbook of methods for the analysis of oceanographic parameters at the Cariaco Time-Series station. 
1142 Li, Z., Tian, J., Lai, Y., Lee, C.H., Cai, Z. and Yu, C.F. 2020. Puffer fish gut microbiota studies revealed 1143 unique bacterial co-occurrence patterns and new insights on tetrodotoxin producers. Marine $1144 \quad$ drugs. 18(5): 278. doi:10.3390/md18050278

1145 Liu, X., Huang, M., Bao, S., Tang, W. and Fang, T. 2020. Nitrate removal from low carbon-to-nitrogen 1146 ratio wastewater by combining iron-based chemical reduction and autotrophic 1147 denitrification. Bioresource technology. 301:122731. doi: 10.1016/j.biortech.2019.122731

1148 Louati, I., Pascault, N., Debroas, D., Bernard, C., Humbert, J.F. and Leloup, J. 2015. Structural diversity of bacterial communities associated with bloom-forming freshwater cyanobacteria differs according to the cyanobacterial genus. PloS one. 10(11): p.e0140614. doi:

1152 Love, C.R., Arrington, E.C., Gosselin, K.M., Reddy, C.M., Van Mooy, B.A., Nelson, R.K. and Valentine, D.L. 2021. Microbial production and consumption of hydrocarbons in the global ocean. Nature microbiology. 6(4):489-498. doi: 10.1038/s41564-020-00859-8

1155 Lovley, D.R., Dwyer, D.F. and Klug, M.J.1982. Kinetic analysis of competition between sulfate reducers and methanogens for hydrogen in sediments. Applied and Environmental Microbiology, 43(6):

1158 Lozupone, C.A., Hamady, M., Kelley, S.T. and Knight, R. 2007. Quantitative and qualitative $\beta$ diversity measures lead to different insights into factors that structure microbial communities. Applied and environmental microbiology. 73(5): 1576-1585. doi: 10.1128/AEM.01996-06

1161 Mandal, S., Van Treuren, W., White, R.A., Eggesbø, M., Knight, R. and Peddada, S.D. 2015. Analysis of composition of microbiomes: a novel method for studying microbial composition. Microbial ecology in health and disease. 26(1): 27663. doi: 10.3402/mehd.v26.27663 
1164 Martin, M., 2011. Cutadapt removes adapter sequences from high-throughput sequencing reads. EMBnet. Journal. 17(1): 10-12. doi: 10.14806/ej.17.1.200

1166 Mayali, X. and Azam, F. 2004. Algicidal bacteria in the sea and their impact on algal blooms 1. Journal of Eukaryotic Microbiology. 51(2): 139-144. doi: 10.1111/j.1550-7408.2004.tb00538.x

1168 Mei, R., Nobu, M.K., Narihiro, T. and Liu, W.T. 2020. Metagenomic and Metatranscriptomic Analyses Revealed Uncultured Bacteroidales Populations as the Dominant Proteolytic Amino Acid Degraders in Anaerobic Digesters. Frontiers in microbiology. 11: 2763.

1172 Meyer, K.M., Macalady, J.L., Fulton, J.M., Kump, L.R., Schaperdoth, I. and Freeman, K.H. 2011. Carotenoid biomarkers as an imperfect reflection of the anoxygenic phototrophic community in meromictic Fayetteville Green Lake. Geobiology. 9(4): 321-329. doi: 10.1111/j.1472-

1179 Morgulis, A., Coulouris, G., Raytselis, Y., Madden, T.L., Agarwala, R., and Schäffer, A.A. 2008. Database 4669.2011.00285.x

Moffitt, S.E., Moffitt, R.A., Sauthoff, W., Davis, C.V., Hewett, K. and Hill, T.M. 2015. Paleoceanographic insights on recent oxygen minimum zone expansion: lessons for modern oceanography. PloS one. 10(1): p.e0115246. doi: 10.1371/journal.pone.0115246 indexing for production MegaBLAST searches. Bioinformatics 15:1757-1764. doi: 10.1093/bioinformatics/btn322

Morris, B.E., Henneberger, R., Huber, H. and Moissl-Eichinger, C. 2013. Microbial syntrophy: interaction for the common good. FEMS microbiology reviews. 37(3): 384-406. doi: 10.1111/15746976.12019

Morrison, J.M., Baker, K.D., Zamor, R.M., Nikolai, S., Elshahed, M.S. and Youssef, N.H. 2017. Spatiotemporal analysis of microbial community dynamics during seasonal stratification events in 
a freshwater lake (Grand Lake, OK, USA). PLoS One. 12(5): p.e0177488. doi:/10.1371/journal.pone.0177488

1189 Nadkarni, M.A., Martin, F.E., Jacques, N.A. and Hunter, N. 2002. Determination of bacterial load by real1190 time PCR using a broad-range (universal) probe and primers set. Microbiology. 148(1): $257-266$. doi: 10.1099/00221287-148-1-257

1192 Nedelkova, M., Radeva, G. and Selenska-Pobell, S. 2005. Molecular bacterial diversity in water at the deep-well monitoring site at Tomsk-7. Developments in Water Science. 52: 521-536. doi: $10.1016 / \mathrm{S} 0167-5648(05) 52041-0$

1195 Nizzoli, D., Carraro, E., Nigro, V. and Viaroli, P. 2010. Effect of organic enrichment and thermal regime on denitrification and dissimilatory nitrate reduction to ammonium (DNRA) in hypolimnetic sediments of two lowland lakes. Water Research. 44(9): 2715-2724. doi: 10.1016/j.watres.2010.02.002

Nobu, M.K., Narihiro, T., Kuroda, K., Mei, R. and Liu, W.T. 2016. Chasing the elusive Euryarchaeota class WSA2: genomes reveal a uniquely fastidious methyl-reducing methanogen. The ISME journal. 10(10): 2478-2487. doi: 10.1038/ismej.2016.33

Ploug, H., Kuhl, M., Buchholz-Cleven, B., and Jørgensen, B.B. 1997. Anoxic aggregates-an ephermeral phenomenon in the pelagic environment? Aquat Microb Ecol 13: 285-294. doi:10.3354/ame013285 
1210 Porter, K.G. and Feig, Y.S. 1980. The use of DAPI for identifying and counting aquatic microflora 1.

1211 Limnology and oceanography. 25(5): 943-948. doi:10.4319/lo.1980.25.5.0943

1212 Price M.N., Dehal P.S. and Arkin A.P. 2010. FastTree 2-approximately maximum-likelihood trees for 1213 large alignments. PLoS ONE. 5: e9490. doi: 10.1371/journal.pone.0009490

1214 Robinson, J.A. and Tiedje, J.M. 1984. Competition between sulfate-reducing and methanogenic bacteria 1215 for $\mathrm{H}_{2}$ under resting and growing conditions. Archives of Microbiology. 137(1): 26-32. doi: 10.1007/BF00425803

1217 Rojas, C.A., De Santiago Torio, A., Park, S., Bosak, T. and Klepac-Ceraj, V. 2021. Organic electron 1218 donors and terminal electron acceptors structure anaerobic microbial communities and interactions in a permanently stratified sulfidic lake. Frontiers in microbiology. 12: 847. doi: 10.3389/fmicb.2021.620424

Salcher, M.M., Pernthaler, J. and Posch, T., 2011. Seasonal bloom dynamics and ecophysiology of the freshwater sister clade of SAR11 bacteria 'that rule the waves'(LD12). The ISME journal. 5(8): 1242-1252. doi: 10.1038/ismej.2011.8

Sarmiento, J.L. and Gruber, N. 2013. Ocean biogeochemical dynamics. Princeton University Press. doi: $10.1515 / 9781400849079$

Schönheit, P., Kristjansson, J.K. and Thauer, R.K. 1982. Kinetic mechanism for the ability of sulfate reducers to out-compete methanogens for acetate. Archives of Microbiology. 132(3): 285-288. doi: 10.1007/BF00407967

Scranton, M.I., Taylor, G.T., Thunell, R., Benitez-Nelson, C.R., Muller-Karger, F., Fanning, K., 1230 Lorenzoni, L., Montes, E., Varela, R. and Astor, Y. 2014. Interannual and subdecadal variability in the nutrient geochemistry of the Cariaco Basin. Oceanography, 27(1):148-159 
1232 Shannon, C. E., and Weaver, W., 1949. The Mathematical Theory of Communication. Urbana: University 1233 of Illinois Press.

1234 Shin, B., Bociu, I., Kolton, M., Huettel, M. and Kostka, J.E. 2019. Succession of microbial populations and nitrogen-fixation associated with the biodegradation of sediment-oil-agglomerates buried in a Florida sandy beach. Scientific reports. 9(1): 1-11. doi: 10.1038/s41598-019-55625-6

Sieber, J.R., McInerney, M.J. and Gunsalus, R.P. 2012. Genomic insights into syntrophy: the paradigm for anaerobic metabolic cooperation. Annual review of microbiology. 66: 429-452. doi: 10.1146/annurev-micro-090110-102844

Singh, N., Marwa, N., Mishra, J., Verma, P.C., Rathaur, S. and Singh, N. 2016. Brevundimonas diminuta mediated alleviation of arsenic toxicity and plant growth promotion in Oryza sativa

Smith, D.C., Simon, M., Alldredge, A.L. and Azam, F. 1992. Intense hydrolytic enzyme activity on marine L. Ecotoxicology and environmental safety. 125: 25-34. doi: 10.1016/j.ecoenv.2015.11.020

Song, H. and Liu, J. 2019. Forward osmosis membrane bioreactor using Bacillus and membrane aggregates and implications for rapid particle dissolution. Nature. 359(6391): 139-142. doi: $10.1038 / 359139 \mathrm{a} 0$

Smith, M.W., Herfort, L., Fortunato, C.S., Crump, B.C. and Simon, H.M. 2017. Microbial players and processes involved in phytoplankton bloom utilization in the water column of a fast-flowing, riverdominated estuary. Microbiology Open. 6(4): e00467. doi: 10.1002/mbo3.467

1252 Stramma, L., Johnson, G.C., Sprintall, J. and Mohrholz, V. 2008. Expanding oxygen-minimum zones in 1253 the tropical oceans. Science. 320(5876): 655-658. doi: 10.1126/science.1153847 
1254 Sun, L., Toyonaga, M., Ohashi, A., Tourlousse, D.M., Matsuura, N., Meng, X.Y., Tamaki, H., Hanada, S., Cruz, R., Yamaguchi, T. and Sekiguchi, Y. 2016. Lentimicrobium saccharophilum gen. nov., sp. nov., a strictly anaerobic bacterium representing a new family in the phylum Bacteroidetes, and proposal of Lentimicrobiaceae fam. nov. International journal of systematic and evolutionary

Suominen, S., Dombrowski, N., Sinninghe Damsté, J.S. and Villanueva, L. 2020. A diverse uncultivated microbial community is responsible for organic matter degradation in the Black Sea sulphidic zone. Environmental microbiology. doi:10.1111/1462-2920.14902

Suter, E.A., Pachiadaki, M., Taylor, G.T., Astor, Y. and Edgcomb, V.P. 2018. Free-living chemoautotrophic and particle-attached heterotrophic prokaryotes dominate microbial assemblages along a pelagic redox gradient. Environmental microbiology. 20(2): 693-712. doi: $10.1111 / 1462-2920.13997$

Taylor, G.T., Iabichella, M., Ho, T.Y., Scranton, M.I., Thunell, R.C., Muller-Karger, F. and Varela, R. 2001. Chemoautotrophy in the redox transition zone of the Cariaco Basin: a significant midwater source of organic carbon production. Limnology and Oceanography. 46(1): 148-163. doi:10.4319/10.2001.46.1.0148

Taylor, G.T., Way, J. and Scranton, M.I., 2003. Planktonic carbon cycling and transport in surface waters of the highly urbanized Hudson River estuary. Limnology and Oceanography.48(5): 1779-1795. doi: $10.4319 / 10.2003 .48 .5 .1779$

Taylor, G.T., Thunell, R., Varela, R., Benitez-Nelson, C. and Scranton, M.I. 2009. Hydrolytic ectoenzyme activity associated with suspended and sinking organic particles within the anoxic Cariaco Basin. Deep Sea Research Part I: Oceanographic Research Papers. 56(8): 1266-1283. doi: 10.1016/j.dsr.2009.02.006 
1277 Taylor, G.T., Suter, E.A., Pachiadaki, M.G., Astor, Y., Edgcomb, V.P. and Scranton, M.I. 2018. Temporal 1278 shifts in dominant sulfur-oxidizing chemoautotrophic populations across the Cariaco Basin's redoxcline. Deep Sea Research Part II: Topical Studies in Oceanography, 156: 80-96. doi: 10.1016/j.dsr2.2017.11.016

Thiele, S., Fuchs, B.M., Amann, R. and Iversen, M.H. 2015. Colonization in the photic zone and subsequent changes during sinking determine bacterial community composition in marine snow. Applied and environmental microbiology. 81(4): 1463-1471. doi: 10.1128/AEM.02570-14

Thompson, J.B., Ferris, F.G. and Smith, D.A. 1990. Geomicrobiology and sedimentology of the mixolimnion and chemocline in Fayetteville Green Lake, New York. Palaios. 5(1): 52-75.

Thompson, J.B., S., Schultze-Lam, S., Beveridge, T.J. and Des Marais, D.J. 1997. Whiting events:

Torgersen, T., Hammond, D.E., Clarke, W.B. and Peng, T.H. 1981. Fayetteville, Green Lake, New York: 26(1): 110-122. doi: 10.4319/1o.1981.26.1.0110

1292 Torres-Beltrán, M., Mueller, A., Scofield, M., Pachiadaki, M.G., Taylor, C., Tyshchenko, K., Michiels, microbial community structure and potential activity in a seasonally anoxic fjord: Saanich Inlet, British Columbia. Frontiers in Marine Science. 6: 132. doi: 10.3389/fmars.2019.00132 methanotrophic archaea and sulfate-reducing bacteria through statistical comparison of nested Magneto-FISH enrichments. PeerJ, 4: p.e1913. doi: 10.7717/peerj.1913 
Van der Zaan, B.M., Saia, F.T., Stams, A.J., Plugge, C.M., de Vos, W.M., Smidt, H., Langenhoff, A.A. and Gerritse, J. 2012. Anaerobic benzene degradation under denitrifying conditions: Peptococcaceae as dominant benzene degraders and evidence for a syntrophic process. Environmental microbiology, 14(5):1171-1181. doi: 10.1111/j.1462-2920.2012.02697.x

Van Vliet D. M., Ayudthaya S. P. N., Diop S., Villanueva L., Stams A. J. M., Sánchez-Andrea I. 2019. Anaerobic degradation of sulfated polysaccharides by two novel Kiritimatiellales strains isolated from black sea sediment. Front. Microbiol. 10: 253. doi:10.3389/fmicb.2019.00253

Wieczorek, A.S., Schmidt, O., Chatzinotas, A., von Bergen, M., Gorissen, A. and Kolb, S. 2019. Ecological functions of agricultural soil bacteria and microeukaryotes in chitin degradation: a case study. Frontiers in microbiology. 10: 1293. doi:10.3389/fmicb.2019.01293

1311 Yan, Z., Zhang, Y., Wu, H., Yang, M., Zhang, H., Hao, Z. and Jiang, H. 2017. Isolation and characterization of a bacterial strain Hydrogenophaga sp. PYR1 for anaerobic pyrene and benzo [a] pyrene biodegradation. RSC advances. 7(74): 46690-46698. doi:10.1039/C7RA09274A

Wright, J.J., Konwar, K.M. and Hallam, S.J. 2012. Microbial ecology of expanding oxygen minimum zones. Nature Reviews Microbiology. 10(6): 381-394. doi:10.1038/nrmicro2778 
bacterial iron-only nitrogenase. Nature microbiology. 3(3): 281-286. doi: 10.1038/s41564-0170091-5

1324 Zheng, Q., Lin, W., Wang, Y., Li, Y., He, C., Shen, Y., Guo, W., Shi, Q. and Jiao, N. 2020. Highly enriched $1325 \mathrm{~N}$-containing organic molecules of Synechococcus lysates and their rapid transformation by 1326 heterotrophic bacteria. Limnology and Oceanography. doi: 10.1002/lno.11608

1327 Zhou Z, Pan J, Wang F, Gu JD, Li M. 2018. Bathyarchaeota: globally distributed metabolic generalists in anoxic environments. FEMS microbiology reviews. 42(5):639-55. doi: 10.1093/femsre/fuy023

1329 Zhou, S., Zhang, Y., Huang, T., Liu, Y., Fang, K. and Zhang, C. 2019. Microbial aerobic denitrification 1330 dominates nitrogen losses from reservoir ecosystem in the spring of Zhoucun reservoir. Science of 1331 The Total Environment. 651: 998-1010. doi: 10.1016/j.scitotenv.2018.09.160 


\section{SUPPLEMENTARY MATERIALS}

1334 Treatment of sensor data and chemical metadata

1335 To create a table of metadata values that corresponded to DNA sampling depths, pre-

1336 existing chemical data sets and our continuous sensor data required further processing. Pre-cast

1337 readings in air and upcasts were removed from continuous sensor data sets and replicated depth

1338 readings were averaged. Pre-cast readings were distinguished from the downcast by finding the

1339 maximum difference in conductivity within the first two meters of water. The downcast and upcast

1340 were distinguished by designating the deepest depth with the earliest time stamp as the true

1341 downcast end. Linear splines were then fit to data points in pre-existing chemical data sets and

1342 cleaned, averaged continuous sensor data sets. Continuous sensor data splines were used to solve

1343 for the value of the variable at each DNA sampling depth and the chemical data splines were used

1344 to solve for values at each DNA sampling depth if a discrete sample was not taken at that exact

1345 depth.

$1346 \underline{\text { Tables }}$

1347 Table S1 Kruskal-Wallace pairwise tests of Pielou-evenness alpha diversity against metadata bins. 1348 PS=Particulate sulfur; $\mathrm{Phyco}=$ phycoerythrin; ORP $=$ oxidation reduction potential; ox. 1349 cat=oxygen/redox category; ICA=inorganic carbon assimilation; BHP=bacterial heterotrophic production; Temp=temperature. If no units are specified, biological and chemical data is concentration.

\begin{tabular}{|c|c|c|c|c|}
\hline variable & Group 1 & Group 2 & $p$ & $q$ \\
\hline $0.2-0.4 \mu \mathrm{m} P S$ & $<0.045(\mathrm{n}=8)$ & $>=0.045(\mathrm{n}=8)$ & 0.67 & 0.67 \\
\hline \multirow[t]{3}{*}{$>0.4 \mu m P S$} & $<0.01(\mathrm{n}=8)$ & $>=0.01<0.05(\mathrm{n}=6)$ & 0.70 & 1.00 \\
\hline & $<0.01(\mathrm{n}=8)$ & $>=0.05(n=2)$ & 1.00 & 1.00 \\
\hline & $>=0.01<0.05(\mathrm{n}=6)$ & $>=0.05(\mathrm{n}=2)$ & 0.74 & 1.00 \\
\hline \multirow{3}{*}{ 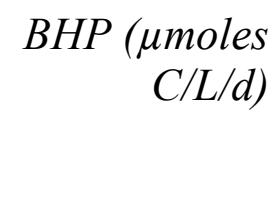 } & $<0.4(\mathrm{n}=16)$ & $>=0.4<1.1(\mathrm{n}=10)$ & 0.49 & 0.49 \\
\hline & $<0.4(\mathrm{n}=16)$ & $>=1.1(\mathrm{n}=4)$ & 0.07 & 0.11 \\
\hline & $>=0.4<1.1(\mathrm{n}=10)$ & $>=1.1(\mathrm{n}=4)$ & 0.05 & 0.11 \\
\hline
\end{tabular}




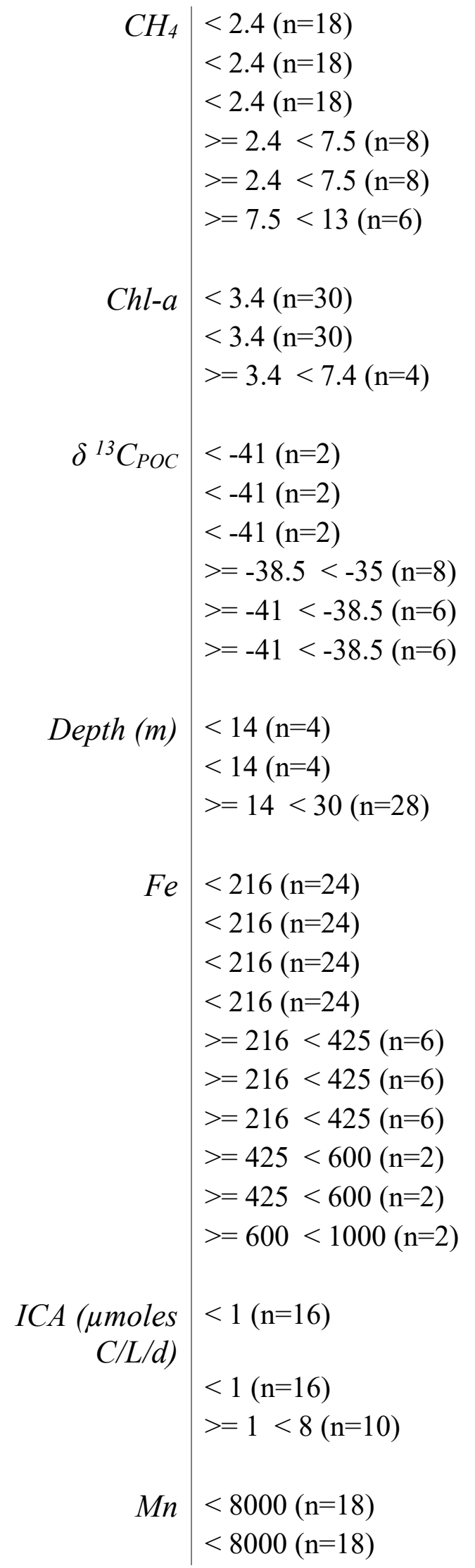

$>=13(\mathrm{n}=4)$

$>=2.4<7.5(\mathrm{n}=8)$

$>=7.5<13(\mathrm{n}=6)$

$>=13(\mathrm{n}=4)$

$>=7.5<13(\mathrm{n}=6)$

$>=13(\mathrm{n}=4)$

$>=3.4<7.4(\mathrm{n}=4)$

$>=7.4(\mathrm{n}=2)$

$>=7.4(\mathrm{n}=2)$

$>=-35(\mathrm{n}=3)$

$>=-38.5<-35(\mathrm{n}=8)$

$>=-41<-38.5(n=6)$

$>=-35(\mathrm{n}=3)$

$>=-35(\mathrm{n}=3)$

$>=-38.5<-35(n=8)$

$>=14<30(\mathrm{n}=28)$

$>=30(\mathrm{n}=4)$

$>=30(\mathrm{n}=4)$

$>=1000(\mathrm{n}=2)$

$>=216<425(\mathrm{n}=6)$

$>=425<600(\mathrm{n}=2)$

$>=600<1000(\mathrm{n}=2)$

$>=1000(\mathrm{n}=2)$

$>=425<600(\mathrm{n}=2)$

$>=600<1000(\mathrm{n}=2)$

$>=1000(\mathrm{n}=2)$

$>=600<1000(\mathrm{n}=2)$

$>=1000(\mathrm{n}=2)$

$>=1<8(\mathrm{n}=10)$

$>=8(\mathrm{n}=4)$

$>=8(\mathrm{n}=4)$

$>=30000<52000(\mathrm{n}=4)$

$>=52000(\mathrm{n}=2)$
$0.55 \quad 0.66$

$0.07 \quad 0.20$

$0.32 \quad 0.48$

$\begin{array}{ll}0.13 & 0.25\end{array}$

$0.03 \quad 0.17$

$0.67 \quad 0.67$

$0.03 \quad 0.10$

$0.10 \quad 0.15$

$1.00 \quad 1.00$

$0.08 \quad 0.17$

$\begin{array}{ll}0.19 & 0.23\end{array}$

$0.05 \quad 0.17$

$0.07 \quad 0.17$

$0.12 \quad 0.18$

$0.25 \quad 0.25$

$0.25 \quad 0.38$

$0.15 \quad 0.38$

$0.61 \quad 0.61$

$0.44 \quad 0.63$

$0.64 \quad 0.80$

$0.34 \quad 0.63$

$0.15 \quad 0.50$

$0.32 \quad 0.63$

$0.74 \quad 0.82$

$0.05 \quad 0.46$

$0.44 \quad 0.63$

$0.12 \quad 0.50$

$1.00 \quad 1.00$

$0.92 \quad 0.92$

$0.05 \quad 0.14$

$\begin{array}{ll}0.26 & 0.39\end{array}$

$0.27 \quad 0.53$

$0.10 \quad 0.43$ 


$\operatorname{Nonth}_{\text {Oxycline pos. }} \mid \begin{aligned} & <=8000(\mathrm{n}=18) \\ & >=30000<52000(\mathrm{n}=4) \\ & >=8000<30000(\mathrm{n}=12) \\ & \end{aligned}$

$\begin{array}{lll}>=8000<30000(\mathrm{n}=12) & 0.97 & 0.97 \\ >=52000(\mathrm{n}=2) & 0.35 & 0.53 \\ >=30000<52000(\mathrm{n}=4) & 0.63 & 0.75 \\ >=52000(\mathrm{n}=2) & 0.14 & 0.43\end{array}$

late July $(\mathrm{n}=20)$

$0.24 \quad 0.24$

$>=150<325(\mathrm{n}=4) \quad 0.39 \quad 0.59$

$>=325(\mathrm{n}=2) \quad 0.50 \quad 0.60$

$>=50<150(\mathrm{n}=8) \quad 0.05 \quad 0.19$

$>=325(\mathrm{n}=2) \quad 0.16 \quad 0.33$

$>=150<325(\mathrm{n}=4) \quad 0.06 \quad 0.19$

$>=325(\mathrm{n}=2)$

$0.60 \quad 0.60$

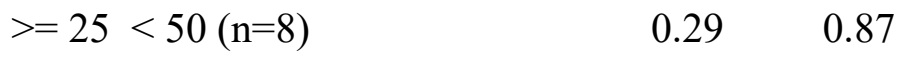

$>=50(\mathrm{n}=4) \quad 0.50 \quad 0.99$

$>=6<25(\mathrm{n}=6) \quad 1.00 \quad 1.00$

$>=50(\mathrm{n}=4) \quad 0.13 \quad 0.76$

$>=25<50(\mathrm{n}=8) \quad 0.80 \quad 1.00$

$>=50(\mathrm{n}=4) \quad 0.83 \quad 1.00$

$>=250<500(\mathrm{n}=6) \quad 0.91 \quad 1.00$

$>=3.5<22(\mathrm{n}=14) \quad 0.95 \quad 1.00$

$>=500(\mathrm{n}=2) \quad 0.52 \quad 1.00$

$>=90<250(\mathrm{n}=4) \quad 0.57 \quad 1.00$

$>=500(\mathrm{n}=2) \quad 0.74 \quad 1.00$

$>=250<500(\mathrm{n}=6) \quad 0.80 \quad 1.00$

$>=500(\mathrm{n}=2) \quad 0.75 \quad 1.00$

$>=90<250(\mathrm{n}=4) \quad 0.60 \quad 1.00$

$>=250<500(\mathrm{n}=6) \quad 0.39 \quad 1.00$

$>=500(\mathrm{n}=2) \quad 1.00 \quad 1.00$

$>=-180<0(\mathrm{n}=2) \quad 0.20 \quad 0.71$

$>=-350<-180(\mathrm{n}=4) \quad 1.00 \quad 1.00$

$>=0(\mathrm{n}=18) \quad 0.97 \quad 1.00$

$>=0(\mathrm{n}=18) \quad 0.31 \quad 0.71$

$>=-180<0(\mathrm{n}=2) \quad 0.35 \quad 0.71$

$>=0(\mathrm{n}=18) \quad 1.00 \quad 1.00$

below $(\mathrm{n}=14) \quad 0.29 \quad 0.54$ 


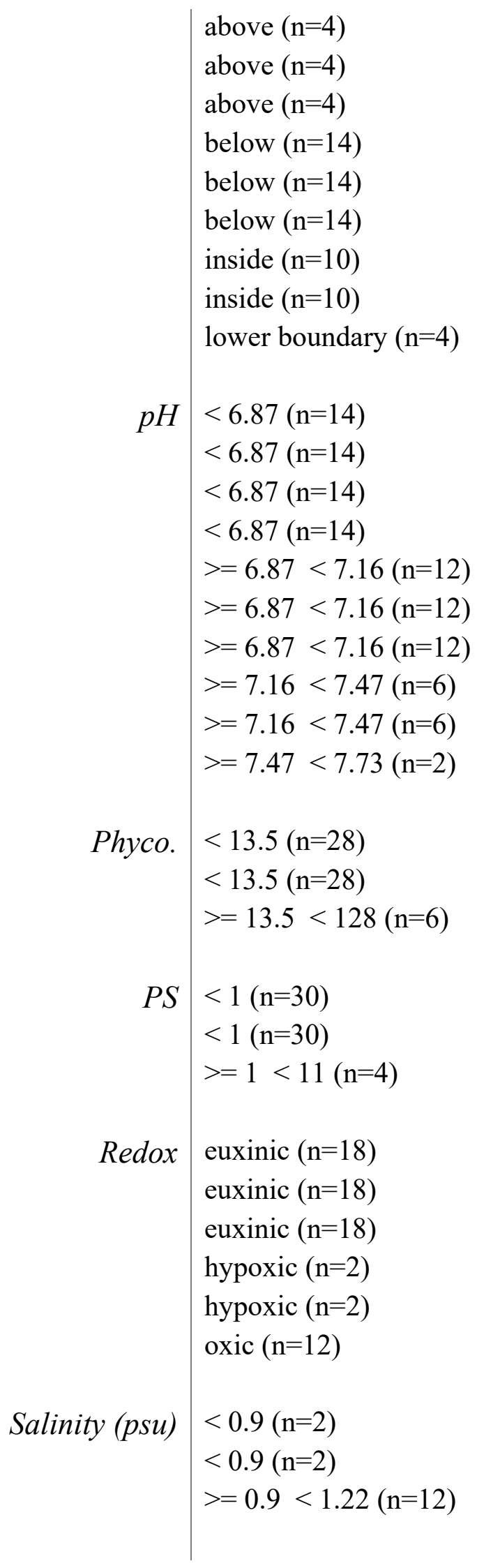

inside $(\mathrm{n}=10)$

lower boundary $(\mathrm{n}=4)$

upper boundary $(\mathrm{n}=4)$

inside $(\mathrm{n}=10)$

lower boundary $(\mathrm{n}=4)$

upper boundary $(\mathrm{n}=4)$

lower boundary $(\mathrm{n}=4)$

upper boundary $(\mathrm{n}=4)$

upper boundary $(\mathrm{n}=4)$

$>=6.87<7.16(\mathrm{n}=12)$

$>=7.16<7.47(\mathrm{n}=6)$

$>=7.47<7.73(\mathrm{n}=2)$

$>=7.73(\mathrm{n}=2)$

$>=7.16<7.47(\mathrm{n}=6)$

$>=7.47<7.73(\mathrm{n}=2)$

$>=7.73(\mathrm{n}=2)$

$>=7.47<7.73(\mathrm{n}=2)$

$>=7.73(\mathrm{n}=2)$

$>=7.73(\mathrm{n}=2)$

$>=128(\mathrm{n}=2)$

$>=13.5<128(\mathrm{n}=6)$

$>=128(\mathrm{n}=2)$

$>=1<11(\mathrm{n}=4)$

$>=11(\mathrm{n}=2)$

$>=11(\mathrm{n}=2)$

hypoxic $(\mathrm{n}=2)$

oxic $(\mathrm{n}=12)$

suboxic $(n=4)$

oxic $(\mathrm{n}=12)$

suboxic $(\mathrm{n}=4)$

suboxic $(\mathrm{n}=4)$

$>=0.9<1.22(\mathrm{n}=12)$

$>=1.22(\mathrm{n}=22)$

$>=1.22(\mathrm{n}=22)$
$0.32 \quad 0.54$

$0.77 \quad 0.86$

$0.04 \quad 0.22$

$0.95 \quad 0.95$

$0.29 \quad 0.54$

$0.52 \quad 0.71$

$0.26 \quad 0.54$

$0.57 \quad 0.71$

$0.04 \quad 0.22$

$\begin{array}{ll}0.72 & 0.97\end{array}$

$0.87 \quad 0.97$

$0.20 \quad 0.51$

$0.75 \quad 0.97$

$1.00 \quad 1.00$

$\begin{array}{ll}0.14 & 0.48\end{array}$

$\begin{array}{ll}0.86 & 0.97\end{array}$

$0.05 \quad 0.46$

$\begin{array}{ll}0.74 & 0.97\end{array}$

$0.12 \quad 0.48$

$\begin{array}{ll}0.13 & 0.32\end{array}$

$0.28 \quad 0.32$

$\begin{array}{ll}0.32 & 0.32\end{array}$

$0.08 \quad 0.12$

$0.07 \quad 0.12$

$1.00 \quad 1.00$

$\begin{array}{ll}0.31 & 0.60\end{array}$

$0.64 \quad 0.64$

$\begin{array}{ll}0.50 & 0.60\end{array}$

$0.36 \quad 0.60$

$0.35 \quad 0.60$

$0.47 \quad 0.60$

$\begin{array}{ll}0.07 & 0.18\end{array}$

$\begin{array}{ll}0.12 & 0.18\end{array}$

$0.43 \quad 0.43$ 


\begin{tabular}{|c|c|c|c|c|}
\hline SizeFrac & $0.2-2.7(n=18)$ & $>2.7(n=18)$ & 0.45 & 0.45 \\
\hline $\mathrm{SO}_{4}^{-2}$ & $<13(\mathrm{n}=26)$ & $>=13(n=10)$ & 0.09 & 0.09 \\
\hline \multirow[t]{3}{*}{ Sulfide } & $<400(\mathrm{n}=20)$ & $>=2000(n=2)$ & 0.30 & 0.51 \\
\hline & $<400(\mathrm{n}=20)$ & $>=400<2000(n=14)$ & 0.97 & 0.97 \\
\hline & $>=400<2000(n=14)$ & $>=2000(n=2)$ & 0.34 & 0.51 \\
\hline \multirow[t]{3}{*}{$T D S$} & $<1550(\mathrm{n}=12)$ & $>=1550<1766.7(\mathrm{n}=20)$ & 0.51 & 0.54 \\
\hline & $<1550(\mathrm{n}=12)$ & $>=1766.7(n=4)$ & 0.54 & 0.54 \\
\hline & $>=1550<1766.7(\mathrm{n}=20)$ & $>=1766.7(\mathrm{n}=4)$ & 0.49 & 0.54 \\
\hline \multirow[t]{6}{*}{$\operatorname{Temp}\left({ }^{\circ} \mathrm{C}\right)$} & $<7.2(\mathrm{n}=2)$ & $>=15(\mathrm{n}=2)$ & 0.12 & 0.23 \\
\hline & $<7.2(\mathrm{n}=2)$ & $>=7.2<8.3(\mathrm{n}=8)$ & 0.19 & 0.23 \\
\hline & $<7.2(\mathrm{n}=2)$ & $>=8.3<15(\mathrm{n}=24)$ & 0.08 & 0.23 \\
\hline & $>=7.2<8.3(\mathrm{n}=8)$ & $>=15(\mathrm{n}=2)$ & 0.04 & 0.22 \\
\hline & $>=7.2<8.3(\mathrm{n}=8)$ & $>=8.3<15(n=24)$ & 0.38 & 0.38 \\
\hline & $>=8.3<15(\mathrm{n}=24)$ & $>=15(\mathrm{n}=2)$ & 0.18 & 0.23 \\
\hline Thiosulfate & $<0.5(\mathrm{n}=26)$ & $>=0.5(n=10)$ & 0.92 & 0.92 \\
\hline \multirow[t]{6}{*}{ Total cells } & $<2.0 \mathrm{e}+09(\mathrm{n}=2)$ & $>=1.2 \mathrm{e}+10(\mathrm{n}=2)$ & 1.00 & 1.00 \\
\hline & $<2.0 \mathrm{e}+09(\mathrm{n}=2)$ & $>=2.0 \mathrm{e}+09<7.0 \mathrm{e}+09(\mathrm{n}=22)$ & 0.06 & 0.18 \\
\hline & $<2.0 \mathrm{e}+09(\mathrm{n}=2)$ & $>=7.0 \mathrm{e}+09<1.2 \mathrm{e}+10(\mathrm{n}=4)$ & 0.35 & 0.53 \\
\hline & $>=2.0 \mathrm{e}+09<7.0 \mathrm{e}+09(\mathrm{n}=22)$ & $>=1.2 \mathrm{e}+10(\mathrm{n}=2)$ & 0.06 & 0.18 \\
\hline & $>=2.0 \mathrm{e}+09<7.0 \mathrm{e}+09(\mathrm{n}=22)$ & $>=7.0 \mathrm{e}+09<1.2 \mathrm{e}+10(\mathrm{n}=4)$ & 0.32 & 0.53 \\
\hline & $>=7.0 \mathrm{e}+09<1.2 \mathrm{e}+10(\mathrm{n}=4)$ & $>=1.2 \mathrm{e}+10(\mathrm{n}=2)$ & 0.64 & 0.77 \\
\hline \multirow{6}{*}{$\begin{array}{r}\text { Turbidity } \\
(F N U)\end{array}$} & $<0.5(\mathrm{n}=18)$ & $>=0.5<1.35(\mathrm{n}=4)$ & 0.44 & 0.53 \\
\hline & $<0.5(\mathrm{n}=18)$ & $>=1.35<35(\mathrm{n}=12)$ & 0.29 & 0.53 \\
\hline & $<0.5(\mathrm{n}=18)$ & $>=35(n=2)$ & 0.26 & 0.53 \\
\hline & $>=0.5<1.35(\mathrm{n}=4)$ & $>=1.35<35(\mathrm{n}=12)$ & 0.90 & 0.90 \\
\hline & $>=0.5<1.35(\mathrm{n}=4)$ & $>=35(\mathrm{n}=2)$ & 0.35 & 0.53 \\
\hline & $>=1.35<35(\mathrm{n}=12)$ & $>=35(n=2)$ & 0.27 & 0.53 \\
\hline Year & $2016.0(n=16)$ & $2017.0(n=20)$ & 0.24 & 0.24 \\
\hline
\end{tabular}

1352 Table S2 Permutational analysis of variance (PERMANOVA) performed on the Bray-Curtis dissimilarity. $\mathrm{PS}=$ Particulate sulfur; $\mathrm{Phyco}=$ phycoerythrin; $\mathrm{ORP}=$ oxidation reduction potential; ox. cat $=$ oxygen/redox category; $\mathrm{ICA}=$ inorganic carbon assimilation; $\mathrm{BHP}=$ bacterial heterotrophic 1355 production; TDS=total dissolved solids; Temp=temperature. If no units are specified, biological 
1356 and chemical data is concentration.

1357

\begin{tabular}{|c|c|c|c|c|}
\hline variable & $\begin{array}{l}\text { sample } \\
\text { size }\end{array}$ & $\begin{array}{l}\text { no. } \\
\text { groups }\end{array}$ & & \\
\hline $\mathrm{Fe}$ & 36 & & 5 & 0.001 \\
\hline $\mathrm{CH}_{4}$ & 36 & & 4 & 0.001 \\
\hline $\mathrm{NH}_{4}$ & 20 & & 4 & 0.001 \\
\hline BHP $(\mu$ moles $C / L / d)$ & 30 & & 3 & 0.001 \\
\hline Thiosulfate & 36 & & 2 & 0.001 \\
\hline$T D S$ & 36 & & 3 & 0.001 \\
\hline Salinity (psu) & 36 & & 3 & 0.001 \\
\hline$M n$ & 36 & & 4 & 0.001 \\
\hline Oxcat & 36 & & 4 & 0.001 \\
\hline$p H$ & 36 & & 5 & 0.001 \\
\hline$O R P(m V)$ & 36 & & 4 & 0.001 \\
\hline $\operatorname{Temp}\left({ }^{\circ} \mathrm{C}\right)$ & 36 & & 4 & 0.001 \\
\hline Turbidity (FNU) & 36 & & 4 & 0.001 \\
\hline $\mathrm{O}_{2}$ & 36 & & 5 & 0.001 \\
\hline Sulfide & 36 & & 3 & 0.001 \\
\hline oxyclinepos & 36 & & 5 & 0.001 \\
\hline $\mathrm{SO}_{4}^{-2}$ & 36 & & 2 & 0.001 \\
\hline $\mathrm{NO}_{3}^{--}$ & 36 & & 4 & 0.001 \\
\hline Phyco. & 36 & & 3 & 0.002 \\
\hline Depth (m) & 36 & & 3 & 0.003 \\
\hline Total cells & 30 & & 4 & 0.005 \\
\hline$I C A(\mu$ moles $C / L / d)$ & 30 & & 3 & 0.005 \\
\hline$P S$ & 36 & & 3 & 0.007 \\
\hline SizeFrac & 36 & & 2 & 0.013 \\
\hline$\delta^{13} C_{P O C}$ & 19 & & 4 & 0.019 \\
\hline Month & 36 & & 2 & 0.03 \\
\hline Year & 36 & & 2 & 0.033 \\
\hline$>0.4 \mu \mathrm{m} P S$ & 16 & & 3 & 0.079 \\
\hline Chl-a & 36 & & 3 & 0.147 \\
\hline $0.2-0.4 \mu \mathrm{m} P S$ & 16 & & 2 & 0.18 \\
\hline
\end{tabular}

Figures

1360 In all figures below, broken lines represent oxycline boundaries. Figures A.1-A.9 show 1361 measurements acquired with a YSI EXO1 sonde. 
1362

1363

(a)

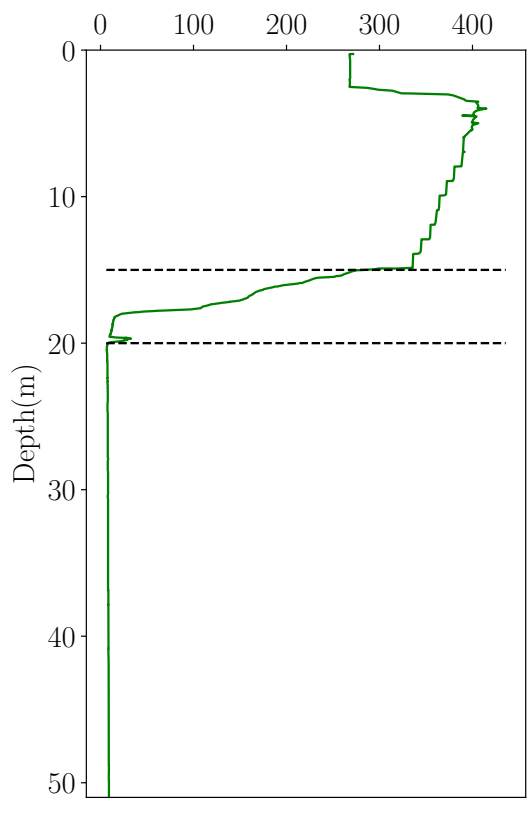

(b)

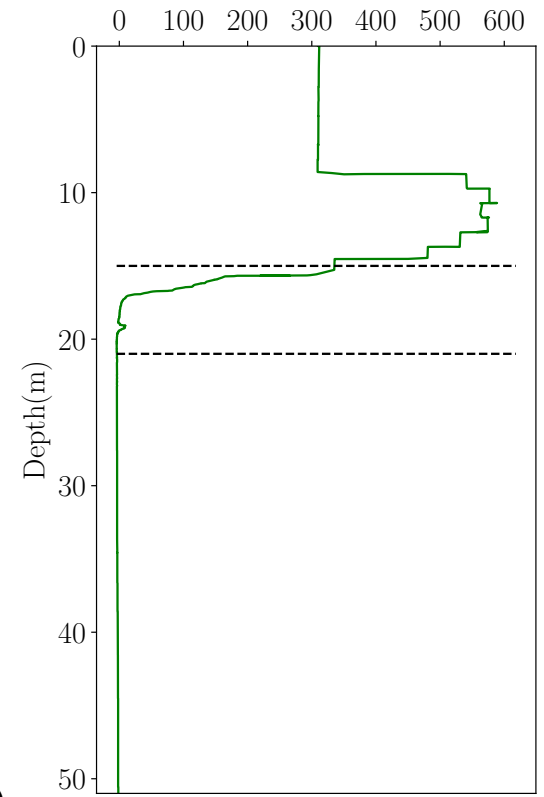

Figure S1 Oxygen concentration in (a) July and (b) October.

TDS $(\mathrm{mg} / \mathrm{L})$

1364

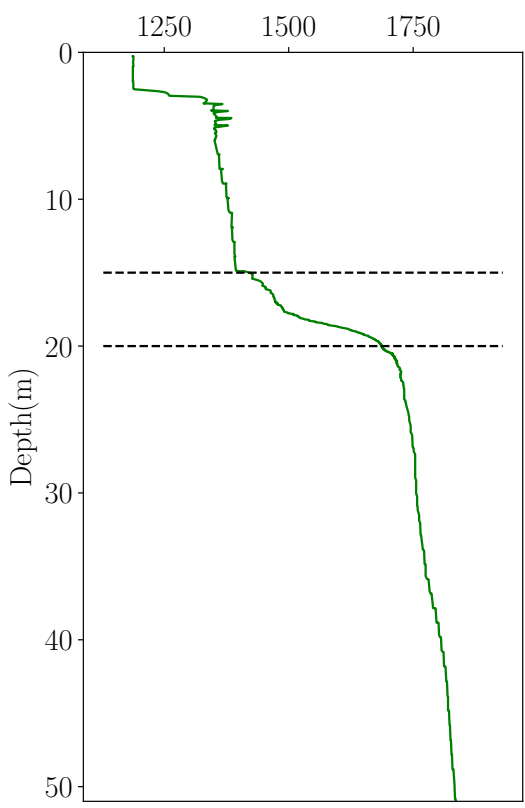

(a)

(b)

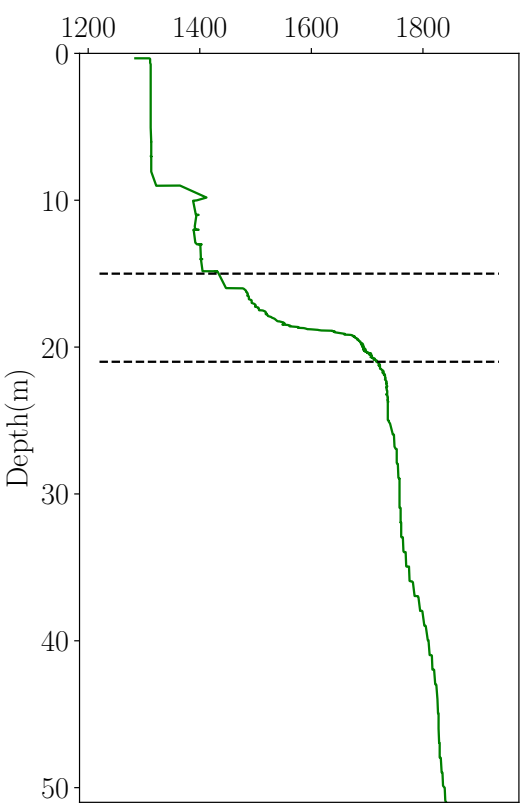

1365 Figure S2 Total Dissolved Solids (TDS) in (a) July and (b) October. 
bioRxiv preprint doi: https://doi.org/10.1101/2021.11.24.469905; this version posted November 25, 2021. The copyright holder for this preprint (which was not certified by peer review) is the author/funder, who has granted bioRxiv a license to display the preprint in perpetuity. It is made available under aCC-BY-NC-ND 4.0 International license.

1366

1367

(a)

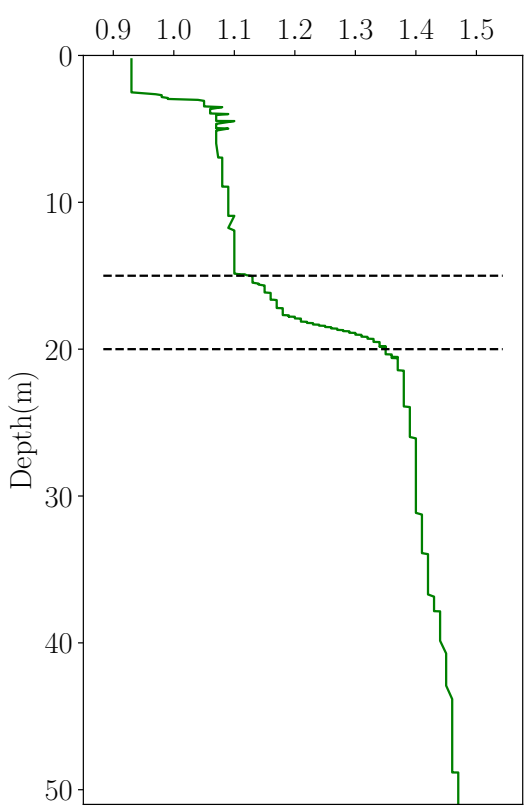

(b)

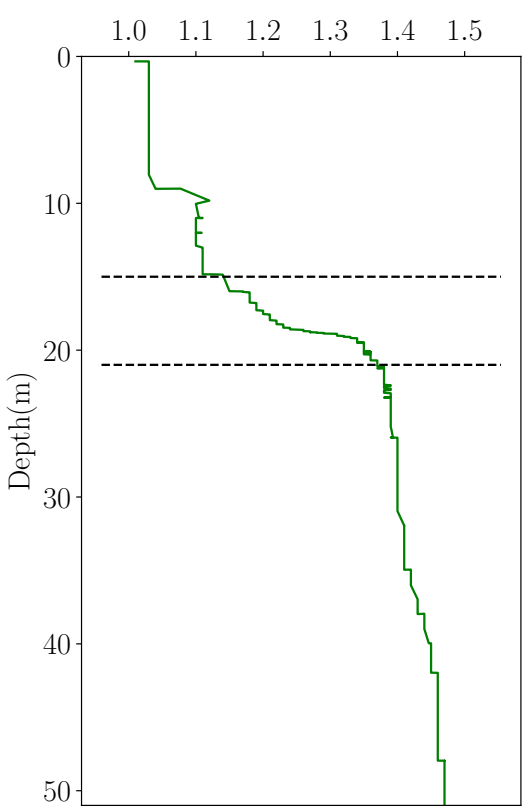

Figure S3 Salinity in (a) July and (b) October.

Temp $\left({ }^{\circ} \mathrm{C}\right)$

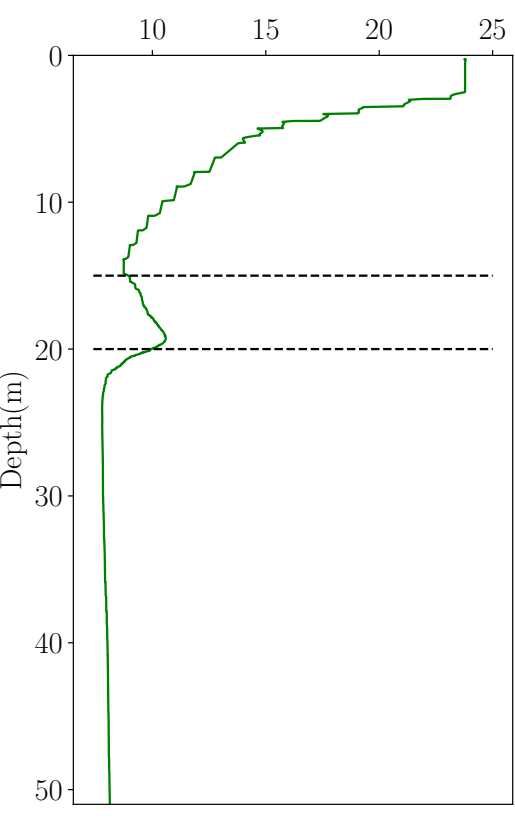

1368

(a)

(b)

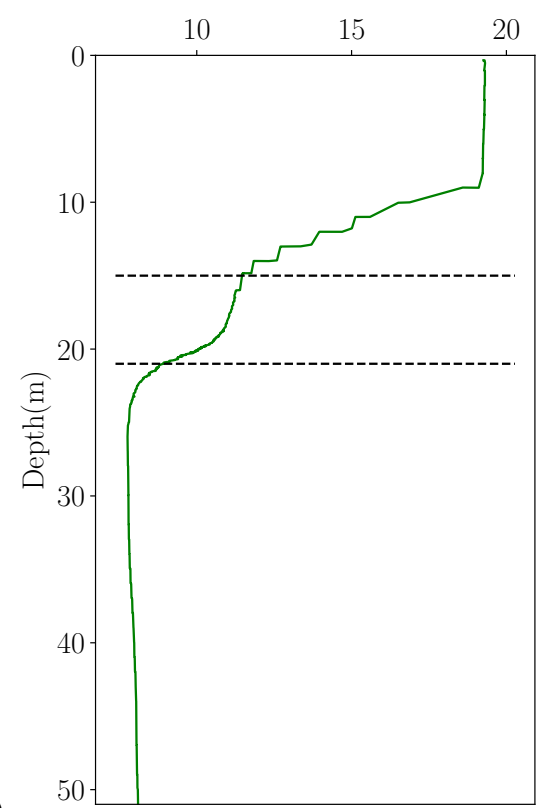

Figure S4 Temperature in (a) July and (b) October. 
1370

1371

(a)

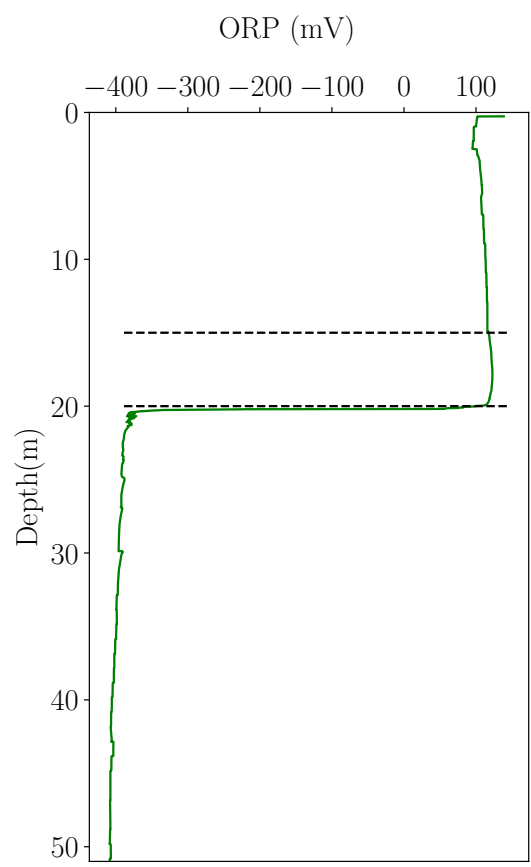

(b)

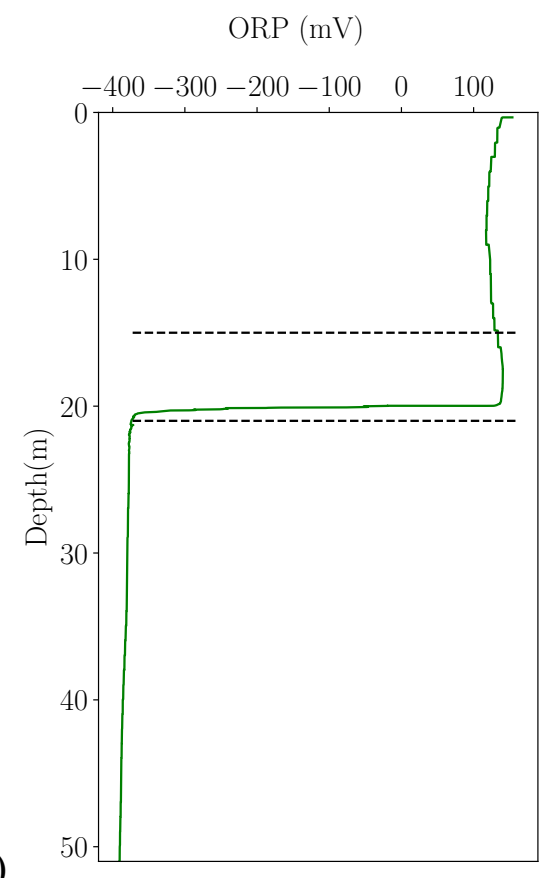

Figure S5 Oxidation reduction potential (ORP) in (a) July and (b) October.

$\mathrm{pH}$

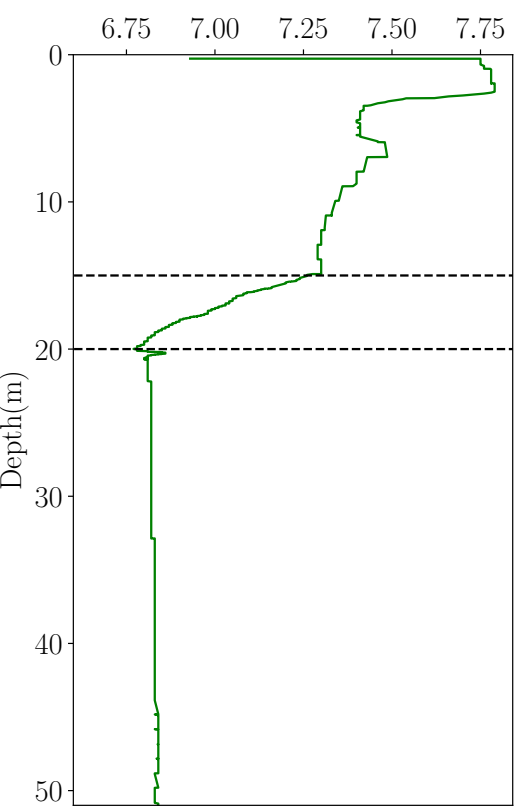

1372

(a)

(b)

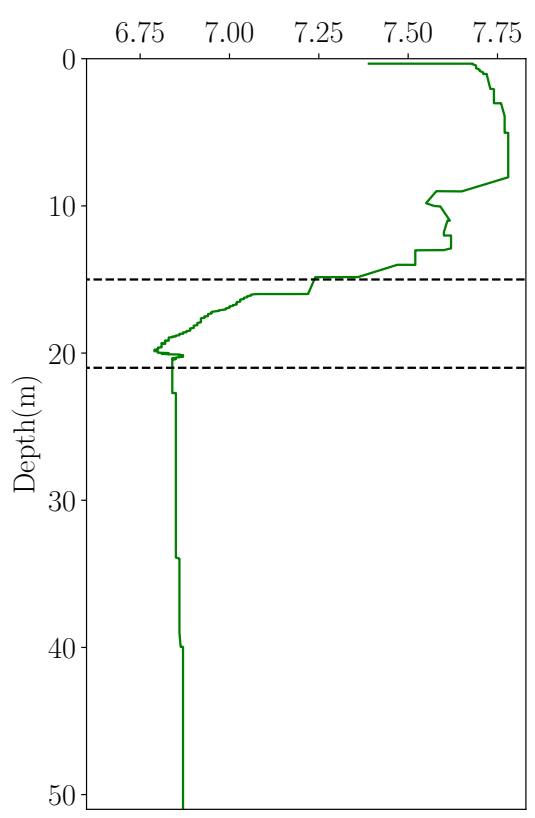

1373 Figure $\mathbf{S 6} \mathrm{pH}$ in (a) July and (b) October. 
bioRxiv preprint doi: https://doi.org/10.1101/2021.11.24.469905; this version posted November 25, 2021. The copyright holder for this preprint (which was not certified by peer review) is the author/funder, who has granted bioRxiv a license to display the preprint in perpetuity. It is made available under aCC-BY-NC-ND 4.0 International license.

1374

1375

(a)

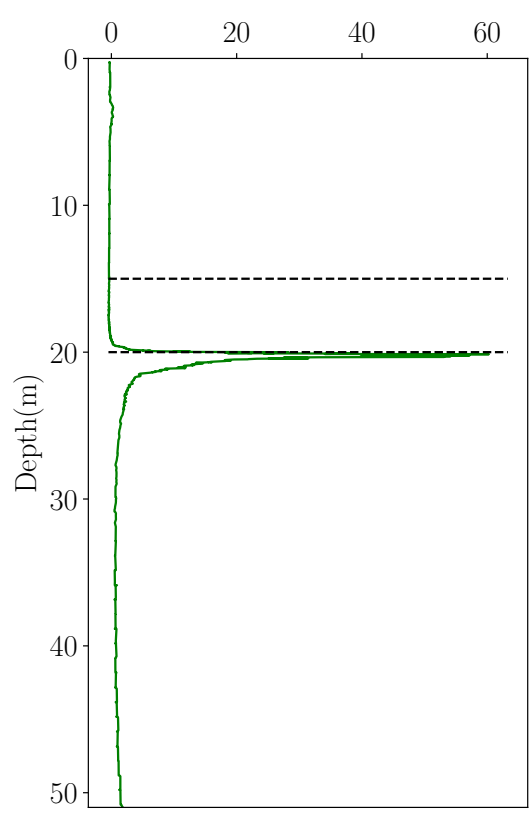

(b)

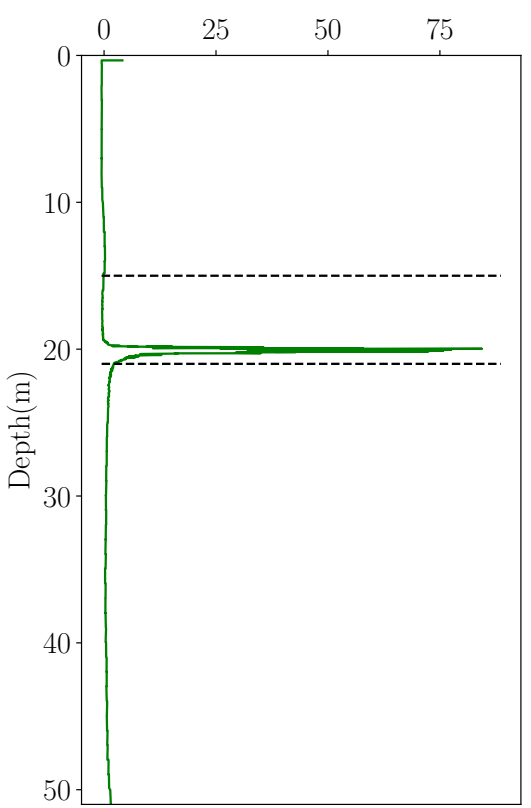

Figure S7 Turbidity in (a) July and (b) October.

BGA-PE ( $\mu / \mathrm{g} / \mathrm{L})$

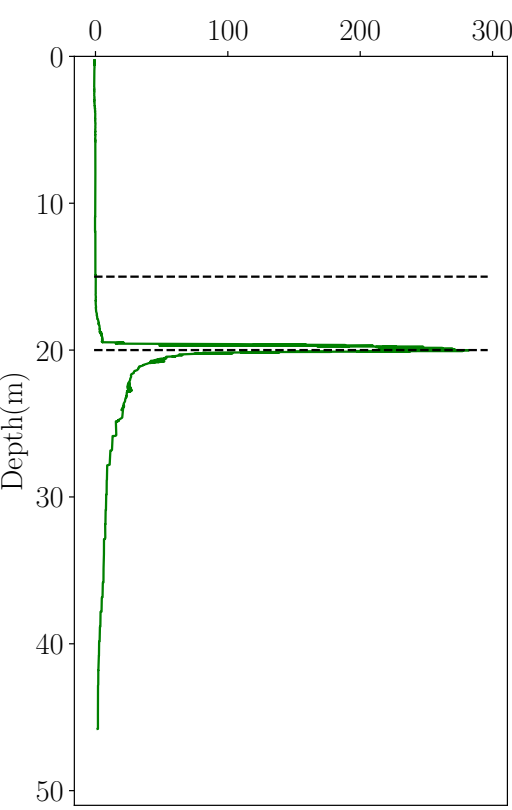

1376

(a)

(b)

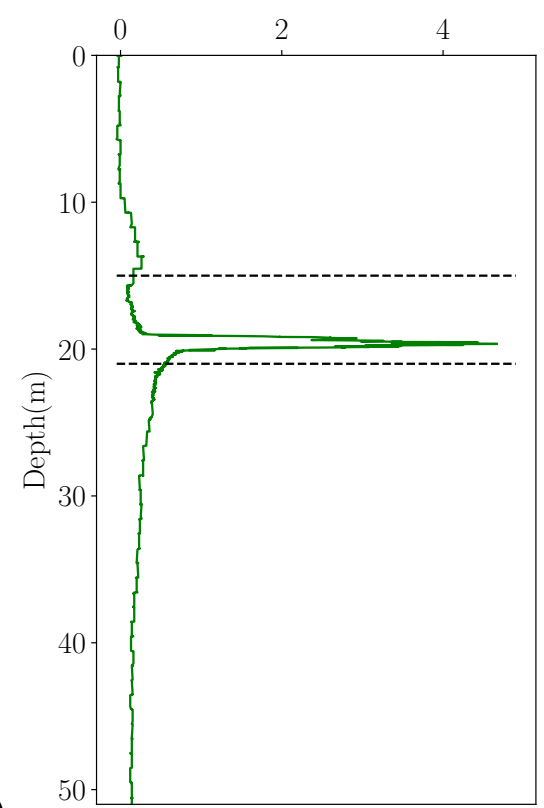

1377 Figure S8 Phycoerythrin concentration in (a) July and (b) October. 
1378

1379

(a)

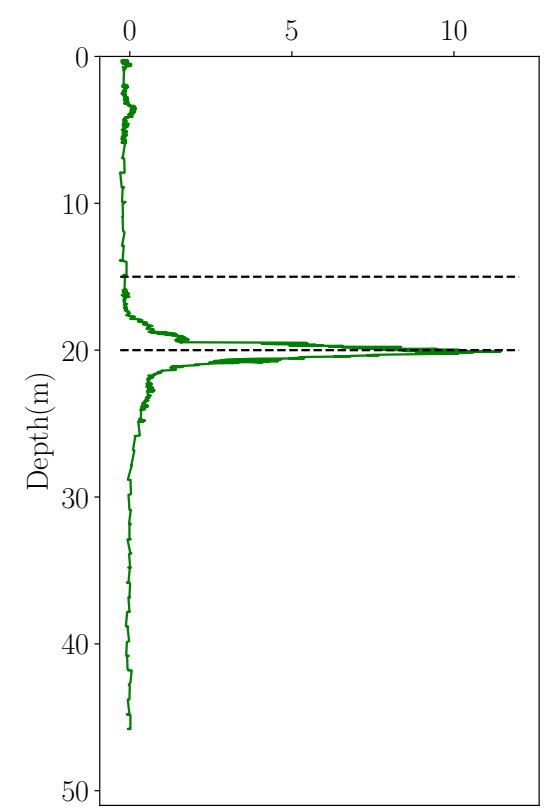

Chlorophyll ( $\mathrm{\mu g} / \mathrm{L})$

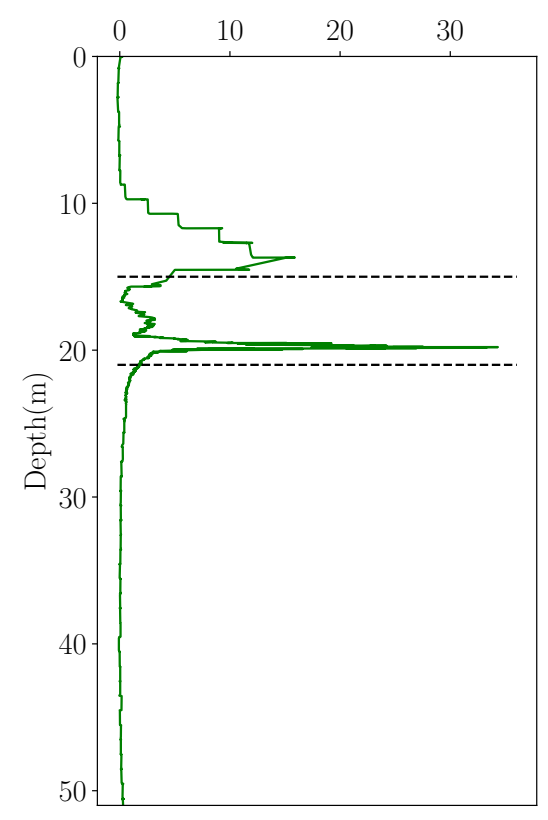

(b)

Figure S9 Chlorophyll-a concentration in (a) July and (b) October.

Relative Abundance

1380

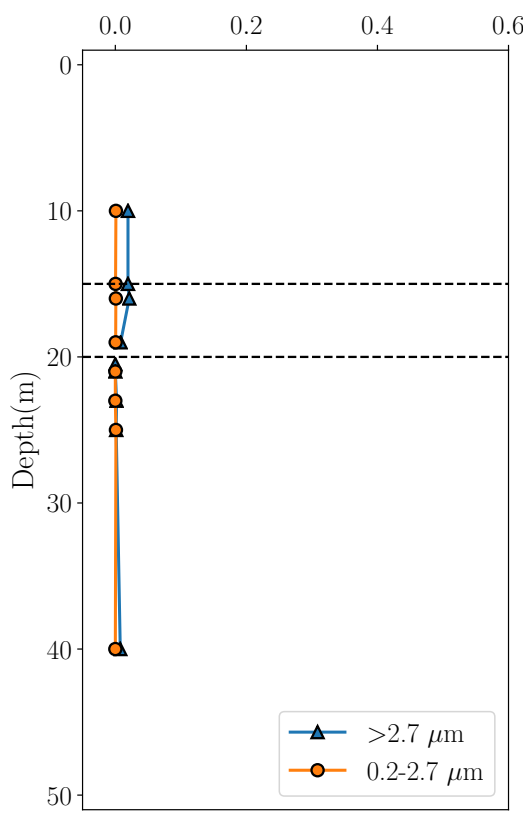

(a)

(b)

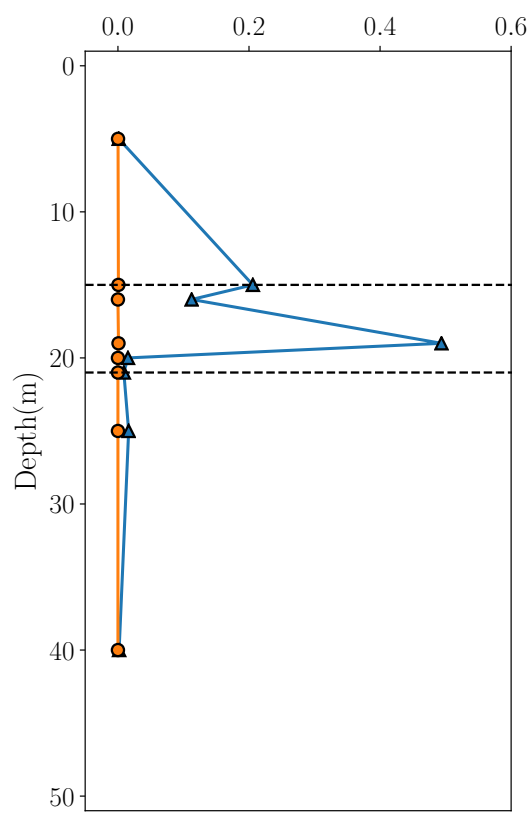

1381 Figure S10 The relative abundance of all chlorophyte mitochondrion and chloroplast 16S DNA 1382 sequences present in the $>2.7 \mu \mathrm{m}$ (PA) and 0.2-2.7 $\mu \mathrm{m}$ (FL) size fractions in 16S rRNA libraries, 1383 for (a) July and (b) October. 